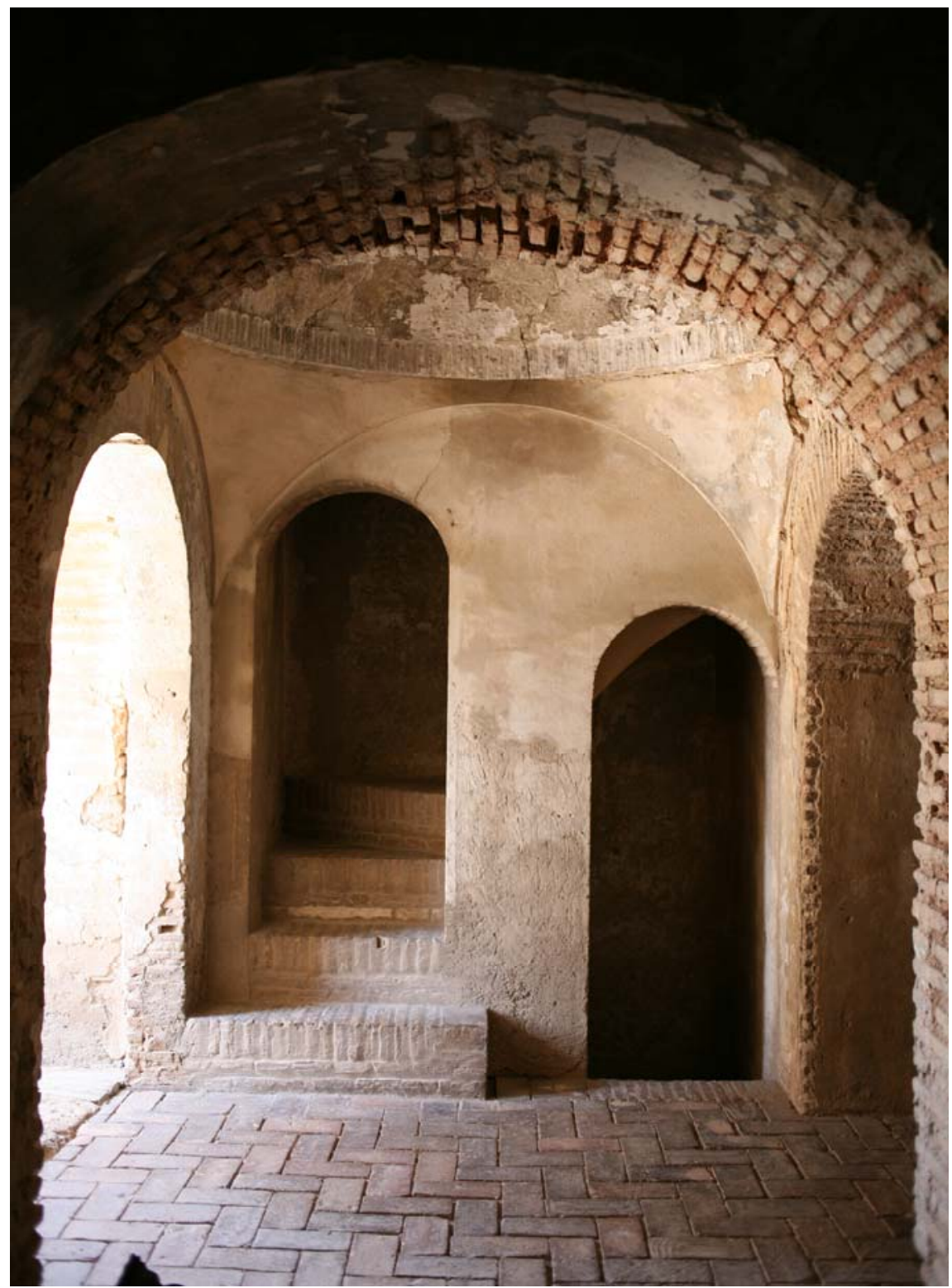

MASTER DE ESTRUCTURAS-UNIVERSIDAD DE GRANADA Trabajo final de Máster 2011-2012

\title{
ANÁLISIS ESTRUCTURAL DEL PATRIMONIO HISTÓRICO \\ TORRE DEL HOMENAJE DE LA ALHAMBRA
}

Tutores: Enrique Hernández Montes Víctor Compán Cardiel

Rafael Castro Trigueros

\section{Alumno:}

David Villegas Cerredo 

ÍNDICE

INTRODUCCIÓN

CONTEXTO HISTÓRICO Y CULTURAL DEL EDIFICIO

AL-ANDALUS

LOS CUATRO PERÍODOS NAZARÍES

LA ALCAZABA

ESTILOS ARQUITECTÓNICOS

DESCRIPCIÓN DEL EDIFICIO

NIVEL 1

NIVEL 2

NIVEL 3

NIVEL 4

NIVEL 5

NIVEL 6 Y TERRAZA

ASPECTOS GENERALES

EJECUCIÓN DEL TAPIAL CALICOSTRADO

LA DIVERSIDAD DE APAREJOS

LA CONSECUCIÓN DEL PISO HORIZONTAL

LA EJECUCIÓN SIN CIMBRA

CARACTERIZACIÓN DE LOS MATERIALES

ANÁLISIS LÍMITE. LÍNEAS DE EMPUJE

BREVE DESCRIPCIÓN DEL MÉTODO

ANÁLISIS POR NIVELES

ANÁLISIS DE SECCIONES PRINCIPALES 
Análisis estructural del patrimonio histórico. Torre del Homenaje de la Alhambra

Trabajo Final de Máster. Máster de Estructuras - Universidad de Granada

David Villegas Cerredo [Septiembre 2012]

ANÁLISIS GLOBAL DE LA TORRE

INFLUENCIA DE LAS CONDICIONES DE CONTORNO EN LA TORRE 65

ANÁLISIS MODAL

69

DESCRIPCIÓN DEL MODELO EMPLEADO

OBTENCIÓN DE LAS FRECUENCIAS FUNDAMENTALES DEL EDIFICIO 69

DISCUSIÓN DE RESULTADOS

CONCLUSIONES GENERALES Y TRABAJO FUTURO

75

CONCLUSIONES GENERALES

75

TRABAJOS FUTUROS

BIBLIOGRAFÍA

77

ANEXO I. PLANIMETRÍA DEL EDIFICIO

79 


\section{INTRODUCCIÓN}

En el presente trabajo se pretende profundizar en la documentación de la Torre del Homenaje de la Alhambra, uno de los casos más paradigmáticos por su configuración y construcción del medievo hispanomusulmán.

En este trabajo se ofrece un análisis del patrimonio histórico desde un punto de vista técnico y desde la perspectiva del análisis estructural de edificio. Se tratará de establecer el estado de la estructura general, a partir del análisis pormenorizado de sus elementos, así como se formularán hipótesis a cerca de algunas de las incertidumbres que rodean su construcción y las técnicas empleadas.

En un primer lugar se realizará un estudio detallado del edificio, describiendo todos sus elementos y detallando los procesos constructivos empleados, así como las sucesivas etapas de construcción de las que tenemos constancia en la actualidad. El conjunto se someterá a un análisis estático, con el que obtendremos las conclusiones principales del trabajo y estableceremos las tensiones de trabajo a que está sometida la torre. El estudio se completará con un análisis modal donde se calcularán las frecuencias propias de vibración de la estructura, partiendo de un modelo numérico. 



\section{CONTEXTO HISTÓRICO Y CULTURAL DEL EDIFICIO}

El edificio se enmarca dentro del medievo hispanomusulmán. Su construcción data de principios del siglo XIII, siendo uno de los edificios más antiguos de cuantos se conservan en el conjunto monumental de la Alhambra. A continuación se apunta brevemente el contexto histórico y cultural del edificio para su correcta contextualización.

\section{AL-ANDALUS}

A la conquista de la Península Ibérica por parte de los musulmanes en el año 711 le siguieron 45 años en los que el gobierno local dependía del califato de los Omeya, en Damasco. A la caída de la dinastía la familia del califa fue masacrada, aunque uno de sus hijos 'Abd al-Rahman I' consiguió escapar y se asentó en la Península Ibérica, fundando un emirato independiente en el año 756.

El dominio musulmán de la península puede dividirse en tres períodos principales, en los que Al-Andalus ha tenido diferentes extensiones (se conoce como Al-Andalus al territorio conquistado).

El primer período (756-1031) abarca el Emirato y el Califato de los Omeyas, con capital en Córdoba.

El segundo período (1031-1232) abarca tres fases políticas: En un primer momento se disuelve la soberanía de los Omeyas en reinos independientes, conocidos como reinos Taifas. En un segundo momento, se produce la invasión Almorávide, con la consiguiente reunificación de Al-Andalus bajo la autoridad del Maghrib, con capital en Marrakush y con segunda capital en Sevilla. Por último, en un tercer momento cae la dinastía Almorávide, el conjunto vuelve a dividirse en reinos taifas y la conquista Almohade provoca, de nuevo, la reunificación del territorio bajo el poder del Norte de África, manteniendo las capitales.

El tercer período (1232-1492) abarca el sultanato de los nazaríes, que controlaban una porción ya muy pequeña de territorio, concentrada en una región montañosa al sur-este de la península, Granada.

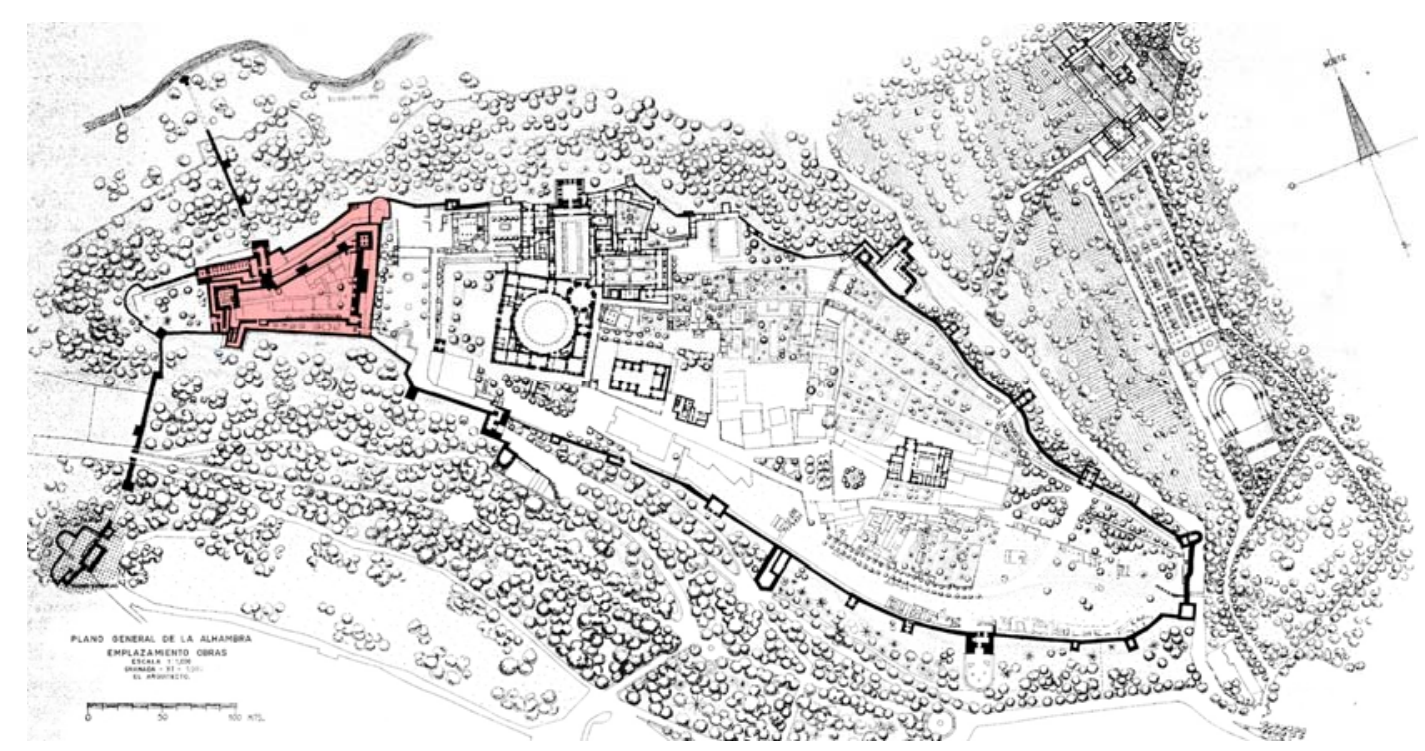

Fig.01 - Plano general de la Alhambra, con la Alcazaba resaltada 


\section{LOS CUATRO PERÍODOS NAZARÍES}

Dentro del califato nazarí, es frecuente hablar de cuatro períodos claramente diferenciados en cuanto a estilo arquitectónico y decorativo se refiere:

El primer período (1231-1314) abarca un período de marcada influencia almohade. Tras la conquista de Córdoba, Jaén y Sevilla; muchos artistas almohades se trasladaron a Granada en busca de refugio. Aunque la aportación estilística se hace notar en algunos edificios, especialmente en los primeros palacios nazaríes, la mayor parte de los edificios levantados en esta época fueron de carácter defensivo. Se completó la muralla de la Alcazaba, se levantaron torres defensivas y se construyó, al menos parcialmente, la muralla perimetral que protegía todo el cerro de la Sabika (nombre con que se designa en la literatura musulmana al cerro donde se ubica la Alhambra).

En el segundo período (1314-1354) se llevaron a cabo construcciones de carácter mucho más monumental, con ornamentos mucho más clásicos, donde se desarrolló enormemente el arte de las 'armaduras' (techos de madera), cuya geometría y complejidad alcanzó su máximo esplendor.

En el tercer período (1354-1391) la decoración alcanza su máxima evolución con el uso continuado de los mocárabes, produciendo decoraciones muy barrocas, con complejas distribuciones en planta y alzado, produciendo efectos ilusorios y perspectivas y espacios de enorme complejidad.

El cuarto período (1392-1492) es un período de decadencia, con una breve etapa de ornamento, seguida de un período de colapso artístico muy marcado por las incesantes e intensas guerras que se venían librando.

\section{LA ALCAZABA}

Algunos restos arqueológicos encontrados o reutilizados en las murallas hacen pensar que el origen de este asentamiento puede remontarse a época romana o visigoda tardía, aunque no hay datos suficientes para aseverarlo.

Los primeros escritos que sí dejan constancia de la existencia de una pequeña fortaleza en la colina de Sabika se remontan al siglo VIII. Desde entonces hasta el siglo XIII la Alhambra (castillo rojo) fue uno de tantos otros castillos a las afueras de poblaciones andaluzas.

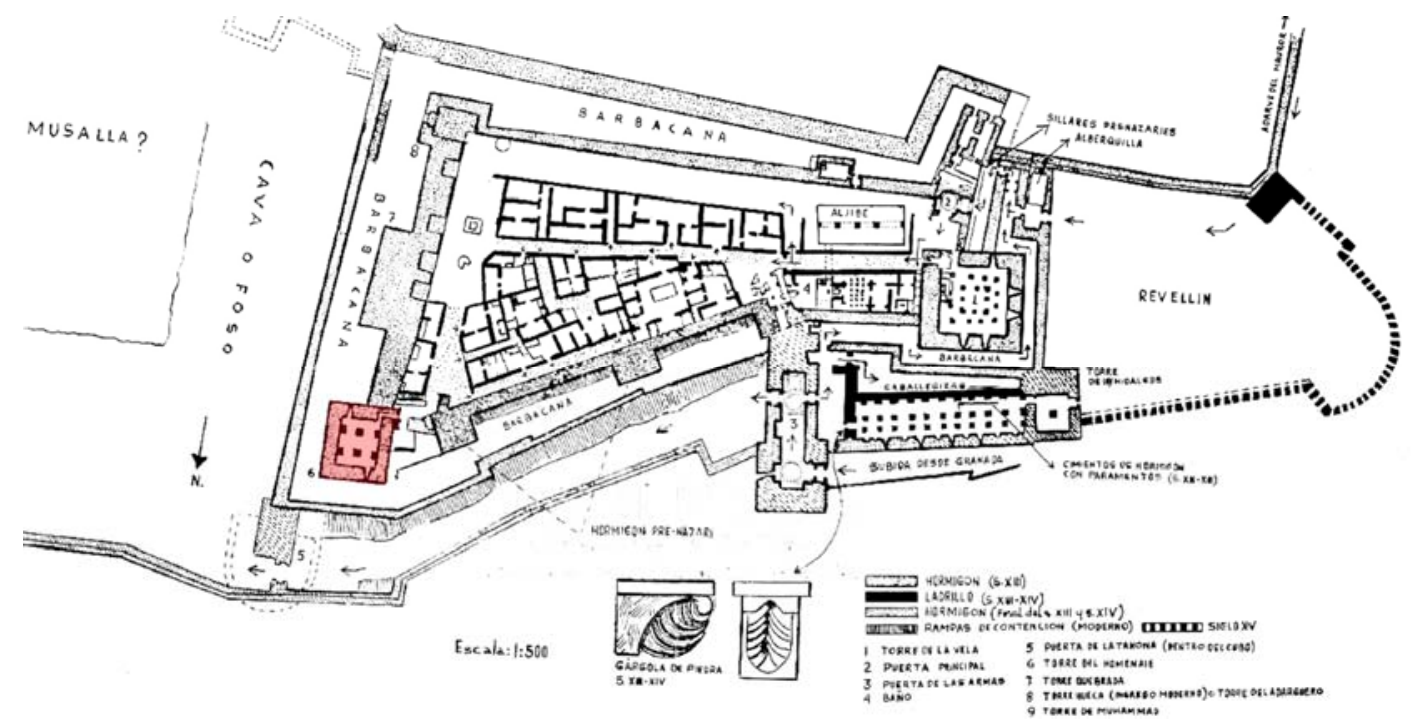

Fig.02 - Plano general de la Alcazaba (según B.Pavón) con la Torre del Homenaje resaltada 
Entre el siglo IX y el siglo XII se encuentran documentados varios episodios donde tropas musulmanas se cobijaban en este pequeño recinto para protegerse de la población local primero y para defenderse de invasiones almorávides y almohades después.

Su existencia se limitaba a un refugio ocasional o a un enclave vigía de la ciudad. La configuración que, probablemente tendría en el siglo XI comprende un recinto trapezoidal (parecido al que se conserva en la actualidad) amurallado y alguna construcción a modo de pequeño castillo del que no se tiene constancia.

A principio del siglo XIII, el monarca Mohamed Ibn ben Alhamar había sido obligado por el rey Fernando III a participar en el asedio de Sevilla, a cambio del control de la ciudad de Granada; donde fundaría la primera dinastía Nazarí, iniciando el tercer período de AlAndalus. El monarca usó el emplazamiento del antiguo castillo de la Alhambra como lugar donde erigir el centro gubernamental y defensivo de su reino. A tal efecto, la primera tarea fue dotar al conjunto de un importante poder defensivo. Esto condujo a una primera campaña constructiva donde se reforzaron las murallas existentes y se levantaron algunas nuevas hasta completar el recinto y mejorar el adarve. Se levantaron también dos importantes torres (la de la Vela al Oeste y la del Homenaje al Este), inusuales por su envergadura en la época, hasta conformar la alcazaba como ciudad castrense a la defensa del reino, de la medina y de la zona palatina.

Casi al mismo tiempo se fue levantando el palacio nazarí. Sendas campañas serían terminadas por su hijo Mohammad II, que conformó el aspecto general de la Alcazaba en los siglos XIII y XIV.

Son atribuibles al siglo XIII los actuales adarves, las barbacanas existentes entre el muro exterior e interior, las caballerizas y las dos torres antes mencionadas.

Más tarde, a finales del siglo XIV Isma'il I levantó la Puerta de las Armas, lo que tuvo que suponer necesariamente una reestructuración de la zona norte, demoliendo parte de las caballerizas y habilitando una entrada para las subidas desde Granada.

Otra modificación importante se atribuye a Yusuf I, que construyó la Torre Quebrada y el adarve del flanco Este, cerrando el recinto superior.

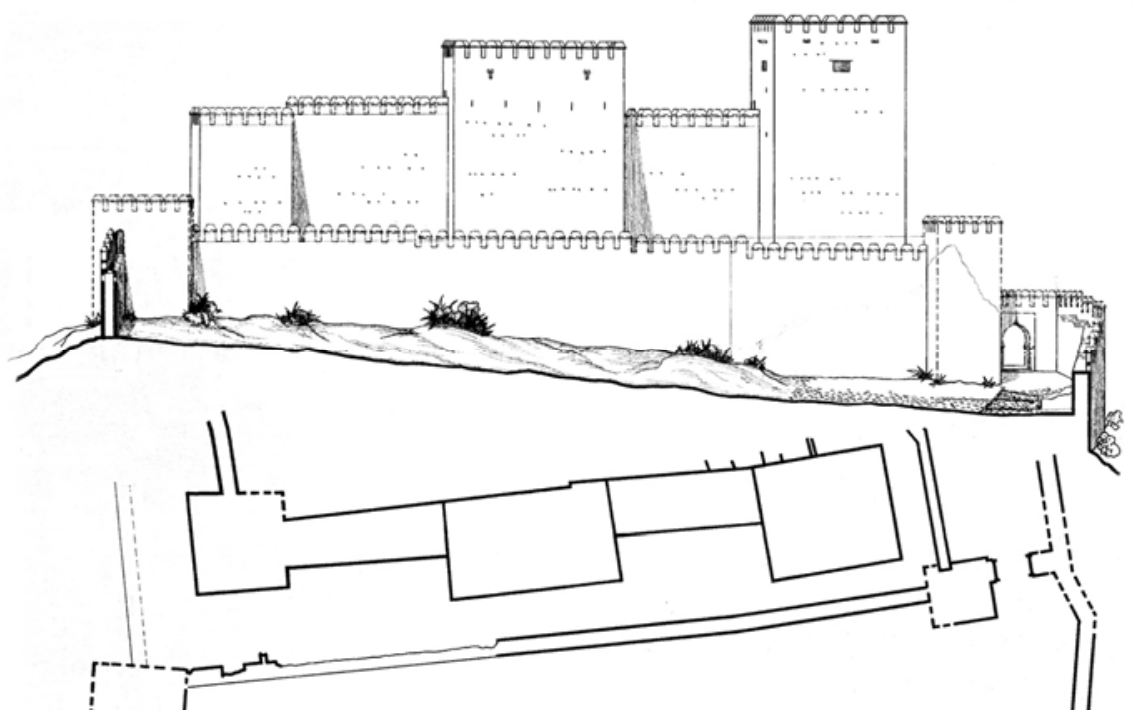

Fig.03 - Alzado Este en el siglo XV 
Parece ser que la cimentación del flanco Este, entre la Torre del Homenaje y la Torre del Adarguero (vaciada en el siglo $\mathrm{XVI}$ ) era bastante pobre, por lo que tuvieron que ser reforzadas para completar adecuadamente el lienzo. Muy probablemente el acceso desde el nivel cinco de la torre hacia el adarve date de esta fecha.

En el siglo XV, la fortaleza nazarí fue de nuevo reforzada con un gran bastión de artillería en la zona oeste (revellín) que venía a adaptar a la Alcazaba a un nuevo sistema defensivo en el nivel inferior contra la artillería de fuego. Además, se construyó una entrada en la esquina noreste, conocida como puerta de la Tahona.

Ya en época cristiana, algunos muros de la Alcazaba fueron reconstruidos. Son de especial mención las intervenciones en la zona sur de la Torre de la Vela y la reconstrucción y mejora, empleando la muralla existente, del muro exterior del flanco Este; sustituyendo además la Puerta de la Tahona por la Torre del Cubo y realizando una nueva entrada a la barbacana, más centrada en el alzado Este. También fueron reconstruidas en el siglo XVI las torres de los Hidalgos y de la Pólvora.

\section{ESTILOS ARQUITECTÓNICOS}

Dos fases pueden diferenciarse claramente en los edificios granadinos de la época: La primera, que pudiéramos llamar de resistencia, está compuesta con arcos, bóvedas y su decoración es prácticamente nula. La segunda, se caracteriza por ser efectista, con estructuras engañosas, a base de carpinterías murales, mocárabes y todo lujo de detalles y adornos.

Como resulta evidente, las torres defensivas de la época están enmarcadas dentro del primer tipo de edificios "lisos".

Mucho se ha escrito a cerca de estos llamativos recursos de los edificios "efectistas" y mucha ha sido la atención prestada a todo lo relacionado con el arte decorativo hispanomusulmán de la época, sin embargo, se ha dejado muy de lado todo aspecto técnico que pudiera atribuirse a los edificios, descuidando enormemente el lugar en la historia que pudieron tener los alarifes y constructores de la época.

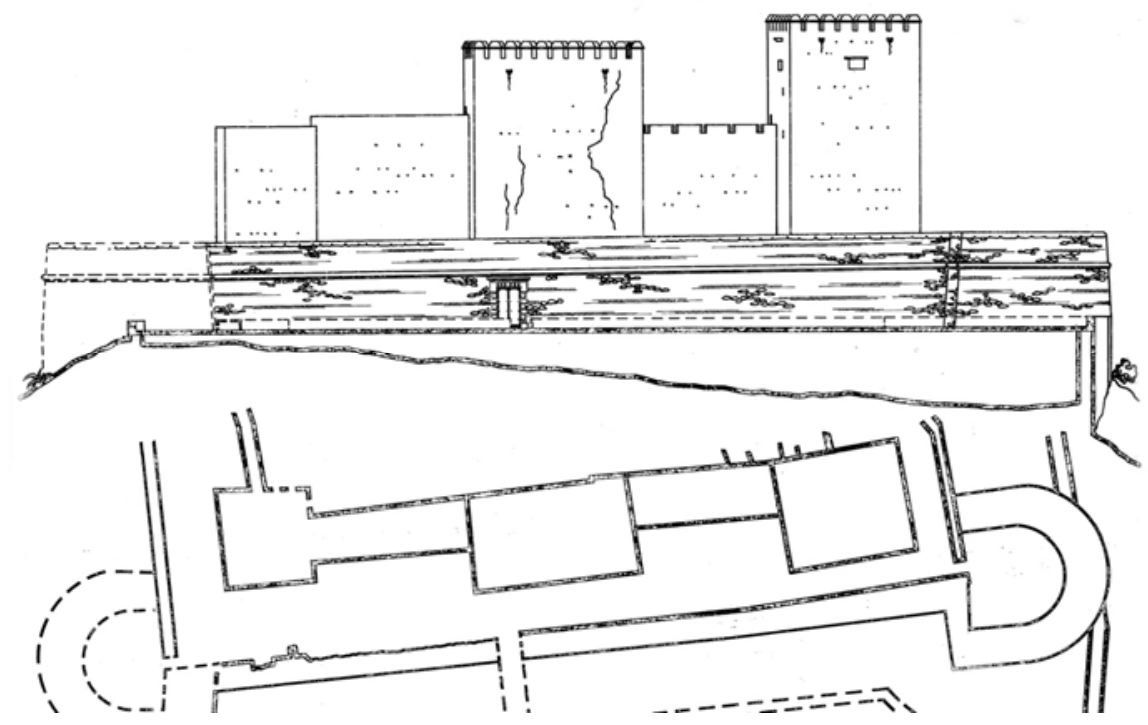

Fig.04 - Alzado Este en el siglo XVII 
Este descuido por los aspectos técnicos es atribuible a varias razones. En primer lugar, resulta complejo su conocimiento, ya que en el grupo de edificios donde la ornamentación es llevada al extremo, la verdadera estructura queda oculta y, si bien es posible en muchos casos adivinar su morfología, difícilmente puede investigarse su técnica de ejecución o sus pormenores.

Un segundo aspecto es la escasa documentación escrita que se dispone. No sería hasta una época muy posterior cuando el mundo musulmán empezó a dejar constancia escrita de sus técnicas constructivas y de las composiciones que debían seguir las ciudades y edificios. No hay que olvidar que, desde el inicio de la religión musulmana en el siglo VII la expansión del imperio fue vertiginosa, conquistando enormes territorios en apenas dos siglos. Esto es debido, entre otras cosas, al carácter poco "invasivo" con las poblaciones conquistadas. La mayoría de los edificios existentes eran aprovechados, reutilizados y el no tener unas directrices claras más allá de la organización básica de la ciudad, hizo que se confiara mucho en la destreza de los constructores locales que, dependiendo de la zona conquistada tenían una influencia mayor del mundo romano, del imperio bizantino o del imperio armenio.

Por otro lado, no hay que olvidar que en la religión musulmana está prohibida cualquier representación humana, divina o de animales, por lo que en su iconografía rara vez aparecen escenas donde se observe un proceso constructivo o se describa el trabajo de algún gremio.

Así pues, no puede hablarse de novedades constructivas ni estructurales de consideración hasta épocas posteriores, sin embargo existen muchos edificios donde se ha llevado a cabo una clara experimentación de estilos y donde se han anticipado algunos recursos que, con posterioridad, se han adoptado como habituales.

En cuanto a las fuentes que disponían los musulmanes en el siglo XIII (que nos ocupa principalmente) en cuanto a aspectos constructivos y organizativos de la ciudad tampoco está muy claro que fueran más allá de la pura experiencia acumulada por sus alarifes, por los gremios de construcción y por los artesanos locales.

Por ejemplo, no se tiene constancia que el Tratado de Vitruvio fuera traducido hasta una época posterior, sin embargo existen varios elementos presentes en la alcazaba que ya se describían en este tratado, como son la colocación de las torres a "no más de un tiro de flecha", la protección del muro mediante un antemuro que dejara una barbacana o las entradas en recodo; nunca frontales y siempre de izquierdas, para que el pecho del atacante quedara descubierto.

En cambio, hay otros elementos que contradicen las pesquisas del Tratado de Vitruvio, como son la no colocación de las torres en una posición avanzada respecto de la muralla. En la alcazaba todas las torres avanzan parcialmente de la muralla, pero en casi ningún caso se presentan como torres exentas. Esto tiene la ventaja de poder recorrer toda la muralla pasando de torre a torre, pero tiene la desventaja de sucumbir más fácilmente ante un ataque. En el tratado se recomienda colocarlas exentas y colocar en ese intervalo una estructura de madera en el muro que, de ser conquistada, pudiera ser quemada para aislar la muralla por trozos.

Tampoco se atiende a las recomendaciones de crear torres circulares para evitar que "las esquinas débiles de las torres rectangulares", más vulnerables al ataque de artillería pesada. En general, todas las torres de la Alhambra son de planta cuadrada o rectangular, habiéndose primado claramente la sencillez constructiva, su mejor organización interior y su mejor trabazón con la muralla.

Todos estos elementos pudieron ser incorporados por la propia experiencia o porque se conocieran escritos de la antigüedad al respecto; no puede aseverarse con razonable certidumbre ninguna de las dos afirmaciones. 
En otro orden de cosas, si en el período de los reinos taifas el arte de la fortificación adquiere un principal protagonismo, perfeccionándose poco a poco hasta llegar a la época almohade; de la Alhambra podríamos decir que no existe parangón en cuanto a la variedad de soluciones y escalas en sus puertas y torres. Desde las primeras campañas constructivas de Alhamar, las torres de la Vela y del Homenaje manifiestan esa voluntad de innovación y superación respecto de lo anterior.

En contraposición a la arquitectura lisa y monótona habitual en estos edificios castrenses de voluntad puramente defensiva, en la Torre del Homenaje encontramos un repertorio de bóvedas y cúpulas que se amoldan a los distintos espacios interiores de la torre y que son un ejemplo de sabiduría constructiva. En contraposición a los recursos empleados en la arquitectura palatina, donde los espacios se cierran con bóvedas de armadura de madera o mocárabes de yeso, en la torre la eficacia estructural se une a un tratamiento visual acorde al lugar que ocupan. 


\section{DESCRIPCIÓN DEL EDIFICIO}

La torre se encuentra en la esquina noreste de la alcazaba de la Alhambra y es la entrada norte al recinto. El lienzo mural en este flanco cuenta con dos torres más, una colocada en el centro, conocida como Torre Quebrada y una segunda de menor entidad conocida como Torre del Adarguero. Ambas torres rebasan parcialmente la alineación del muro, de forma que para recorrer la muralla es preciso adentrarse en las mismas.

El flanco oeste está protegido por la Torre de la Vela, de grandes dimensiones en planta y que flanquea un ingreso quebrado y enrevesado como pocos se conocen en la época medieval. Esta tortuosa entrada, unida a su posición privilegiada en lo alto de la colina, la convertían en una entrada prácticamente inexpugnable.

El recinto dibuja aproximadamente un cuadrilátero en planta, siendo el lienzo Este el más extenso, con unos $75 \mathrm{~m}$. Desde aquí hasta el lienzo Oeste, de unos $30 \mathrm{~m}$, el recinto va estrechándose. Aparecen además algunas torres de menor dimensión en las murallas norte y sur que mejoran la capacidad defensiva del conjunto.

Este perímetro se encuentra defendido además por un antemuro que, al oeste es revellín de artillería y que al norte, al sur y al este forma una barbacana defensiva.

Al sur, este antemuro es al mismo tiempo la última muralla que dispone la Alhambra y que linda con el escarpe del cerro. Al este, el antemuro linda con la zona palaciega del conjunto (en la época sólo existía el palacio nazarí y la plaza de los aljibes)

Por último, al norte este antemuro cuenta con un tercer lienzo mural que es el que linda con el cerro. Este último lienzo es posterior y data del siglo XIV-XV, época en la que se levantó la puerta de la Tahona (en la zona este), que unía con las caballerizas y la puerta de las armas, también de la misma época.

La Torre del Homenaje, si bien en altura es levemente superada por la Torre de la Vela, su posición en un lugar más elevado la convierten en el punto más alto del recinto defensivo y en un puesto de vigilancia privilegiado. Podemos decir que, en el siglo XIV, la Torre del Homenaje era, junto con la Torre de la Vela, el principal bastión defensivo de la Alhambra, controlando la Alcazaba y ofreciendo protección al recinto palatino y a la medina.

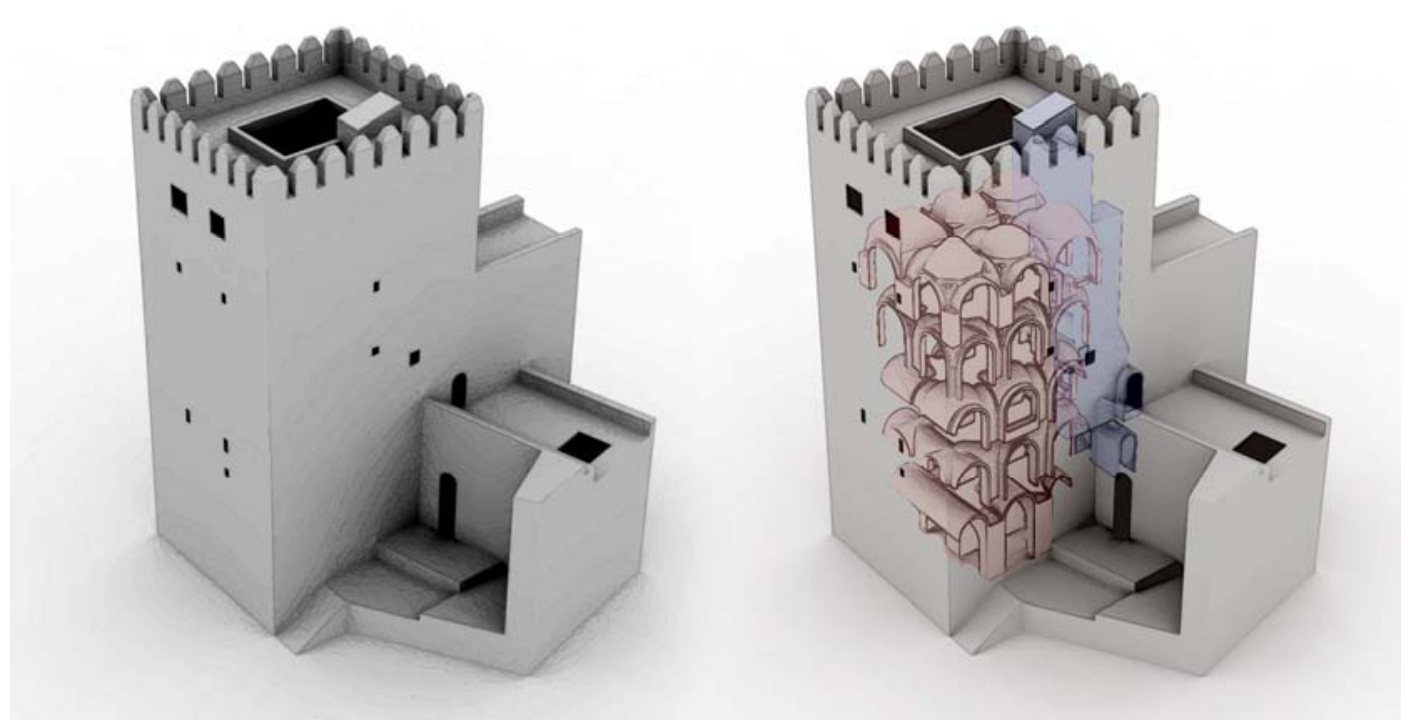

Fig.05 - Torre del Homenaje (Vista desde el N-O). Aspecto exterior y sistema interior. 
Ya en época cristiana, el recinto adquiere la morfología actual, en la que la puerta de la Tahona es reforzada, queda contenida en la Torre del Cubo y se abre una entrada en el antemuro Este que da directamente al conjunto palatino.

La Torre del Homenaje dibuja un rectángulo en planta de unos 12.20x10.40m. Cuenta con seis niveles más el nivel de terraza y almenas. Su posición en esquina flanquea un acceso en doble codo y en subida al recinto de la alcazaba. En vertical, la torre se encuentra independizada en dos zonas bien diferenciadas.

La zona inferior comprende los dos primeros niveles, su acceso se hace desde el segundo de ellos, bajo la muralla norte, a través de un pasaje cubierto por una bóveda de cañón.

La zona superior está conformada por el resto de niveles (conectados entre sí por un núcleo de comunicaciones vertical interno). El acceso se realiza desde lo alto de la muralla norte, en el nivel tres, pero desde una posición deprimida respecto al muro este. Es ya en el nivel quinto donde se encuentra el último acceso, éste ya en lo alto del adarve del muro Este.

En planta, todos los niveles (a excepción del primero y el último) están divididos en 6 espacios cuadrados o sensiblemente rectangulares, dejando en la zona central dos pilares de gran dimensión que recorren el edificio en toda su altura (a excepción del nivel 6 que se conforma en patio). Estos espacios están cubiertos por diferentes sistemas de bóvedas y cúpulas hasta conformar el suelo del nivel inmediatamente superior.

Conforme vamos subiendo en altura, el muro perimetral reduce su sección por la cara interior; pasando de los $2.35 \mathrm{~m}$ del nivel más inferior hasta los $0.80 \mathrm{~m}$ del nivel superior. Las soluciones variadas y experimentales de cubrición empleadas en el interior contrastan con la contundencia y monotonía del aspecto exterior; siendo difícil imaginar de un vistazo los pormenores que esconde.

El núcleo vertical se sitúa en la esquina sur-oeste de la torre, en el ángulo entre el lienzo de la muralla norte y la muralla este. Aunque la posición en la torre debilita sustancialmente el muro, la resistencia que ofrecen las murallas anexas compensa esta asimetría en la rigidez transversal, aunque abordaremos esto con más detalle más adelante.

Como ya se ha comentado, la torre data de principios del siglo XIII, siendo su construcción casi contemporánea a la torre de la Vela. Algunos autores afirman que la del Homenaje es algo posterior, pues se corrigen algunos errores estructurales que se detectan en la primera.

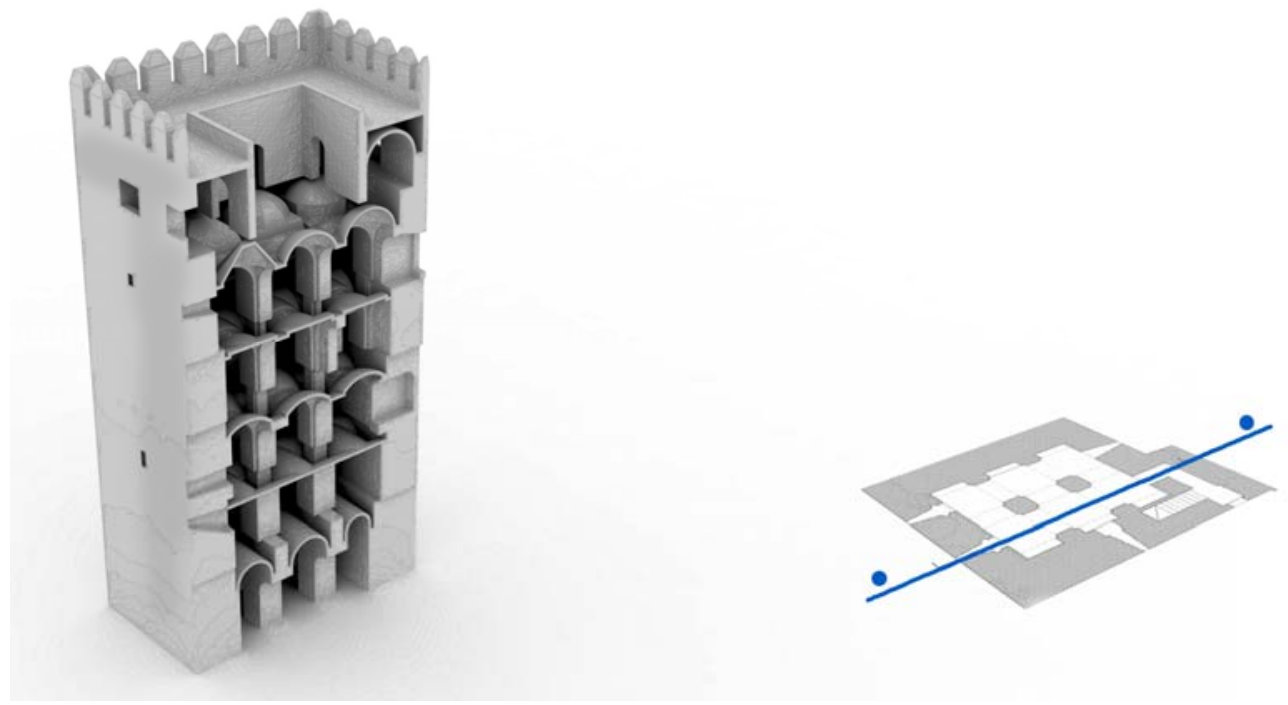

Fig.06 - Vista seccionada general de la torre 
No obstante, a lo largo de la historia la torre ha sufrido no pocas reparaciones. Además de la ampliación y refuerzo de la muralla Este en el siglo XIV-XV, que sin duda conllevó a alguna intervención en la torre, escritos del siglo XVIII hablan del mal estado en que heredaron el recinto en general y la torre en particular los cristianos primero (en el siglo XV) y los españoles después a principios del siglo XIX tras la derrota de las tropas napoleónicas. Pudieron darse varias circunstancias que propiciaran este deterioro. En primer lugar los diferentes asedios sufridos durante siglos. En segundo lugar, era frecuente derribar parcialmente las defensas de la fortaleza en caso de rendición o conquista, tanto con la salida de los árabes como con la salida de los franceses así se encuentra documentado. Por último, se tiene constancia de un terremoto en el siglo XV (1430 aproximadamente) y otro a finales del XVIII que provocaron muchos daños en el conjunto y que, probablemente causaron importantes daños, sobre todo en el nivel superior de la torre.

Por otro lado, aun considerando todas estas circunstancias cabe decir que su estado de conservación siempre ha sido mucho mejor que le de otras torres, como la Quebrada. En la Torre del Homenaje sólo se tiene constancia de grietas interiores y algún derrumbe parcial en el piso superior, pero nunca de una ruina considerable. La última reparación de la que se tiene constancia es la acometida a finales del siglo XIX donde se reconstruyó parte de último nivel (el que deja un patio central) y se levantaron de nuevo las almenas, aunque puede observarse en fotografías de la época que sin mucha fidelidad a la obra original.

Este último nivel que en su estado original estaría compuesto por cuatro bóvedas de cañón conformadas alrededor de un patio rectangular, pasa a tener techos horizontales sobre viguería de madera en tres de sus laterales.

En cuanto a los materiales, se tratará de forma más extensa en apartados posteriores, pero someramente podemos decir que el muro exterior está conformado casi en su totalidad mediante un sistema de tapial calicostrado, típico de la Alhambra, mientras que los elementos resistentes en el interior, como son pilares, bóvedas, arcos de descarga, etc, son de ladrillo cocido. Los suelos son de materiales pesados, dependiendo del nivel se emplean solerías pétreas, cerámicas o ripios, aunque no es posible determinar con exactitud la composición de los rellenos, análisis de otros edificios del conjunto hacen pensar que eran rellenos de tierra, no muy diferentes al tapial exterior.

En las siguientes páginas se describe de forma pormenorizada cada uno de los niveles.

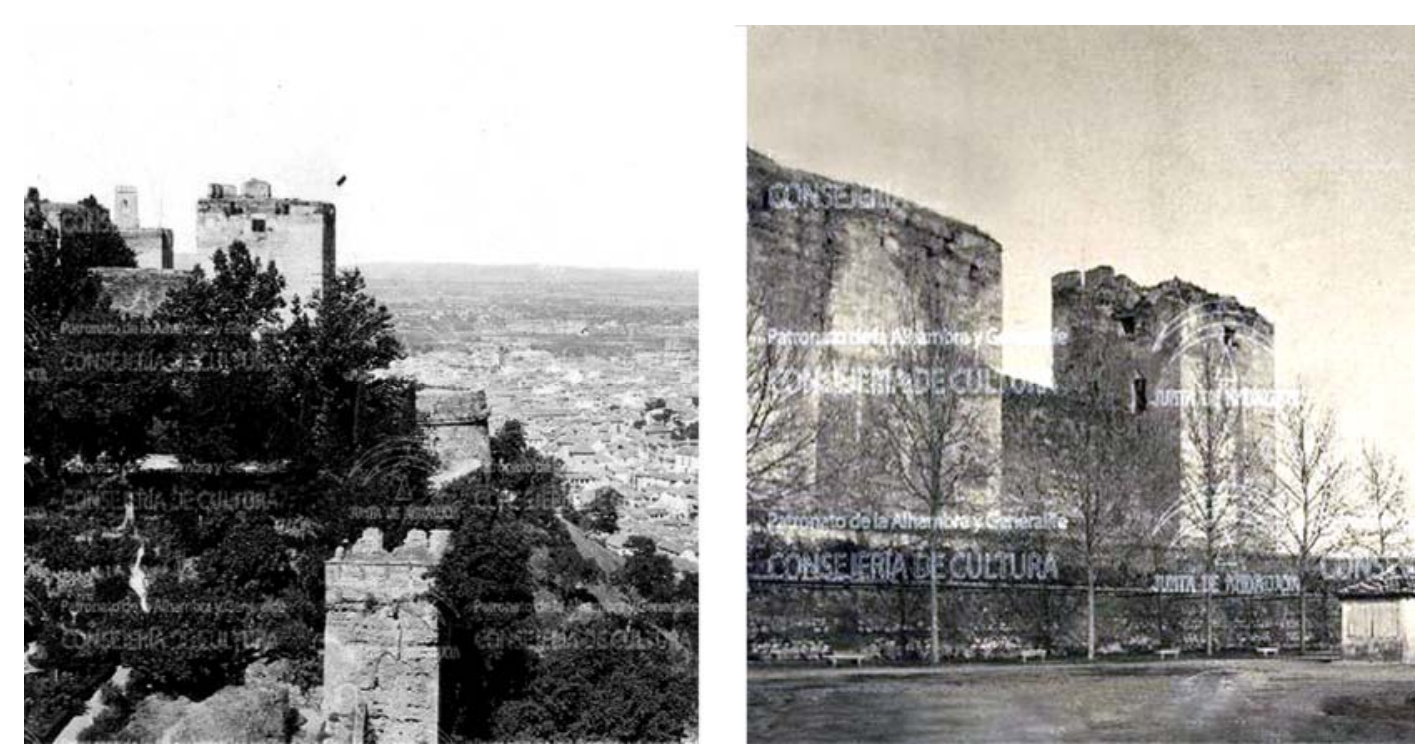

Fig.07 - Estado de la Torre del Homenaje en torno a 1870 
Este nivel era normalmente empleado como almacén o como mazmorra para presos de relativa importancia. Se compone de tres espacios rectangulares cubiertos por bóvedas de cañón de directriz E-O. La nave central es mayor que las dos laterales, siendo a su vez la nave sur la de menor dimensión. Sin embargo, todas están situadas a la misma altura, estando su clave en todos los casos a unos 4,30m del suelo.

El paso de una nave a otra se realiza mediante imponentes arcos de medio punto que descansan en dos pilas centrales y en los muros E-O, y cuya clave está a unos 2,85m del suelo. El recinto no tiene luz natural y se encuentra parcialmente enterrado respecto del nivel exterior. El único acceso posible se realiza a través de una pequeña trampilla en la clave de la nave central, siendo necesario bajar por una cuerda o una escalera de mano. Esto dotaba de extraordinaria seguridad a la mazmorra.

Tanto las bóvedas como los arcos principales y los pilares centrales están ejecutados en ladrillo, siendo las juntas entre ellos casi de igual espesor que los propios ladrillos.

La disposición de éstos en las bóvedas es a testa, pero formando un despiece vertical, lo que hizo necesario, casi con toda seguridad emplear cimbras en su construcción. Una hipótesis razonable es pensar que las naves centrales se ejecutaron con cimbras provisionales que luego se retiraron a través de la nave sur, la menor, cubriéndose ésta en un último momento mediante una bóveda sin cimbra (mucho menor).

En cuanto a las paredes que cierran las bóvedas en los laterales E-O se aprecia una gruesa capa de mortero/hormigón que está parcialmente desprendida, dejando ver el ladrillo empleado como material base. Parece ser que las primeras hiladas de bóveda apoyan sobre esta pared de ladrillo, por lo que también puede ser una hipótesis razonable considerar que el tamaño y material de las juntas era tal que, estando correctamente apoyadas las primeras hileras era posible construir hileras sucesivas sin cimbras.

Los apoyos de las bóvedas se realiza en los muros N-S, apreciándose en éstos, tongadas rojizas y blanquecinas intercaladas. Esto es clara evidencia de un tapial calicostrado, aunque si nos fijamos en el muro exterior, los mechinales que se aprecian en la parte baja del muro no se ven en el interior. Aquí son posibles dos interpretaciones: En primer lugar estos mechinales pudieron emplearse exclusivamente como anclajes de andamios, por lo que no era necesario que atravesaran todo el espesor del muro. En segundo lugar, es posible que sí lo atravesaran, pero con posterioridad se levantara un muro interno donde apoyar las bóvedas. Esta última hipótesis parece menos razonable, ya que hubiera sido más lógico ejecutar este supuesto muro con ladrillo siguiendo la lógica de los muros E-O y la de los pilares centrales.

El suelo, al ser el nivel más inferior, es de tierra compactada, sin que haya sido necesario más tratamiento.
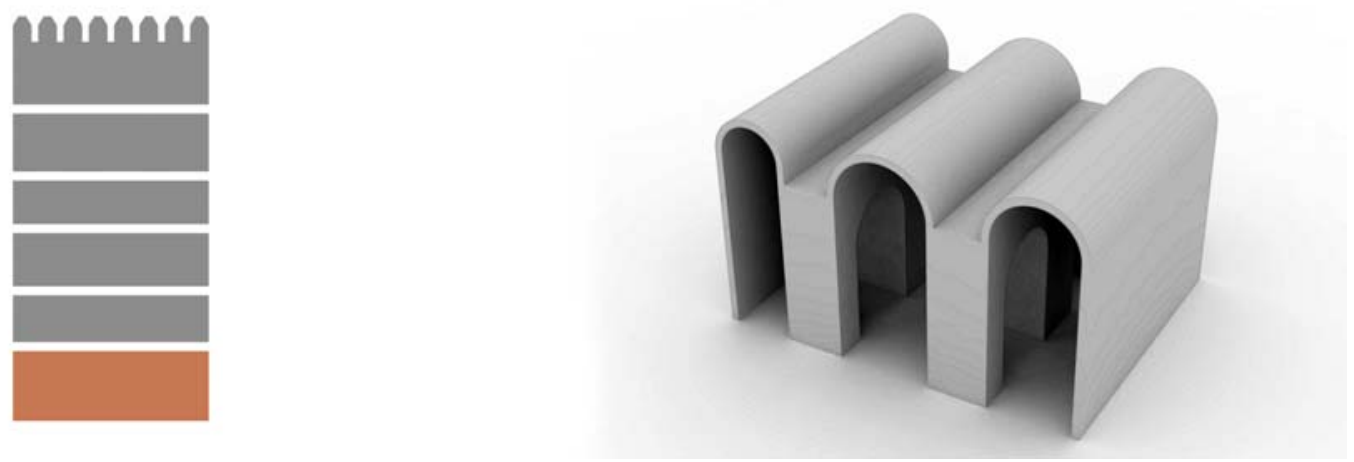

Fig.08 - Sistema estructural interior. Nivel 1 
NIVEL 2

Parece que el uso de este nivel era exclusivo de los guardianes de las mazmorras. Es el nivel donde se controlaría el acceso desde la barbacana a la Alcazaba, sería refugio de los centinelas y, en caso de conquista, sería el último nivel accesible por el enemigo antes de tomar la muralla norte.

El ingreso se produce desde el último recodo de la entrada a la alcazaba bajo el muro norte. Éste está cubierto por una bóveda de cañón de importantes dimensiones disponiéndose en uno de sus frentes 6 escalones laterales que alcanzan la puerta de entrada. Al abrirse, ésta queda embebida en el muro gracias a un rebaje debidamente dispuesto. Se accede por un pasillo cubierto por una pequeña bóveda de cañón que discurre como vaciado del muro sur de la torre y termina en un pequeño quiebro de izquierdas que nos deja en el lateral más al oeste del nivel.

La planta, como en todos los niveles a partir de este, se organiza en seis espacios. En este nivel se construyen bóvedas de cañón de igual altura cuya intersección forma 6 bóvedas de arista. Al no existir arcos de descarga entre los pilares centrales y el muro perimetral toda la planta se reconoce como un único espacio.

Al igual que en el nivel inferior, los pilares centrales y las bóvedas son ejecutadas con ladrillo; mientras que en este caso los muros perimetrales parecen ser del mismo tapial que se reconoce en el exterior. La disposición de los aparejos, tanto por el tamaño de sus juntas, como por la dirección cambiante de los mismo en las bóvedas, sugiere que pudieron realizarse sin cimbra; aunque esta es de nuevo una suposición difícilmente demostrable.

Al tener todas las bóvedas la misma altura la cota general de techo es de unos 3,00m sobre el suelo, en la clave.

Las bóvedas apoyan directamente en los muros norte y sur, mientras que el apoyo en los muros este y oeste se produce mediante pilastras que sobresalen del muro.

El suelo es de ripios de tamaño medio sin que pueda adivinarse si el relleno llega hasta las bóvedas del nivel inferior o existe algún tipo de aligeramiento.

Por último, este nivel se encuentra iluminado mediante ventanas con forma de tronera mucho más altas en la cara exterior del muro que en la cara inferior (donde ya de por sí son bastante altas), creando un alféizar muy empinado. En total son dos, una en la parte sureste y otra en la parte noroeste. No parece que existiera ninguna razón de carácter defensivo en estas ventanas, su única vocación era iluminar el espacio.
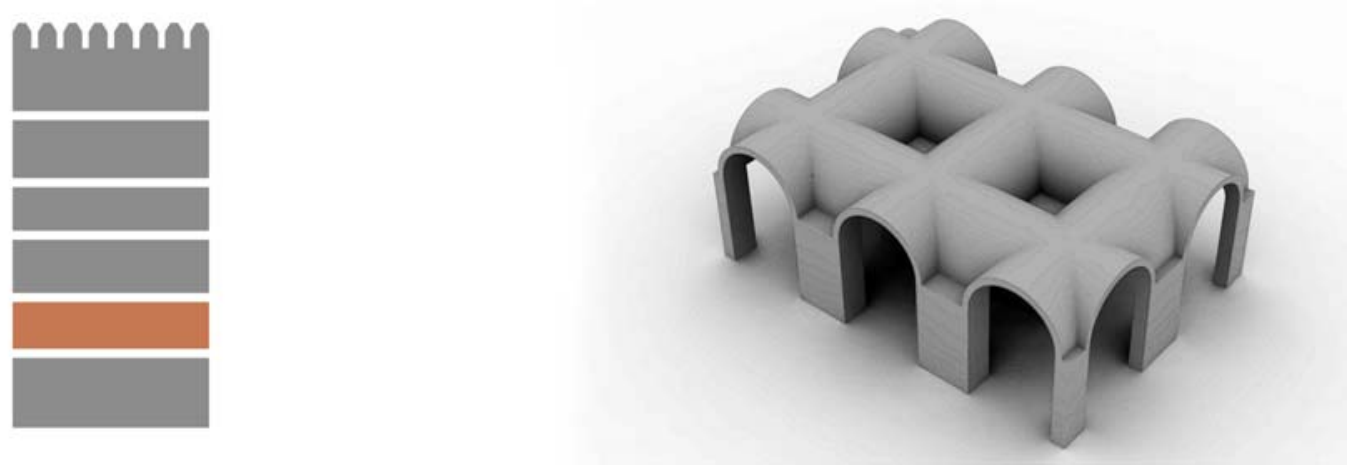

Fig.09 - Sistema estructural interior. Nivel 2 
El acceso a este nivel se realiza a través del adarve de la muralla norte, una vez se ha pasado el recodo de acceso bajo ésta y se ha superado la estrecha y empinada escalera que recorre interiormente el muro.

De nuevo, la entrada se realiza mediante una puerta que queda convenientemente embebida en el muro una vez abierta. El pasillo, cubierto por una bóveda de cañón que trascurre por el interior del muro sur queda esta vez interrumpido en su izquierda por el arranque de la escalera que conduce al nivel superior. Ésta vacía el muro oeste, cuenta con su propia lógica en lo que a cubrición se refiere y dispone de una pequeña ventana que la ilumina en su meseta; se cuentan 12 peldaños hasta el nivel inmediatamente superior.

Volviendo a la entrada, una vez superado el pasillo vuelve a haber un giro de izquierdas que nos introduce en el lateral oeste de la planta, esta vez de una forma mucho más centrada, casi alineados con la ventana que tenemos al fondo.

Otra vez la planta se organiza en seis espacios que dejan dos pilares centrales. Tal y como ocurre en el nivel inferior, las bóvedas descansan directamente en los muros norte y sur, mientras que se emplean arcos de descarga que apoyan en pilastras en los laterales este y oeste. Esta vez, los seis espacios están cubiertos por su propia bóveda vaída, con una altura en la clave de unos 3,30m sobre el suelo. Éstas, a su vez descansan en arcos de descarga cuya cota de clave está alrededor de 2,65m sobre el suelo.

En esta planta los pilares ya no son cuadrados, ya que deben absorber a los arcos de descarga. Esto hace que a partir de esta planta sean cruciformes, aunque en este nivel sean de cruz cuadrada, ya que los arcos en ambas direcciones tienen el mismo ancho.

El espacio está iluminado por cuatro ventanas. Dos de ellas en el muro norte, una en el sur y una más en el muro oeste. Nótese que siempre se evita colocar ventanas en el lateral este, el más vulnerable a ataques de artillería. Las ventanas tienen una geometría similar a la del nivel inferior, aunque en este caso el alféizar es prácticamente horizontal, y bastante más bajo. Esto sugiere que estas ventanas sí podían ser usadas como puestos defensivos de la muralla para arqueros.

El suelo es de ladrillo colocados en testa, excepto en el cuadrante sureste que es de ripios; ignoramos a qué puede ser debida esta diferenciación.

Tanto las bóvedas como los arcos principales son de ladrillo, no obstante no puede afirmarse tal cosa de los muros laterales, que cuentan con un revestimiento que impide ver el material de base. Parece lógico pensar que son del tapial exterior, aunque tampoco habría que descartar que la parte interior de los muros, al menos norte y sur, fueran de ladrillo, ya que se explicaría con mayor facilidad que no existan pilastras sobresalientes aquí.
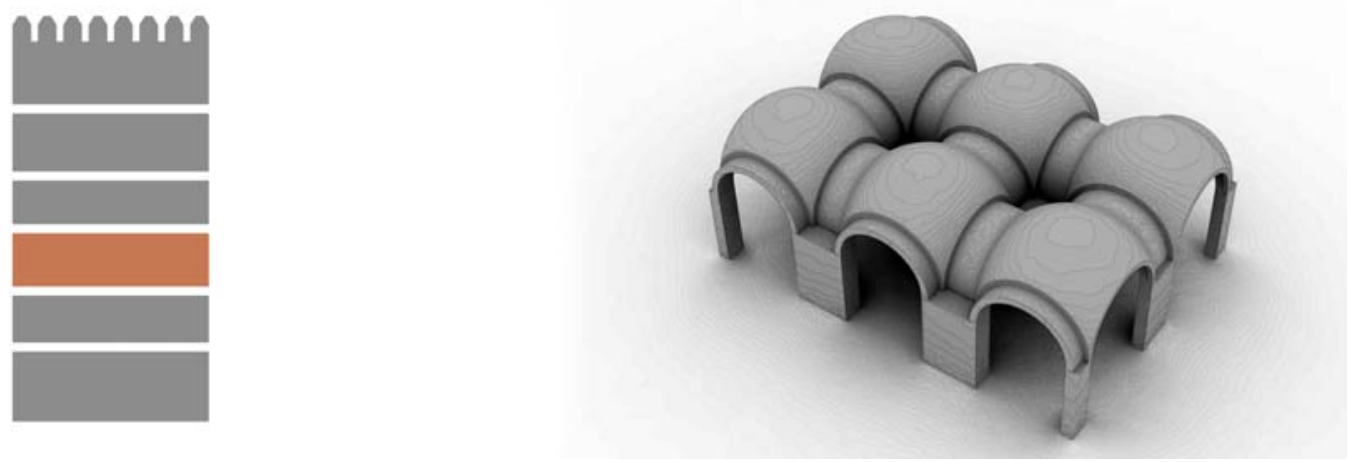

Fig.10 - Sistema estructural interior. Nivel 3 
NIVEL 4

Este nivel sigue un esquema análogo al del nivel inferior, aunque esta vez cada uno de los seis espacios está cubierto por una bóveda de arista cuya clave está a unos 3,10m del suelo. Parece ser que el primero de los ámbitos según se accede desde las escaleras estaba aislado de los demás a modo de recibidor, con dos puertas a norte y este respectivamente.

De nuevo, aparecen arcos de descarga en ambas direcciones, pero esta vez los arcos que van de norte a sur son más anchos que los que discurren de este a oeste. Esta peculiaridad se comentará más adelante, pero puede ser debida al tipo de relleno empleado hasta alcanzar la cota horizontal del nivel inmediatamente superior.

Otra novedad es que aparecen también en los muros norte y sur pilastras que sobresalen del muro donde descansan los arcos principales de descarga; aunque éstas son de menor dimensión a las que se presentan en los muros este y oeste.

Estas asimetrías hacen que los 6 espacios sean sensiblemente rectangulares, más alargados en la dirección este-oeste y originando pilares cruciformes también rectangulares.

En toda la planta, pese a estar parcialmente calcinada, se conservan los revestimientos y es difícil adivinar los materiales. En algunos desprendimientos parciales se aprecia que los pilares, arcos y bóvedas son de ladrillo, quedando como en el resto de casos como incógnita los muros perimetrales. No puede discutirse si fueron o no empleadas cimbras en la construcción de las bóvedas, pero sí puede comentarse que era el nivel donde más difícil resultaba sacar las cimbras una vez finalizado el trabajo, ya que no cuenta con ningún acceso desde el exterior

El suelo es de baldosas cerámicas del tipo $14 \times 29 \mathrm{~cm}$ o de algún derivado del ladrillo empleado, de aparejo convencional. La escalera que da acceso a este nivel, desde el nivel 3, continúa subiendo hacia el nivel 5, contándose diez peldaños hasta el mismo.

Por último, este nivel se encuentra iluminado mediante dos ventanas, una en el muro sur y otra en el muro oeste, ambas abocinadas, situadas a una altura media y con un alféizar ascendente hacia el exterior.
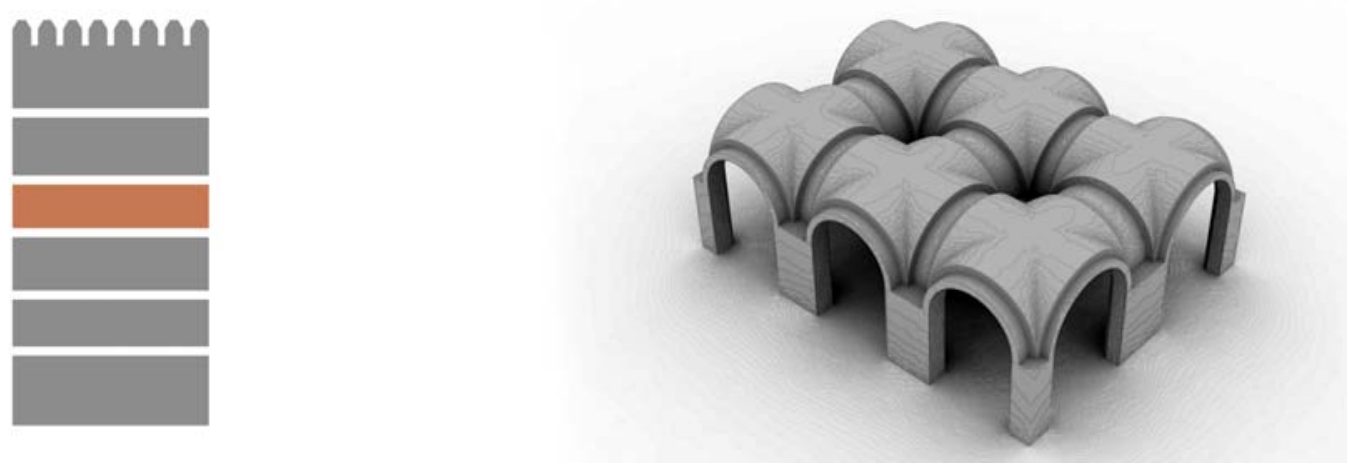

Fig.11 - Sistema estructural interior. Nivel 4 
Este nivel también se encuentra dividido en seis ámbitos. Cada uno de ellos cubierto con un tipo de cúpula distinto, sin que encuentre más explicación razonada que la puramente estilística. Desde el primer ámbito según se sale de las escaleras se accede al adarve de la muralla este, a través de un paso trapezoidal. No está muy claro si este paso es contemporáneo a la torre o no, ya que es sabido que esta muralla fue reforzada y reconstruida en el siglo XIV, no pudiéndose establecer con claridad si la muralla original llegaba a este nivel o fue más bien su refuerzo y la construcción de la torre quebrada lo que propició la aparición de esta entrada.

Como ya ocurría en el nivel inferior, los arcos de descarga están en los cuatro laterales y crean sendas pilastras que sobresalen del muro; de nuevo las ubicadas en los muros norte y sur son de menor dimensión que las dispuestas en los muros este y oeste.

Los arcos de descarga principales vuelven a ser más anchos en la dirección norte-sur, por lo que generan una asimetría en planta que provoca pilares cruciformes rectangulares. Todos estos arcos marcan una altura en la clave de unos $2,85 \mathrm{~m}$ desde el suelo, sin embargo, las diferentes tipologías de cúpula empleadas hacen que las alturas de cubrición de cada espacio varíen.

Al contrario de lo que ocurre en la planta inferior, estas asimetrías no provocan que los espacios sean rectangulares; en este caso se mantienen cuadrados. Esto, probablemente es debido a la mayor complejidad en la ejecución de las cúpulas que requería una geometría más pura. Casi con toda seguridad fue necesario emplear cimbras en la construcción de este nivel.

Si consideramos el ámbito al que accedemos desde la escalera como el número uno y numeramos en el sentido de las agujas del reloj encontramos los siguientes tipos de cúpula:

1.-Casquete esférico rebajado sobre pechinas construidas a partir de bóveda vaída. Cota de clave: (+4,05m sobre el suelo)

2.-Casquete esférico rebajado sobre anillo circular de descarga, apoyado éste sobre arcos de descarga principales y arcos secundarios cerrados con trompas de bóveda de arista. Cota de clave: $(+3,80 \mathrm{~m}$ sobre el suelo)

3.-Bóveda octogonal de espejo y de paños rectos sobre anillo octogonal de descarga, apoyado éste sobre arcos de descarga principales y arcos secundarios cerrados con trompas de bóveda de arista. Cota de clave: (+4,20m sobre el suelo)

4.-Bóveda esquifada de espejo sobre cajón cuadrado sin trompas. Cota de clave: $(+4,05 m$ sobre el suelo)
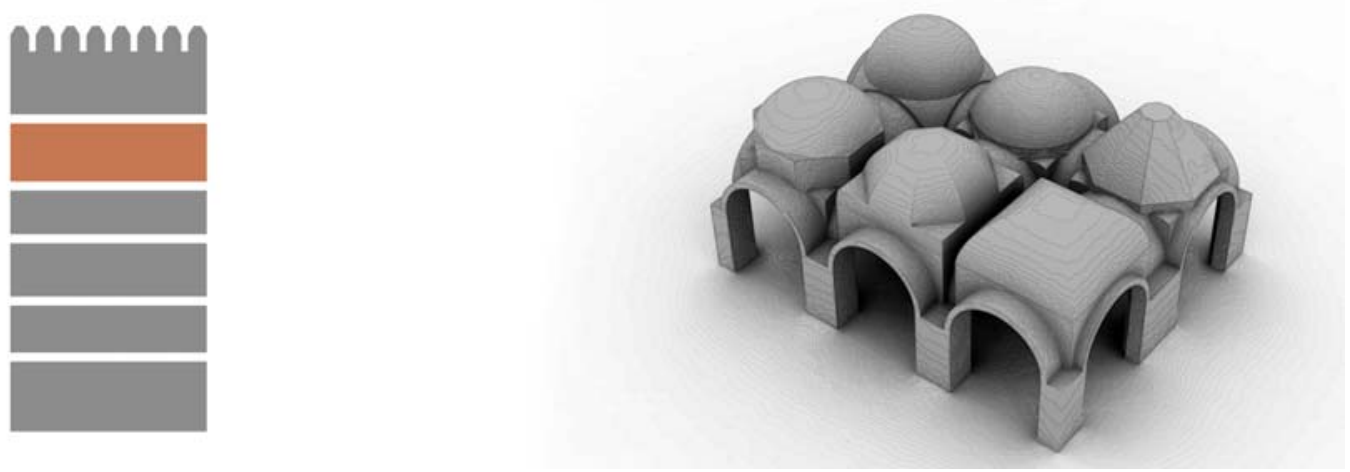

Fig.12 - Sistema estructural interior. Nivel 5 
5.-Bóveda octogonal de espejo apoyada cuatro de sus lados sobre arcos secundarios de descarga que, a su vez descargan sobre los arcos principales. Los otros cuatro paños apoyan sobre arcos secundarios de menor dimensión en las esquinas resueltos con trompas de arista. Cota de clave: $(+4,15 \mathrm{~m}$ sobre el suelo)

6.-Casquete esférico rebajado sobre tambor octogonal con arcos internos, descansando éste sobre un anillo octogonal colocados sobre arcos de descarga primarios y secundarios con trompas de arista en las esquinas. Cota de clave: $(+4,15 \mathrm{~m}$ sobre el suelo)

La iluminación del nivel se realiza mediante 3 ventanas (además de la puerta que da al adarve de la muralla este). Dos de ellas se colocan en el muro norte, mientras que la tercera se coloca en el muro sur. En sección vuelven a tener forma de tronera, con el alféizar inclinado verticalmente hacia el exterior.

Por último, el suelo es de baldosas cerámicas tipo $14 \times 29 \mathrm{~cm}$ o de algún derivado del ladrillo, dispuesta esta vez en aparejo en zig-zag. 


\section{NIVEL 6 Y TERRAZA}

Este nivel es bastante singular, ya que no se tiene constancia de muchos ejemplos donde se reprodujera en la última planta de una torre una vivienda típica alrededor de un patio.

Esta tipología era habitual en las viviendas de alto rango militar dentro de la alcazaba. Se organizaba con cuatro estancias en el perímetro dejando un patio cuadrado en el centro. En su geometría original sólo se conserva la nave sur, que estaba cubierta por una bóveda de cañón. Casi con toda probabilidad el resto de estancias estaban cubiertas con una solución análoga, aunque la solución que se presenta actualmente es de techo horizontal sostenido mediante un entrevigado de madera. Esta restauración se debe al arquitecto Mariano Contreras, que la acometió a mediados del siglo XIX

Aunque algunos textos proponen que el propio Mohammed Alhamar tenía su residencia en la torre, mientras el palacio nazarí estaba en construcción, sólo se encuentra documentado que sirviera de vivienda al alcaide de la alcazaba durante el siglo XIV y XV. En esta planta las dimensiones de los muros están ya muy disminuidas y los huecos en las ventanas son mucho mayores. No está muy claro cómo pudo realizarse de una forma razonable la transición de planta cuadrada a planta con seis ámbitos abovedados, aunque con posterioridad se discute este asunto.

Por último, sobre este nivel y accediendo a través del núcleo de comunicación principal llegamos al último nivel, rodeado de almenas prismáticas coronadas por una pirámide truncada de base rectangular. Como indica el buen haber defensivo, los huecos entre almenas son menores que las propias almenas, de forma que era sencillo para el soldado encontrar cobijo tras de ellas.

La geometría de estas almenas también se debe al arquitecto Mariano Contreras, ya que se tiene constancia por dibujos del siglo XIX que éstas habían sucumbido mucho antes, no sabemos si a causa de algún temblor o por algún asedio de artillería. Parece ser que la geometría actual es muy parecida a la original, aunque se considera que las actuales son bastante más altas que aquellas.
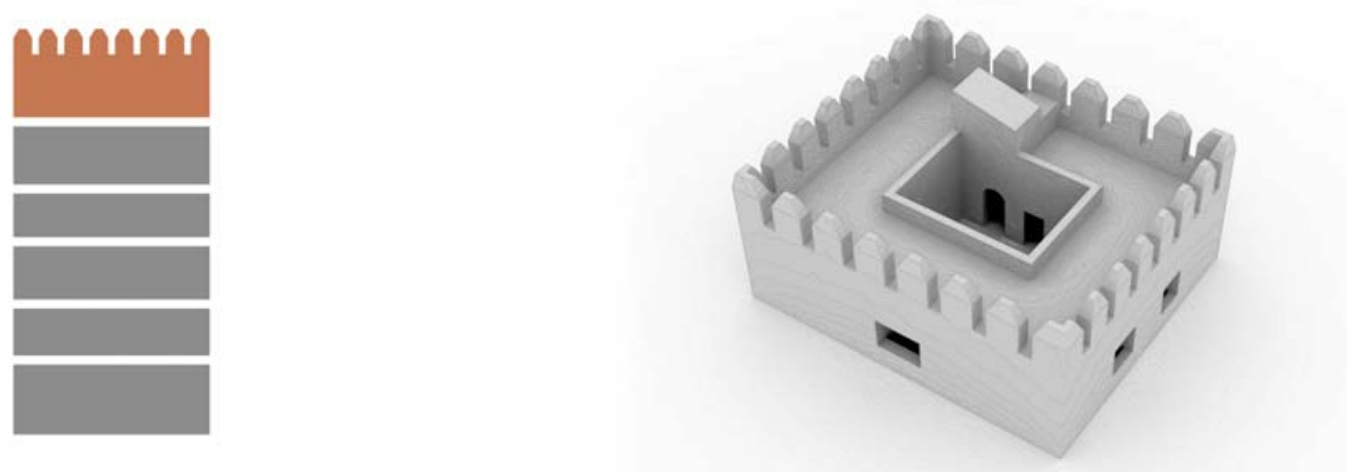

Fig.13 - Sistema estructural interior. Nivel 6 y terraza 


\section{ESTRUCTURAS DE OBRA DE FÁBRICA. ASPECTOS GENERALES}

Conviene recordar brevemente las particularidades de una obra construida principalmente en fábrica. La principal dificultad a la hora de analizar este tipo de construcciones es la diferencia de comportamiento entre funcionamiento a compresión y funcionamiento a tracción. Aunque este comportamiento podría asemejarse al de un hormigón en masa, los elementos de fábrica no tienen la capacidad de enlace que tienen aquellos, presentando además un enorme margen de incertidumbre propiciado por varios motivos:

En primer lugar, por la enorme heterogeneidad de un paramento cuando se analiza en conjunto, más aun si se tiene en cuenta el proceso constructivo de la época. Por ejemplo, la resistencia a compresión de algunas piezas cerámicas es el doble o el triple de otras obtenidas dentro del mismo elemento estructural. Esto es comentado por 'S. Huertas' en su tesis doctoral cuando relaciona varias campañas de ensayos realizadas en edificios de la antigüedad.

En segundo lugar, el mortero es también enormemente variable ya que no siempre se empleaba la misma dosificación y no siempre era posible obtener materiales igual de homogéneos.

En tercer lugar, la mano de obra. Al ser una técnica eminentemente artesanal dependía mucho de la pericia y experiencia de los constructores levantar un muro sólido o uno débil aun contando con la misma materia prima.

Por último, la técnica de aparejo jugaba un papel fundamental. En este tipo de elementos, la geometría juega un papel fundamental como procedimiento de optimización. A lo largo de la historia se han empleado, por ejemplo diversos tipos de aparejos de ladrillo buscando mejorar la cohesión, por ejemplo en la construcción de cúpulas. Así mismo, se constata que el empleo de diferentes espesores de junta estaba relacionado con una voluntad de mejora en la cohesión. Por ejemplo, jugaba un papel importante a la hora de construir bóvedas y arcos sin necesidad de cimbras. En este sentido pueden servir de ejemplo las bóvedas presentes en el nivel $5^{\circ}$ de la torre, donde hay una clara voluntad de experimentación que mezcla la experimentación estilística y la bondad estructural. Se comentará más ampliamente con posterioridad.

Por otro lado, esta heterogeneidad y este comportamiento basado en la cohesión de sus partes convierten a estas estructuras en elementos con una gran capacidad de adaptación a las cargas actuantes, pudiendo cambiar su mecanismo de trabajo. Por ejemplo una cúpula puede fisurarse ampliamente y pasar del modelo de arcos bidireccional a funcionar como un conjunto de arcos independientes, o comportarse como un casquete sin fisurar apoyado sobre un conjunto de arcos. Las hipótesis pueden ser variadas, sólo se precisa que la cantidad de enlaces sea abundante y la bidireccionalidad del elemento alta.

Dado que en general estas estructuras son 'unirresistentes' es preciso cerciorarse que la resultante de pesos y empujes se mantiene dentro de la propia geometría. Es por esto, que el peso propio de la estructura, que dota de mayor resistencia transversal al elemento, unido a la optimización geométrica como camino para reducir los empujes laterales y acotar los posibles mecanismos de falla sean dos de los aspectos principales en el diseño y análisis de este tipo de edificios.

Dado que el trabajo se basa en un edificio ya existente parece que no es necesario pasar por los pasos previos habituales de diseño y predimensionado de elementos, pero esto no es de ninguna manera así. Seguimos necesitándolos para comprender mejor los procesos constructivos que se llevaron a cabo, las razones que condujeron a los mismos y la seguridad que cabe esperar de ellos. En este sentido, aunque no siempre se alcanzará un entendimiento completo de los elementos, los siguientes apartados deben tenerse muy en cuenta en el análisis pormenorizado que se abordará luego. 



\section{SISTEMAS CONSTRUCTIVOS EMPLEADOS EN EL EDIFICIO}

\section{ASPECTOS GENERALES}

En cuanto a los materiales empleados para la construcción de la torre, con carácter general podemos decir que se empleó un tipo de tapial calicostrado para el muro perimetral que va perdiendo espesor conforme se sube de nivel. Al interior, los elementos estructurales son de ladrillo cocido, para el que parece que se emplearon varios tipos de piezas y sobre todo de despieces. Los suelos son pétreos o cerámicos y guardan relación con el ámbito que ocupaban. Se emplearon ripios en las plantas inferiores y piezas cerámicas de mayor calidad en las plantas superiores, más vinculadas a vivienda. El resto de revestimientos son de mortero de cal, tanto al interior como al exterior.

A pesar del espesor de los muros no se tiene ningún indicio razonable de que los tapiales fueran de doble muro. Más aun, parece totalmente descartable si pensamos en el carácter marcadamente defensivo del edificio. Este hecho, unido a la imagen de la Torre Quebrada (siguientes páginas) en estado ruinoso a principios del S.XX, que nos sirve para hacernos una idea de las técnicas empleadas en la Torre del Homenaje nos lleva a asumir todos los muros como continuos en todo su espesor.

Una primera duda que surge en el análisis detallado de la geometría de la planta es si los elementos verticales tienen o no una continuidad que podríamos denominar 'lógica' entre plantas. Con carácter general podemos decir que sí, pero cuando analizamos los pilares cruciformes centrales observamos que los arcos de descarga que acometen en una y otra planta no siempre siguen una lógica de disminución de sección en altura como cabría esperar. No se ha encontrado una explicación razonable a este hecho, incluso se ha llegado a considerar la posibilidad de que existiera un cierto desacoplamiento entre plantas, por ejemplo en la imagen de la torre Quebrada no se aprecia claramente un material que recorra la vertical, más bien se aprecia un todo que inunda la sección, aunque no es menos cierto que se trata de una imagen de una ruina y que poco sabemos en realidad de este procedimiento. Entendemos que existe un núcleo más o menos constante en toda la altura al que se adosan arcos de descarga que no siempre guardan continuidad vertical y que en ocasiones se apean en el pilar vertical principal; se propone esquema al pie.
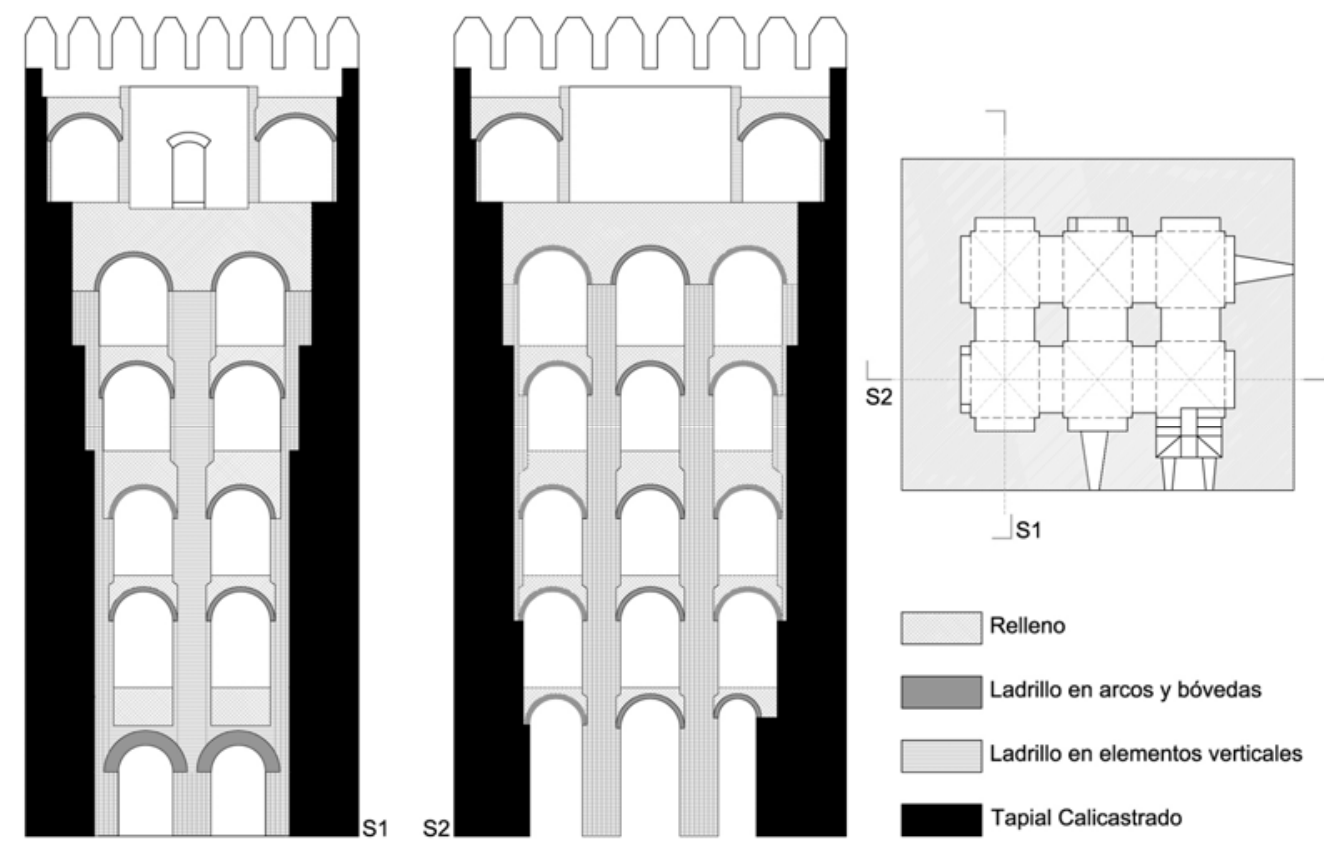

Fig.14 - Materiales y sistema constructivo. Propuesta 
Cuando se analiza la sección tampoco queda muy claro donde termina el tapial y donde comienza el ladrillo ya que en planta, centrándonos sobre todo en los pilares cruciformes y en las pilastras perimetrales surge la duda de si el encofrado del tapial se cajeó; si se hizo un tapial perimetral y luego, una vez levantados los arcos, se rellenó la pilastra o si directamente todo el espesor del elemento es de ladrillo.

Con carácter general parece que se ejecutaba el tapial y luego que construía el interior. Esto es evidente, sobre todo en los dos primeros niveles, como apreciamos en las imágenes al pie de página. En cambio, esta afirmación no es tan clara conforme se va subiendo, ya que el revestimiento y la planeidad de la superficie no dejan claro el procedimiento constructivo seguido. Es bastante posible que en plantas superiores, entre otros motivos por sencillez constructiva, se ejecutaran los arcos de descarga principales sobre las 'esperas' de la planta inferior y luego se usara el ladrillo como encofrado perdido hacia la cara interior del tapial.

Esta hipótesis la barajamos por el modo en que la sección va disminuyendo conforme subimos de nivel. Además, este procedimiento constructivo dotaría de mucho más monolitismo a la torre, ya que estaríamos ante una especie de muro mixto, donde el muro encofrado se levanta de forma que se produzca una mejor trabazón con el tapial, y no construyendo a posteriori. De todas formas insistimos en que es una hipótesis que difícilmente puede ser contrastada si no es por medios de evaluación in-situ que no se disponen para este trabajo.

En cuanto al alza del muro, por la disposición de los mechinales que aparecen en fachada, lo que sí es seguro es que el muro se levantó con sumo esmero, encontrándose éstos cada metro aproximadamente en altura. Conviene resaltar que no todo el muro perimetral, en su aspecto exterior presenta reconocibles estos mechinales. Esto probablemente se debe a sucesivas reparaciones que se harían con posterioridad, aunque llama la atención sobre todo la cara sur de la torre, en la que la parte ejecutada con tongadas de tapial calicostrado está visiblemente libre de estos mechinales sin que tengamos una explicación razonable.
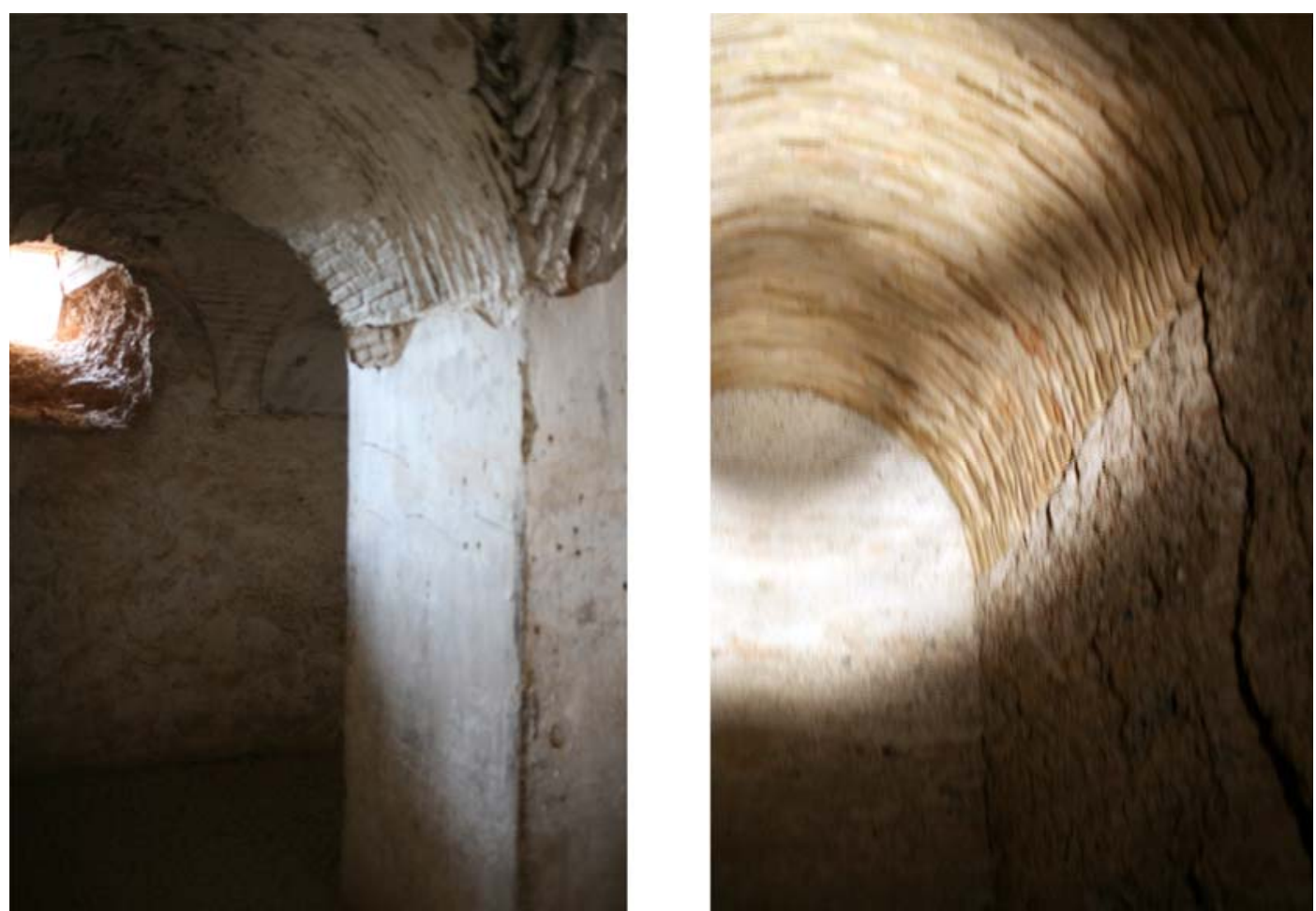

Fig.15 - Interior del nivel 2 (a la izquierda) y del nivel 1 (a la derecha) 


\section{EJECUCIÓN DEL TAPIAL CALICOSTRADO}

El tapial calicostrado del que venimos hablando en el texto se refiere a un tipo de tapial característico de algunas partes de la Alhambra. Se empleó generalizadamente, sobre todo cuando se pretendía un ahorro económico frente al tradicional.

La técnica constructiva era parecida al tradicional. Se conformaban encofrados de madera que se zunchaban con troncos de madera verticales y otros horizontales que atravesaban total o parcialmente el muro. En la parte superior, normalmente los troncos verticales se ataban con cuerdas del exterior al interior del muro de forma que el material no abriera el encofrado.

Una vez listo el encofrado se colocaban tongadas más o menos delgadas del material que se compactaban con algún tipo de pisón pesado. Una vez rellena toda la altura del encofrado éste se retiraba y se continuaba subiendo.

En la Torre del Homenaje los tramos se ejecutaban de metro en metro aproximadamente y las tongadas que se aprecian son de entre 4 y 5 centímetros. No podemos saber si las traviesas horizontales atravesaban el muro por completo o no, ya que al interior el muro se encuentra revestido y no resulta apreciable.

La particularidad de este tipo de tapial reside en que no se usaba un material homogéneo, sino que se iban colocando de forma alterna tongadas más ricas en arcilla (las rojizas) y tongadas más ricas en cal (blanquecinas). En general, las tongadas de cal se colocaban en forma de cuña (ver esquema abajo) y ocupando sólo parte del espesor del muro. Al compactar el conjunto, las capas de cal acababan formando una superficie más o menos homogénea al exterior que, además era impermeable, por lo que no era preciso revestirlas luego.
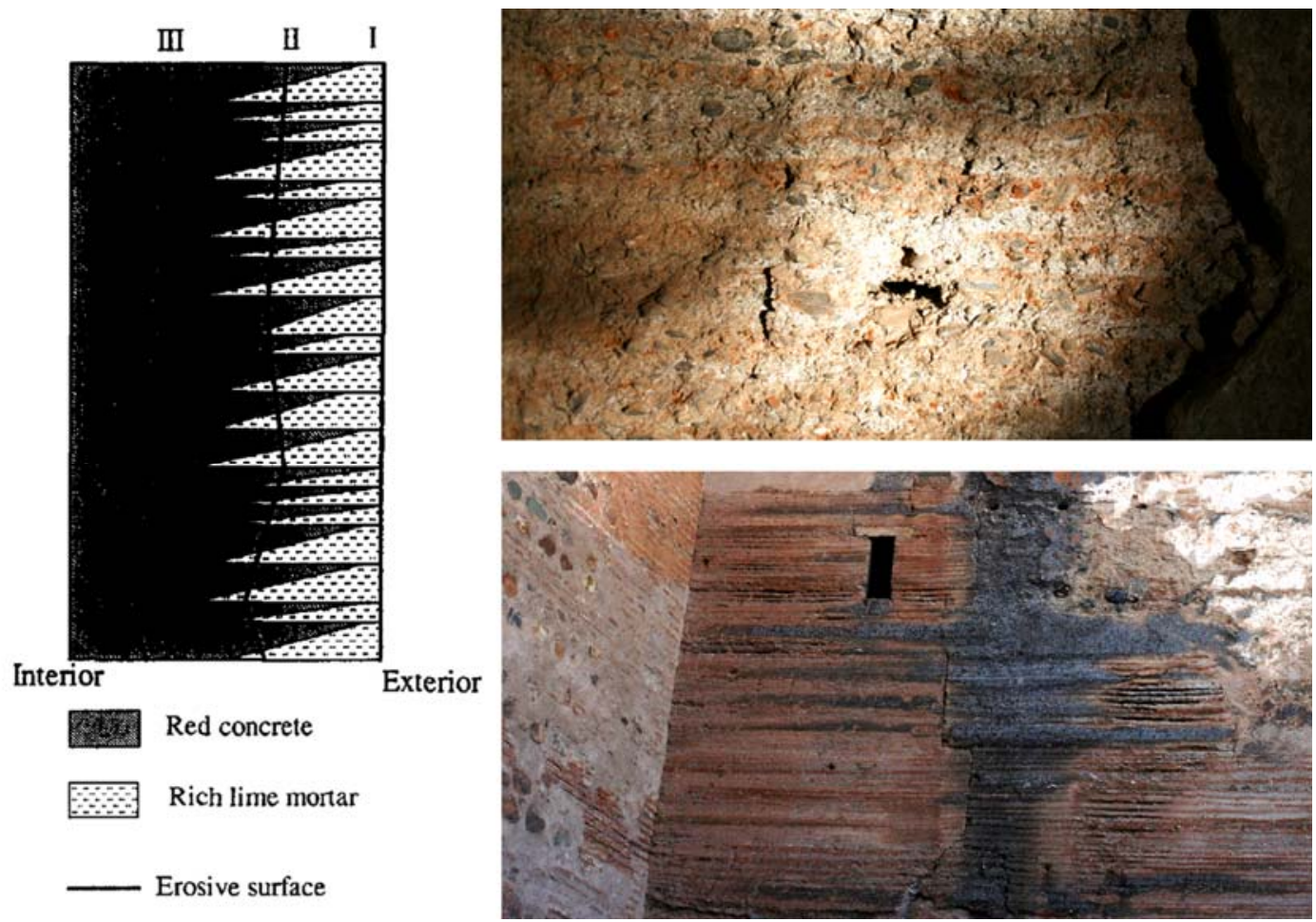

Fig.16 - Esquema del tapial calicostrado (Izquierda). Tapial en el interior del nivel 1 (derecha-arriba). Tapial en parte del muro exterior (derecha-abajo) 
En el primer nivel de la torre, al menos, esta técnica también era empleada al interior. Probablemente, dado que el suelo de este nivel es el propio terreno y que no existían ventanas se preveía una importante concentración de humedad en el ambiente que recomendaban protegerlo. Es por ello que se colocaron tongadas de cal también al interior.

Este sistema tenía varias ventajas evidentes:

-Se ahorraba una cantidad considerable de dinero, comparado con los muros que se ejecutaban en todo su espesor con hormigón de cal. Sobre todo cuando se requería mucho espesor. Además esta técnica no suponía una pérdida de resistencia importante.

-Se ahorraba colocar revestimientos exteriores que además solían acabar por caerse, ya que se ejecutaban posteriormente sobre una superficie más o menos lisa. La capa de cal exterior que resultaba con este tapial, al ser las tongadas en cuña tenía un perfil en diente de sierra que mejoraba mucho la adherencia y propiciaba que fueran mucho más duraderos.

-Mejoraba la durabilidad general del muro. Se observa que los muros ejecutados con esta técnica, frente a lo de arcilla compactada y revestimiento externo están mucho mejor conservados y los procesos de erosión que han sufrido son mucho menos agresivos.

Para la conformación de los huecos, todos abocinados, se empleaba una traviesa de madera a modo de dintel que se colocaría en el mismo momento de la ejecución del tapial. En casi todos los huecos aparece un dintel al interior y otro al exterior.

\section{LA DIVERSIDAD DE APAREJOS}

Como ya se ha comentado, para mejorar la trabazón de la fábrica, los alarifes contaban principalmente con dos recursos, con los que continuamente experimentaban.
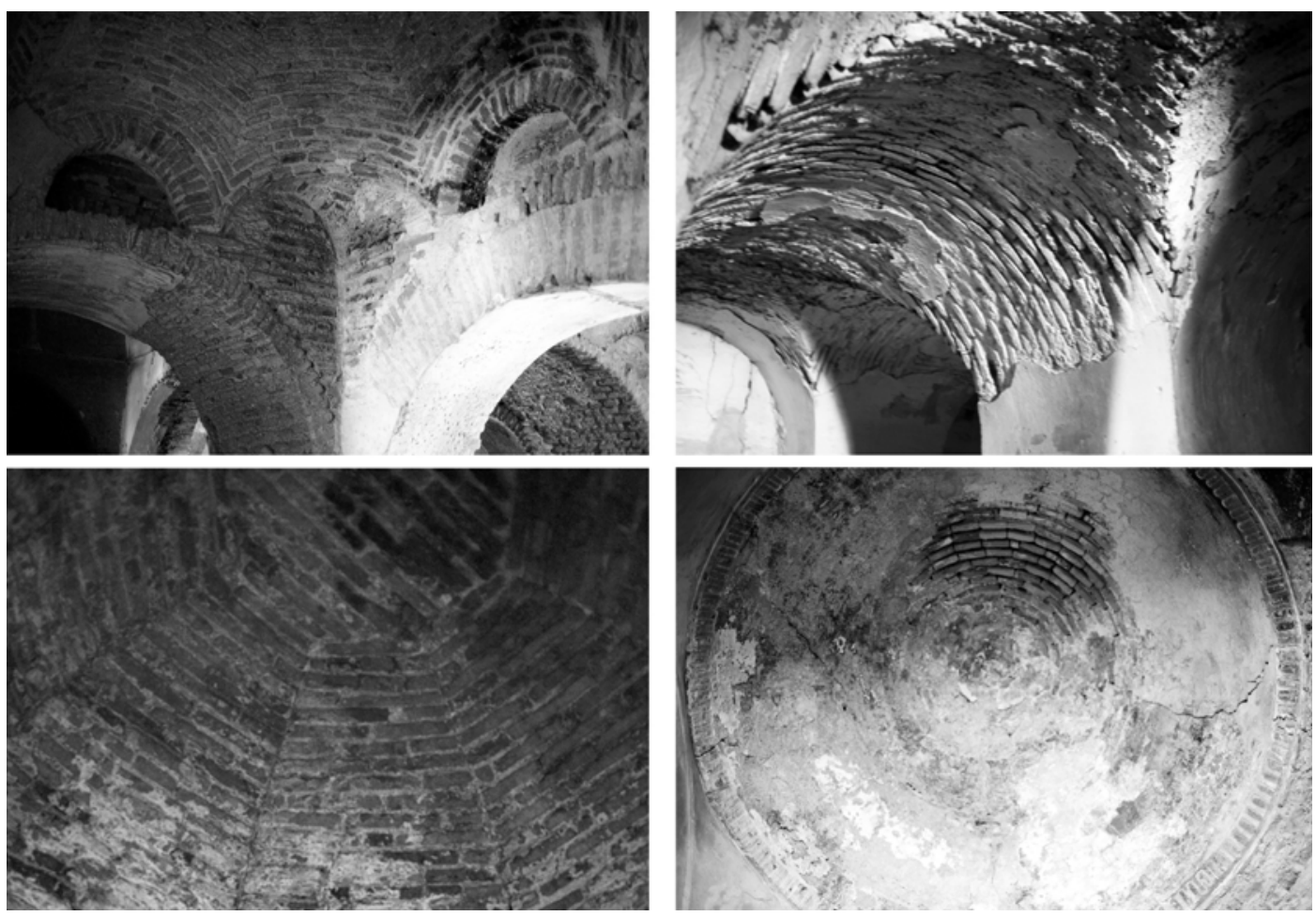

Fig.17 - Algunos de los aparejos empleados en la Torre del Homenaje 
El primero era el manejo del espesor de la junta, encontrándose que las juntas gruesas admiten cierta capacidad de tracción y, sobre todo, mejoran la cohesión consiguiendo mayor resistencia transversal sin necesidad de importantes tensiones axiales.

En segundo lugar, estaba la disposición de los aparejos de ladrillo. En general existían dos tipos de ladrillo. El de dimensiones clásicas (en torno a $25 \times 11 \mathrm{~cm}$ ) y el que se obtenía de partir en triángulo plaquetas cuadradas. Por ejemplo, sabemos que el uso de estas piezas triangulares conseguía una mejor traba, sobre todo cuando se empleaban rellenos en trasdós.

La disposición de los aparejos en la torre es variada, apreciándose una voluntad de experimentación, sobre todo en el nivel 5. Algunas de las tipologías de cúpulas y bóvedas que aquí se ensayaron se generalizaron posteriormente en otras construcciones de la Alhambra. Dependiendo del ámbito y la geometría de que estemos hablando se empleaban despieces en espina de pez, clásicos a soga y tizón, aparejos en testa, etc...

Aunque este asunto requeriría de una mayor atención no es este el objetivo del trabajo y no se tienen datos suficientes para abordar un estudio serio detallado en estos términos.

\section{LA CONSECUCIÓN DEL PISO HORIZONTAL}

En cuanto al método de cubrición que se emplea en la torre, mediante distintos tipos de bóvedas y cúpulas, sin cubriciones planas plantea una dificultad cuando llega a la necesidad inexorable de contar con un piso horizontal en la planta inmediatamente superior.

Es bien sabido, que en este tipo de geometrías el tipo de relleno empleado y la geometría del mismo juega un papel muy importante. Por ejemplo, era habitual en la época cargar los riñones de los arcos para evitar levantamientos en los apoyos, pero al mismo tiempo un relleno excesivo provocaba agrietamientos considerables en las cúpulas. Esto hace inevitable que nos preguntemos como se ejecutaron estas zonas del edificio.

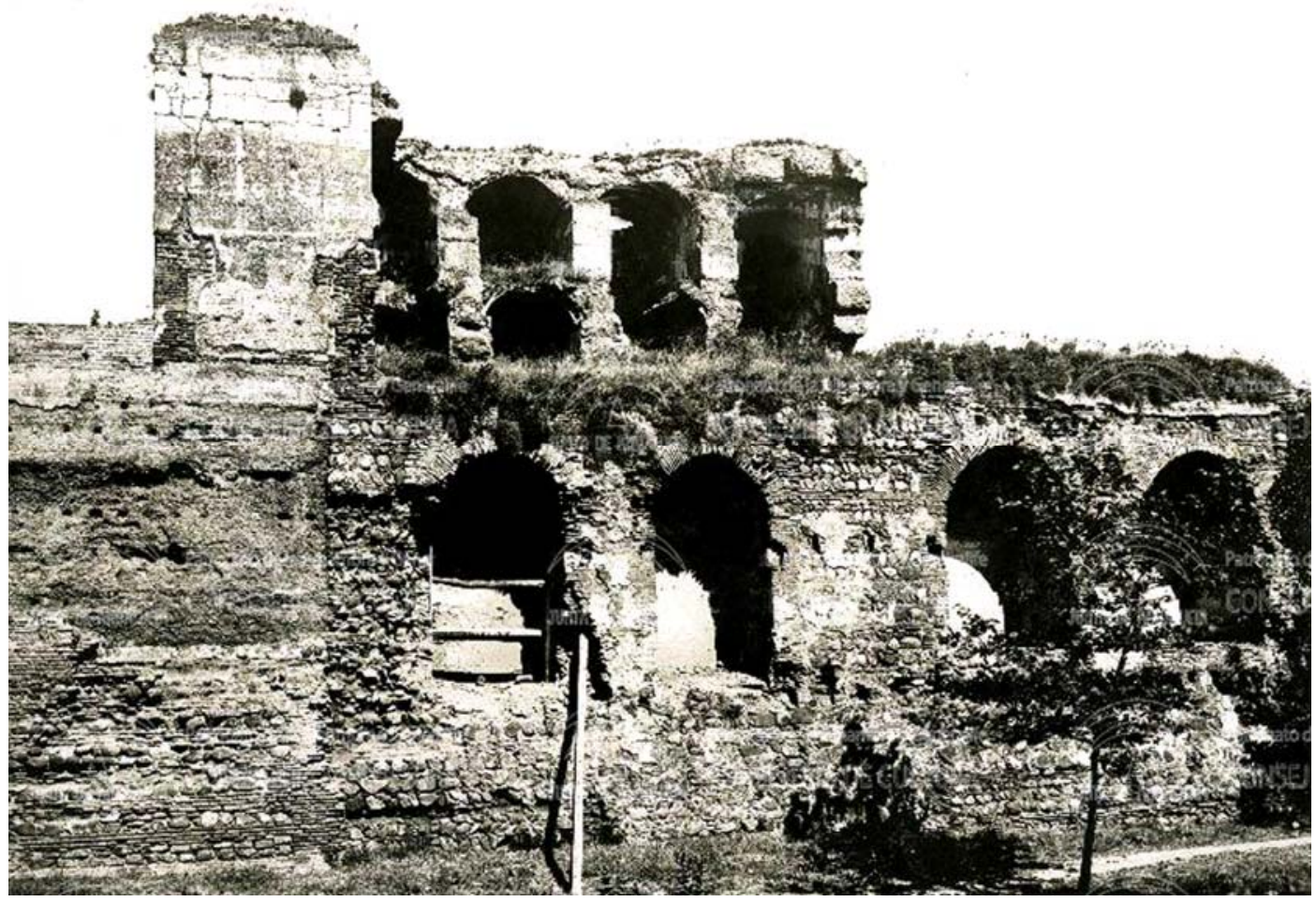

Fig.18 - Ruinas de la Torre Quebrada (Anexa a la Torre del Homenaje). Principios del S.XX 
Por un lado, la hipótesis más plausible, dada las dimensiones reducidas de los ámbitos en planta de la torre, es que se ejecutara un relleno de argamasa y ripios hasta alcanzar el nivel superior, que luego se compactaría hasta quedar horizontal preparándolo así para recibir la solería.

Esta teoría se ve reforzada por la imagen en ruina de la Torre Quebrada, anexa a la Torre del Homenaje, en la que se aprecia que el relleno es más o menos homogéneo hasta llegar al nivel superior.

En el informe técnico elaborado por CEDEX sobre la Torre de Comares, muy cercana a la Torre del Homenaje, se constató que los rellenos eran de un material bastante similar al del tapial y que, casi con toda seguridad no tenía aligeramientos.

Sin embargo, existen algunas particularidades que conviene mencionar y que apoyan la tesis de que se usó cierto aligeramiento.

En primer lugar, está documentado que en la época era habitual emplear una técnica que consistía en una especie de cubierta sobre palomeros. Se levantaban tabiquillos paralelos que nacían en las bóvedas y en los arcos de descarga y que alcanzaban cierta cota horizontal formando un sistema unidireccional de paramentos paralelos que se cubrían con pequeñas bóvedas de cañón rebajadas ejecutadas con ladrillo en testa. Era a partir de estas bóvedas desde donde se rellenaba hasta alcanzar la cota horizontal del nivel superior.

Esta técnica era descrita como beneficiosa para el sistema de cúpulas, ya que aligeraba sustancialmente su interior.

En segundo lugar, el espesor de relleno presente en el edificio varía según en qué nivel estemos. Es bastante menor en los 3 primeros niveles que en los posteriores, esto puede indicar que en las plantas superiores se empleó este sistema de relleno aligerado.

Esta hipótesis se encuentra respaldada, a su vez, por la distribución en planta de los arcos de descarga principales. Podemos observar que, en la línea de carga N-S los arcos cuentan con un mayor ancho que en la dirección E-O. Esto ocurre sólo en el nivel 4 y 5 , siendo en el resto simétricos.

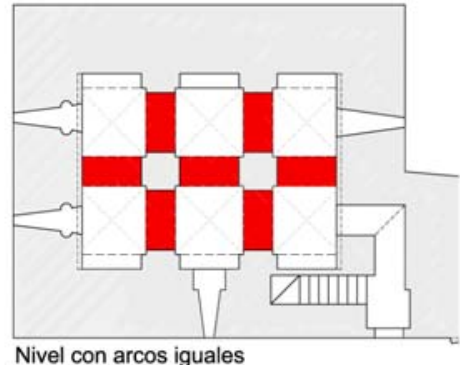

Nivel con arcos iguales

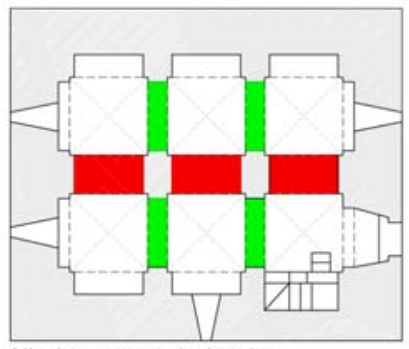

Nivel con arcos desiguales

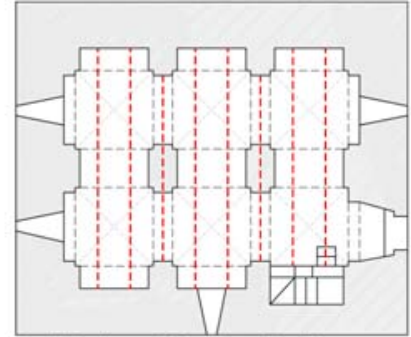

Posible disposición de tabiquillos

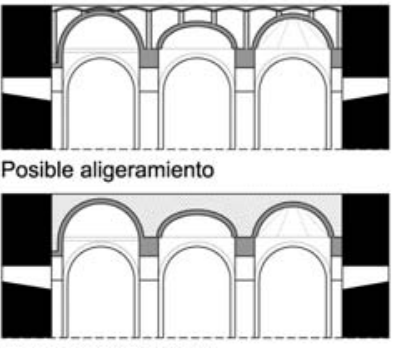

Relleno convencional

Fig.19 - Posible sistema de aligeramiento de la zona de relleno 
Este motivo nos lleva a pensar que pudo incrementarse el ancho de los mismos por razones constructivas, de forma que quedara un mayor espacio para poder apoyar muros de aligeramiento paralelos a la dirección E-O

Por último en las plantas inferiores se emplea como solería terminada ripios o ladrillos de canto, generando una superficie bastante irregular. En cambio, en el nivel 4 y 5 se emplean despieces de solería cerámica más cuidados y de una horizontalidad mucho mayor. Este hecho también puede tener que ver con el procedimiento constructivo que venimos comentando.

\section{LA EJECUCIÓN SIN CIMBRA}

En los escritos de la época, Mohammed Ibn Alhamar, describe como uno de los males de Granada la dificultad para conseguir madera a un precio económico.

Este hecho, unido a las pequeñas luces que se manejan en la torre y a los reducidos y complicados accesos a la misma nos lleva a pensar que, tal vez, muchas de las bóvedas y cúpulas del edificio se ejecutaron sin necesidad de emplear cimbras provisionales de madera.

Los revestimientos que se conservan actualmente en la torre no posibilitan estudiar detalladamente si los aparejos pudieron hacerse con esta intención. No obstante, el empleo de morteros muy gruesos, unido al sistema de construcción del tapial que discutimos con anterioridad en el que el ladrillo se emplearía como encofrado perdido nos hace pensar que es muy probable que, al menos en casi todos los niveles se empleara esta técnica.

Quizá el nivel donde menos probable es que se empleara este sistema es el nivel 5, donde las diferencias entre cúpulas de distintos ámbitos es amplia y los sistemas son de mayor complejidad. En cambio, el nivel 4 parece muy propicio para su ejecución sin cimbra, ya que cada ámbito se encuentra cubierto por una bóveda de arista de reducidas dimensiones que bien puede ajustarse a este procedimiento constructivo.
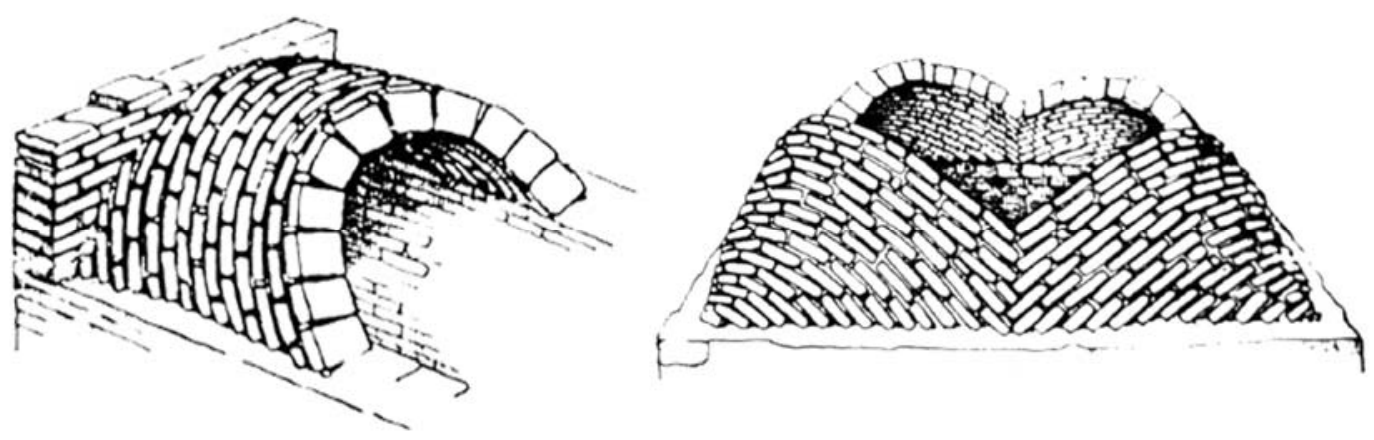

Fig.20 - Disposición de los aparejos para la ejecución de bóveda de cañón y bóveda de arista sin cimbras. 



\section{CARACTERIZACIÓN DE LOS MATERIALES}

Las fuentes para realizar una correcta caracterización de los materiales son bastante diversas y se encuentran más o menos desarrolladas en función del tipo de material que estemos estudiando.

Aunque los trabajos de 'M.J. de la Torre López' son muy completos en cuanto a caracterización de los materiales empleados en la Alhambra, estos se centran en su caracterización química y mineralógica, no ofreciéndose datos a cerca de sus propiedades mecánicas, que son de especial interés en este trabajo.

En cuanto a experimentación directa, sólo disponemos de un estudio para caracterizar los materiales presentes en algunas zonas de la Torre de Comares, que podemos suponer similares a los de nuestro edificio.

Por otro lado, resulta bien distinta la caracterización del tapial y la caracterización del ladrillo. En el caso del tapial, podemos considerar el material más o menos homogéneo en todo el desarrollo de la torre $y$, parece razonable, establecer un valor medio atendiendo a campañas experimentales de elementos similares de la zona.

En cuanto al ladrillo, las referencias son más amplias, pudiendo recoger incluso valores normativos vigentes. En cambio, sus fuentes de heterogeneidad y no-linealidad son mucho mayores, entrando en juego la interfaz ladrillo-mortero y el tipo de aparejo empleado, por lo que este apartado podría dilatarse todo lo que quisiéramos.

Para los estudios que pretendemos realizar consideraremos como suficiente la caracterización de un solo material para el tapial y de un solo material para el ladrillo (ambos isótropos), aunque en los próximos apartados trataremos de recoger de forma más detallada esta disparidad de datos a los que se han hecho referencia.

\section{EL TAPIAL CALICOSTRADO}

Como se ha comentado antes, el comportamiento del tapial puede considerarse más o menos homogéneo $y$, aunque depende del material que lo constituye y del esmero empleado en su compactación, distintos estudios experimentales sitúan su resistencia característica a compresión entre los 3 y los $10 \mathrm{MPa}$

Por otro lado, sabemos que la ejecución del tapial calicostrado suponía una merma en las propiedades resistentes del mismo respecto a uno convencional, por lo que son de esperar valores en el rango inferior de resistencias.

Frente a otros materiales, el tapial cuenta con un vacío normativo en cuanto a valores mínimos y ensayos de caracterización. Sólo algunos países cuentan con normativas al respecto. Por ejemplo, en EEUU los ensayos normalizados para adobe estabilizado son ASTM D559-44 y D560-44

Contamos con datos experimentales elaborados por el CEDEX en el marco de actuación de "Caracterización geotécnica de las condiciones de cimentación del conjunto monumental de la Alhambra y Generalife" que se centran en la caracterización de la Torre de Comares (muy cercana a la Torre del Homenaje) y que emplean ensayos mecánicos similares a los empleados habitualmente en hormigón.

El tapial de la Alhambra, en general, muestra características similares a la denominada "formación Alhambra", terreno sobre el que se asienta. Dicha formación está compuesta por una matriz arcillosa con inclusiones de cal de distinto tamaño, así como zonas donde existe una mayor concentración de arcilla. En cuanto a los áridos, silíceos y calizos, son de forma 
redondeada y de gran variedad de tamaño, siendo menor el tamaño del árido que constituye la estructura que el de la cimentación.

Los resultados medios que se adoptaron en el estudio del CEDEX referido y que asumiremos como válidos en nuestros modelos son:

\begin{tabular}{ccc}
\hline Propiedad & Valor & Ensayo \\
\hline Densidad aparente & $2,25 \mathrm{~g} / \mathrm{cm}^{3}$ & UNE 83.312-90 \\
\hline Resistencia a compresión & $\begin{array}{c}25 \mathrm{Kp} / \mathrm{cm}^{2} \text { (Estructura) } \\
80 \mathrm{Kp} / \mathrm{cm}^{2} \text { (Cimentación) }\end{array}$ & UNE 83.304-84 \\
\hline Resistencia a tracción & $\begin{array}{c}3 \mathrm{Kp} / \mathrm{cm}^{2} \text { (Estructura) } \\
7,5 \mathrm{Kp} / \mathrm{cm}^{2} \text { (Cimentación) } \\
(\text { Relación } 1 / 8 \text { aprox) }\end{array}$ & UNE 83.306-85 \\
\hline Módulo de elasticidad & $\begin{array}{c}12.000 \mathrm{Kp} / \mathrm{cm}^{2} \text { (Estructura) } \\
63.000 \mathrm{Kp} / \mathrm{cm}^{2} \text { (Cimentación) } \\
(\text { (al } 40 \% \text { de la carga de rotura) }\end{array}$ & ASTM C-469-87 \\
\hline Coeficiente de Poisson & 0,3 (Estructura) & ASTM C-469-87 \\
\hline
\end{tabular}

Estos valores ya fueron empleados por 'M.A. Astiz' en su evaluación estructural de la Torre de Comares.

\section{RESISTENCIA DE LAS FÁBRICAS}

En cuanto a la caracterización de las fábricas de ladrillo, como se ha comentado antes, además de las propiedades mecánicas de los elementos que lo componen (piezas de ladrillo y mortero) es preciso tener en cuenta la forma de la matriz de unión entre ambos, que conducirá a unos u otros valores.

En general, juntas estrechas implica poca resistencia a tracción y una resistencia a compresión cercana a la del ladrillo. En cambio, juntas gruesas conducen a un comportamiento mejor en tracción además de mejorarse notablemente la cohesión entre elementos. Por el contrario, conduce a una muy pobre resistencia a compresión, a veces incluso menor que la del mortero como elemento independiente.

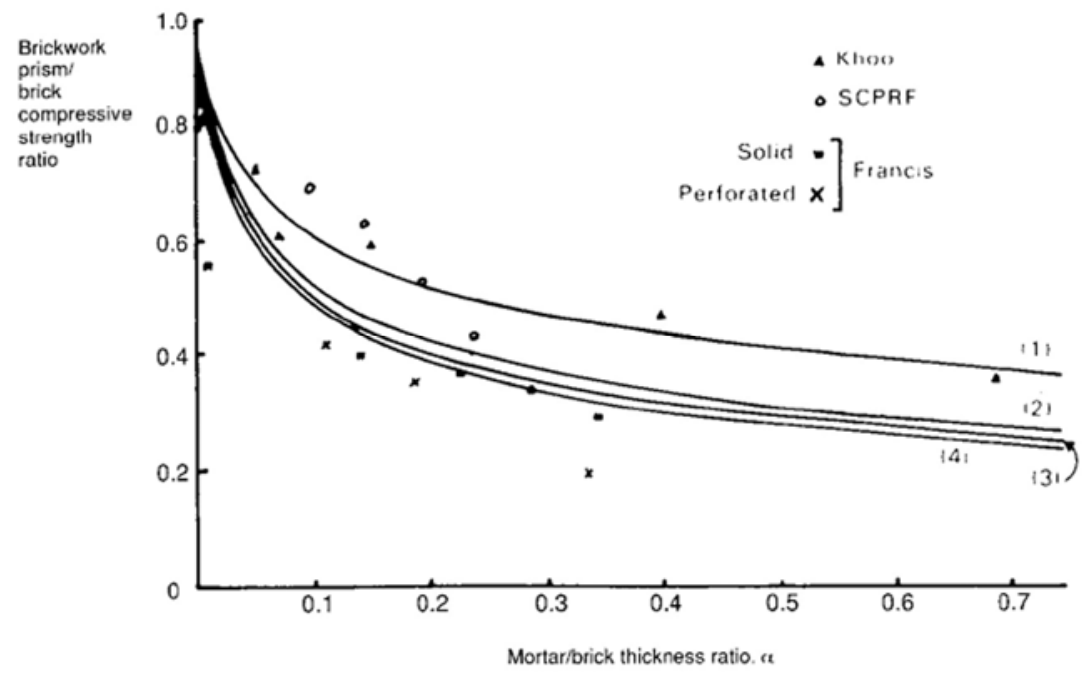

Fig.21 - Influencia del tamaño del espesor de tendel en la resistencia compresión de la fábrica 
Esta influencia ha sido ampliamente discutida por diversos autores, siendo referencia muy recomendable para profundizar en este tema la monografía "Comportamiento mecánico de la obra de fábrica" de J.L.Martínez, J.A.Martín-Caro y J.León

En el estudio del CEDEX se recogen las propiedades de las piezas de ladrillo, no así las del mortero:

\begin{tabular}{ccc}
\hline Propiedad & Valor & Ensayo \\
\hline Densidad aparente & $1,45 \mathrm{~g} / \mathrm{cm}^{3}$ & UNE 67-019-86 \\
\hline Resistencia a compresión & $150 \mathrm{Kp} / \mathrm{cm}^{2}($ Estructura $)$ & UNE 67.026-86 \\
\hline
\end{tabular}

Dado que, además del aparejo y el tamaño de tendeles son de enorme influencia el área efectiva de contacto, la humedad del ladrillo en el momento de la colocación y el nivel tensional, entre otros factores, no es posible determinar experimentalmente las propiedades específicas de un determinado paramento de fábrica. Es por esto que, a partir de las propiedades conocidas del ladrillo y las estimadas del mortero hallaremos los valores de la fábrica según las indicaciones de las normativas vigentes al respecto. En nuestro caso aplicaremos el EC-6 y el CTE-DB-SE-F

\section{EUROCODIGO (EC-6)}

Según la expresión 3.5 del EC-6, la resistencia a cortante asignable a una fábrica es la resistencia inicial más el $40 \%$ de la tensión de compresión perpendicular al esfuerzo cortante:

$$
f_{v k}=f_{v k 0}+0.4 \sigma_{d}
$$

Para los valores de resistencia inicial, pueden tomarse datos, para morteros ordinarios, de la tabla 3.4, que van entre los 0,1 y $0,3 \mathrm{~N} / \mathrm{mm}^{2}$

En cuanto al módulo de deformación, a falta de datos más fiables puede tomarse como módulo de elasticidad secante instantáneo:

$$
E=1000 \cdot f_{k}
$$

Aunque para considerar los efectos de fluencia emplearemos el módulo diferido, corregido por el coeficiente de fluencia a plazo infinito:

$$
E_{\text {diferido }}=\frac{E}{1+\phi_{\infty}}
$$

Como módulo de elasticidad transversal y, a falta de datos más precisos, puede tomarse el $40 \%$ del módulo de deformación longitudinal.

El EC-6 ofrece también una tabla orientativa de valores de fluencia, retracción y dilatación térmica que podemos considerar:

$$
\begin{aligned}
& \text { Fluencia: } \phi_{\infty}=0,5 \text { a 1,5 } \\
& \text { Retracción/Expansión: }-0,2 a+1,0 \\
& \text { Coeficiente de dilatación térmica: } \alpha_{t}=4 a 8\left(10^{-6} / \mathrm{K}\right)
\end{aligned}
$$

Para la determinación de la resistencia de los componentes de la fábrica, el EC-6 remite al anejo nacional, emplearemos el CTE-DB-SE-F 


\section{CTE-DB-SE-F}

El Documento básico que regula el empleo de fábricas en España es el DB-SE-F (deroga la antigua FL-90)

En general, sea cual sea el tipo de pieza, la resistencia a compresión mínima aceptada en España es de $5 \mathrm{~N} / \mathrm{mm}^{2}$

En cuanto al mortero, será suficiente emplear un mortero tipo M1 $\left(1 \mathrm{~N} / \mathrm{mm}^{2}\right)$

Resumidamente y atendiendo a los valores de la tabla 4.4 podemos estimar como resistencia de la fábrica como conjunto:

$$
f_{c k}=3 a 5\left(\mathrm{~N} / \mathrm{mm}^{2}\right)
$$

En cuanto a la resistencia atribuible a cortante, el DB prescribe unos valores parecidos al EC-6, si acaso algo menores para morteros y juntas ordinarias:

$$
f_{v k}=f_{v k 0}+0.36 \sigma_{d} \leq 0.065 f_{b}
$$

Los valores orientativos de resistencia límite a cortante está entre 1,2 y 1,7 N/mm²) para una fábrica maciza convencional.

En cuanto a las consideraciones de deformabilidad, el CTE establece valores análogos al EC-6, por lo que no requiere más comentario.

Con todo esto, los valores medios que adoptaremos en nuestros modelos para caracterizar la fábrica de ladrillo son:

\begin{tabular}{cc}
\hline Propiedad & Valor \\
\hline Densidad aparente & $1,45 \mathrm{~g} / \mathrm{cm}^{3}$ \\
\hline Resistencia a compresión & $40 \mathrm{Kp} / \mathrm{cm}^{2}$ \\
\hline Resistencia a tracción & $2 \mathrm{Kp} / \mathrm{cm}^{2}$ \\
\hline \multirow{2}{*}{ Módulo de elasticidad } & $30.000 \mathrm{Kp} / \mathrm{cm}^{2}$ (Instantáneo) \\
& $16.000 \mathrm{Kp} / \mathrm{cm}^{2}$ (a plazo infinito) \\
\hline Coeficiente de Poisson & 0,25 \\
\hline
\end{tabular}




\section{ANÁLISIS GLOBAL DEL FUNCIONAMIENTO DEL EDIFICIO}

En este apartado vamos a tratar de exponer el mecanismo de funcionamiento del edificio. Si bien parecen evidentes, es conveniente incidir en algunos aspectos y discutir algunas hipótesis antes de validarlos en futuros análisis.

Como resulta evidente, el elemento fundamental en la fiabilidad estructural del edificio es el muro perimetral. Las cargas actuantes son eminentemente el peso propio y el viento.

En general, los problemas en los muros de fachada de edificaciones de la época sobrevienen por un excesivo empuje de los elementos interiores, generalmente arcos o bóvedas, que acaban agrietando el muro, sino llevándolo al colapso.

En la Torre del Homenaje, el sistema de entrepisos dividido en 6 ámbitos independientes es bastante inteligente desde el punto de vista de la optimización del muro perimetral, ya que minimiza el empuje lateral que éste recibe, primando la descarga en los pilares centrales que, por condición de simetría, acaban teniendo una solicitación dominante de compresión centrada.

El camino que recorren las cargas desde el piso horizontal es, primero hacia las cúpulas o bóvedas. Desde éstas, la mayor parte del esfuerzo recae sobre los arcos de descarga, y de éstos directamente al muro o a los pilares centrales.

En algunos niveles parte de las bóvedas descargan directamente sobre el muro perimetral, pero en general podemos decir que el sistema primario de cada planta está compuesto por un sistema de arcos en dos direcciones que conduce las cargas hasta el perímetro o hasta los pilares centrales. Podemos considerar, a efectos prácticos este sistema compuesto por un total de siete arcos que, dependiendo de la planta, se suman a otros diez que aparecen adosados al perímetro y que potencian el comportamiento mediante pilastras adosadas al muro. Puesto que en general se cumplen condiciones de simetría en planta, los esfuerzos horizontales de consideración que llegan al muro se concentran en las esquinas y en los planos de descarga de las pilastras perimetrales.

No parece haber ninguna razón estructural de peso que justifique la asimetría en el ancho de los arcos de descarga. Además de razones funcionales, ya se apuntaron con anterioridad posibles motivos constructivos que justificarían esta morfología.
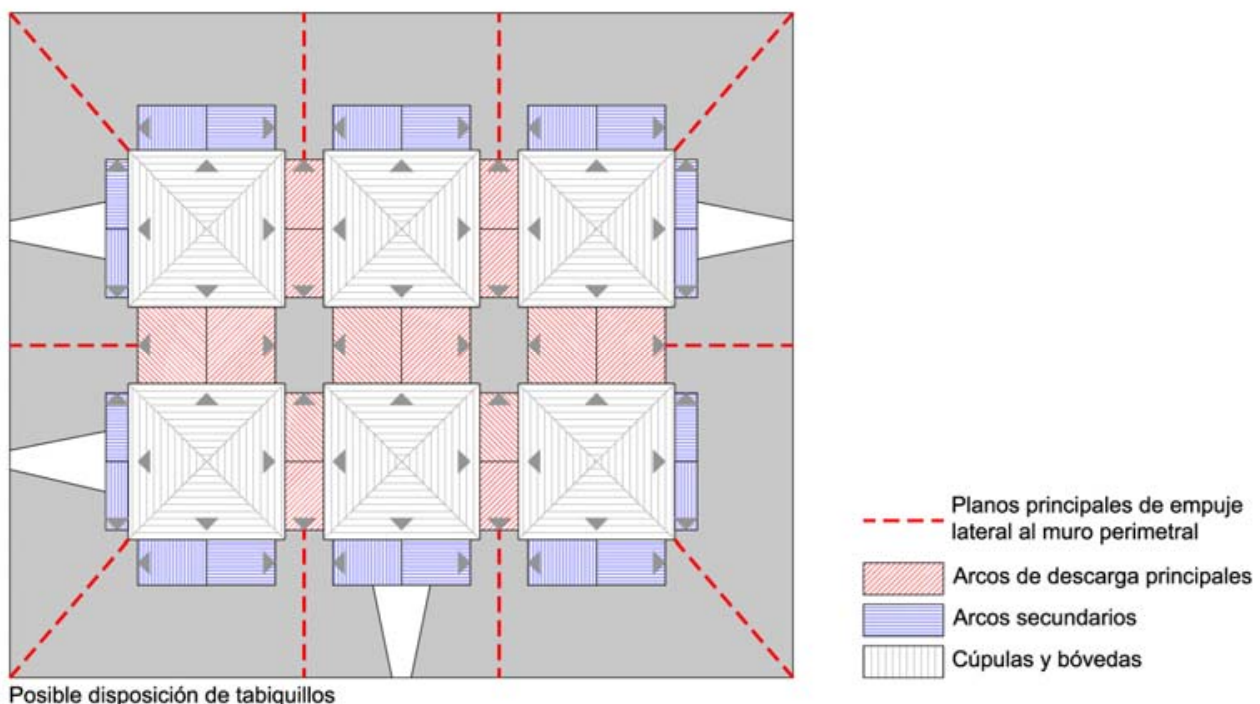

Fig.22 - Esquema de comportamiento global en planta 
Al menos en el nivel 5 parece que esta asimetría es debida a dos motivos principalmente, en primer lugar, al ser las cubriciones más esbeltas del edificio los empujes horizontales son menores. Por otro lado, en casi todos ámbitos se dispone de un tambor de transición entre los arcos de descarga y la bóveda que absorbe los esfuerzos horizontales. Además, los sistemas más o menos complejos que se emplean en esta planta sugieren cierta experimentación y cierto grado de innovación en las técnicas y geometrías empleadas.

Una primera pregunta que deberíamos hacernos es si los arcos de descargas ubicados en el perímetro cuentan con rigidez suficiente como para no transmitir esfuerzos horizontales al muro perimetral y, por tanto, el sistema de descarga a las pilas es el indicado en el esquema anterior o no. Esta cuestión será más convenientemente abordad en los análisis estáticos por plantas.

Sólo en el nivel 1, esta marcada simetría compuesta por seis ámbitos se ve rota. Como vimos en la descripción del edificio, las bóvedas de cañón en este nivel componen en planta tres ámbitos donde, esta vez, los empujes son lineales y directos a los muros norte y sur, mientras que los empujes a los muros este y oeste son prácticamente nulos.

Como ya se ha comentado antes, otra cuestión que debemos plantearnos es si el sistema de ladrillo interior es o no totalmente solidario con el muro de tapial, ya que al levantarse con posterioridad es posible que haya una transferencia de esfuerzos horizontales clara, pero es posible que los esfuerzos verticales se transmitan a través de la pared de ladrillo y no intervengan en el muro de tapial en un primer momento. Esto, unido a su diferente módulo de deformación puede hacer que los acortamientos en uno y otro originen bien esfuerzos rasantes entre ambos, bien un cierto grado de desacoplamiento entre ambos sistemas.

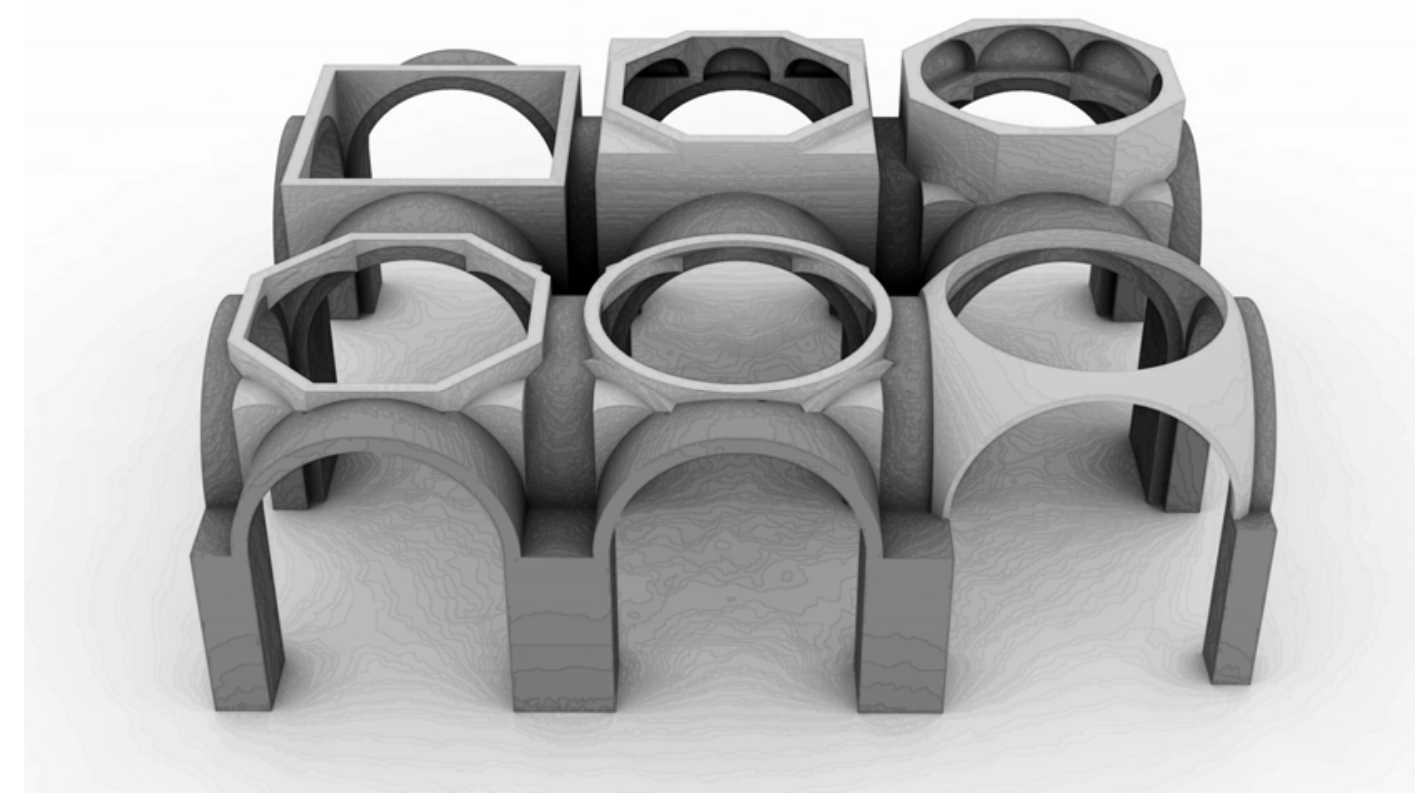

Fig.23 - Sistema de tambores en el nivel 5 


\section{PATOLOGÍAS DOCUMENTADAS HASTA LA FECHA}

Por encargo del patronato de la Alhambra, en 1995 se encargó un estudio titulado "Caracterización Geotécnica de las Condiciones de Cimentación del Conjunto Monumental de la Alhambra y Generalife" al CEDEX, en el que se incluye un amplio registro de patologías detectadas en la Torre del Homenaje, así como de registros de desplomes generales del edificio registrados.

En el informe se hace especial incidencia en la forma troncopiramidal que presenta la torre, con una ligera inclinación del paramento exterior hacia el interior de la misma. Si bien esto es cierto, la variación es mínima y en los posteriores análisis mediante elementos finitos esta particularidad no se ha tenido en cuenta, si bien es cierto que pueden justificar algunas debilidades y matizaciones en las patologías presentadas.

Aunque este documento es muy completo, la mayoría de las patologías no guarda una relación clara entre sí, pudiendo muchas de éstas ser debidas a defectos puntuales o a momentos concretos de la historia del edificio.

Sí cabe destacar, por su especial incidencia algunas apreciaciones de carácter general registradas.

En primer lugar existe una grita de considerable tamaño en el paramento Este, cuya dirección indica la dirección en la que se han producido desplomes o asentamientos de consideración.
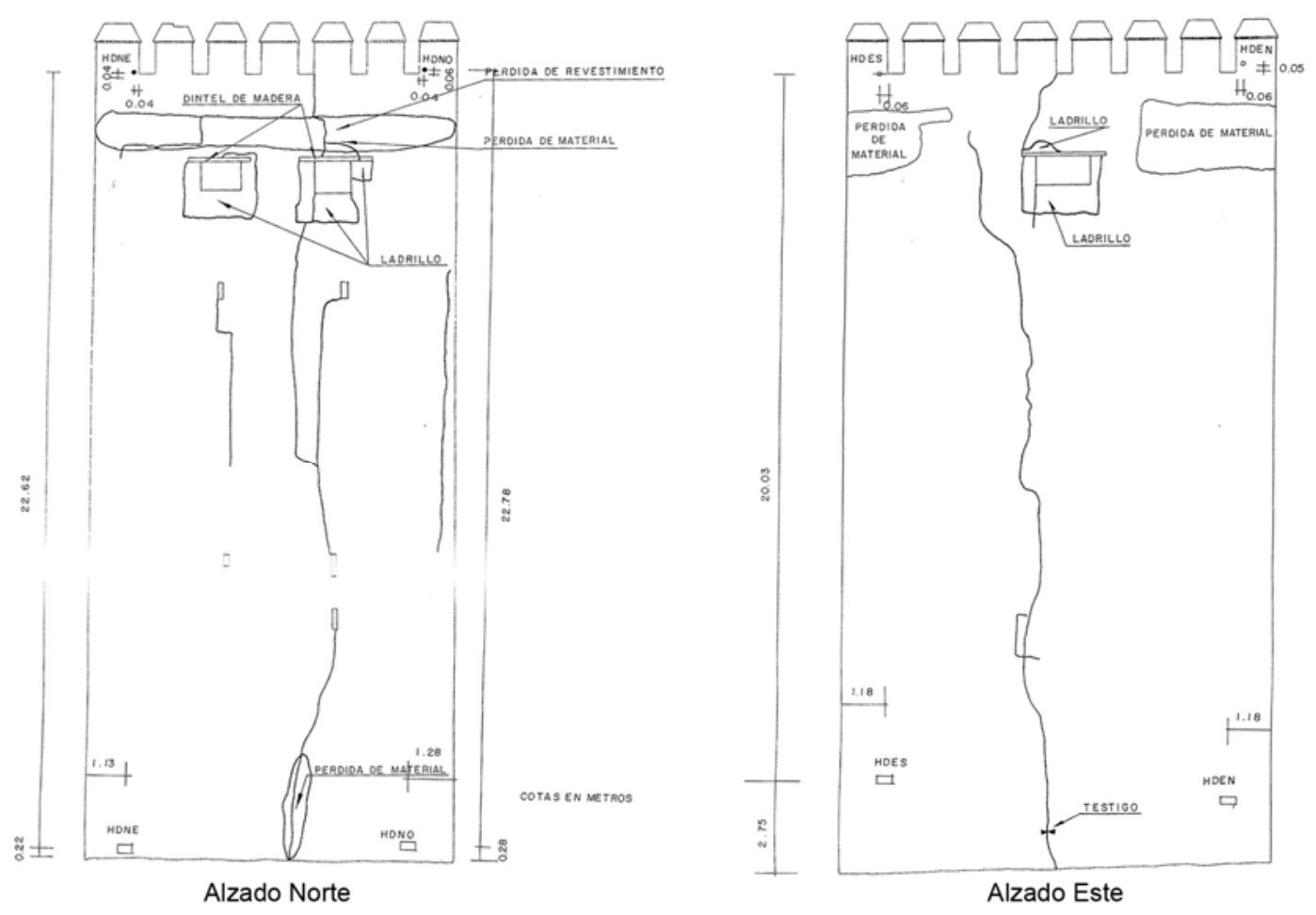

Fig.24 - Levantamiento de grietas en alzados $N$ y $E$ 
En segundo lugar, del estudio de los niveles de planta puede intuirse el movimiento, en cuanto a asientos por planta que experimenta el edificio. Hay que hacer dos matizaciones importantes a la interpretación de los resultados medidos. En primer lugar se han medido puntos en planta coincidentes con las claves de bóveda del nivel inmediatamente inferior, lo que puede hacer que se confundan asientos debidos a un efecto local en la bóveda con asientos globales de muro o pilar. En segundo lugar, no se sigue un comportamiento idéntico en todas las plantas aunque sí parece razonable afirmar que existe un patrón de comportamiento consistente en:

-El ámbito N-O es el más deprimido en casi todos los casos.

-El ámbito N-E es el segundo más deprimido casi siempre, lo que unido a la afirmación anterior confirman un desplome o asiento general hacia el norte y más concretamente hacia el $\mathrm{N}-\mathrm{O}$

-El ámbito S-O es casi siempre el punto más alto, seguido del punto S-E, lo que puede deberse a la mayor rigidez que aportan los adarves de la muralla que acomete.

Estos niveles, medidos in-situ, serán comparados posteriormente con los comportamientos obtenidos por planta, para tratar así de aislar factores globales de factores locales, aunque parece claro que el desplome hacia el lienzo Norte, responde a un empuje importante de la muralla Este.
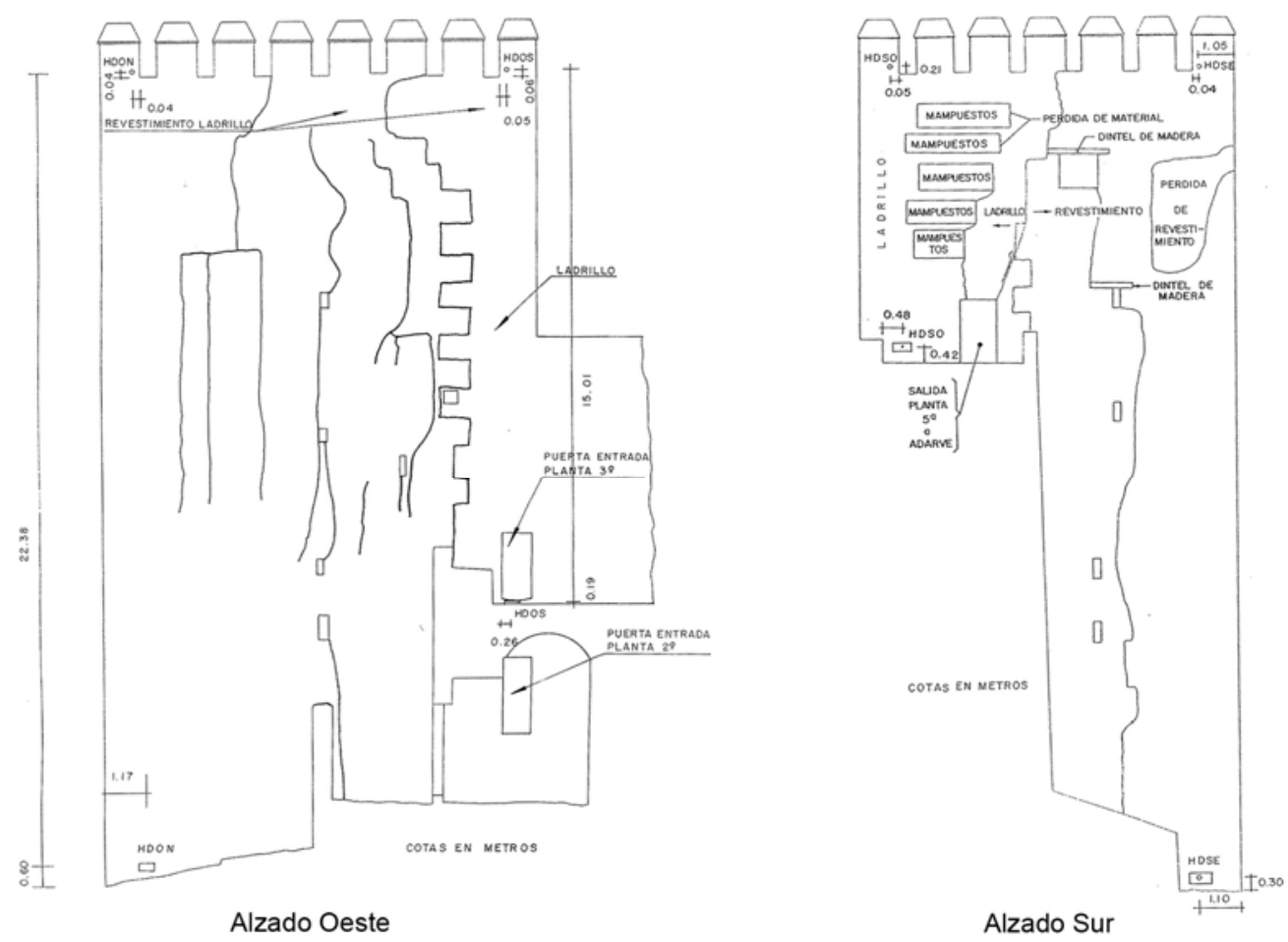

Fig.25 - Levantamiento de grietas en alzados S y O 


\section{ANÁLISIS LÍMITE. LÍNEAS DE EMPUJE}

Como se ha comentado con anterioridad, la asimetría de comportamiento que se da en las obras de fábrica y en las de tapial en cuanto a esfuerzos de tracción y compresión hace que, en general se considere en los análisis de este tipo de edificios la resistencia a tracción como nula o prácticamente nula.

Esto nos lleva a plantear el sistema en una condición de equilibrio pura, donde las líneas de empuje compuestas con las resultantes de los pesos deben mantenerse dentro de la propia geometría de los elementos.

Puesto que este tipo de análisis corresponde a un estudio en rotura, es preciso establecer una configuración de rotura compatible con las cargas actuantes. Estos análisis, basados en principios de estática gráfica fueron popularizados por 'J.Heyman' a principios del S.XVIII

\section{BREVE DESCRIPCIÓN DEL MÉTODO}

El estudio de la línea de empuje en una estructura de obra de fábrica nos permite conocer su grado de 'estabilidad' y nos permite estimar su estado tensional.

Puesto que la estructura es hiperestática, existirá un infinito conjunto de líneas de empuje que sean compatibles con la geometría y las cargas.

La aplicación de la teoría de la elasticidad, así como el principio de mínima deformación permitió a Winkler poder formular la posición de la línea de empuje en un arco biempotrado como: "Entre todas las líneas de empujes posibles para un sistema de fuerzas dado, la verdadera es la que se aparta menos de la directriz del arco".

Aunque la definición ya fue introducido por Hooke en 1670 por su analogía con los cables, su definición rigurosa se debe a Moseley en 1835, enunciándose de la siguiente forma:

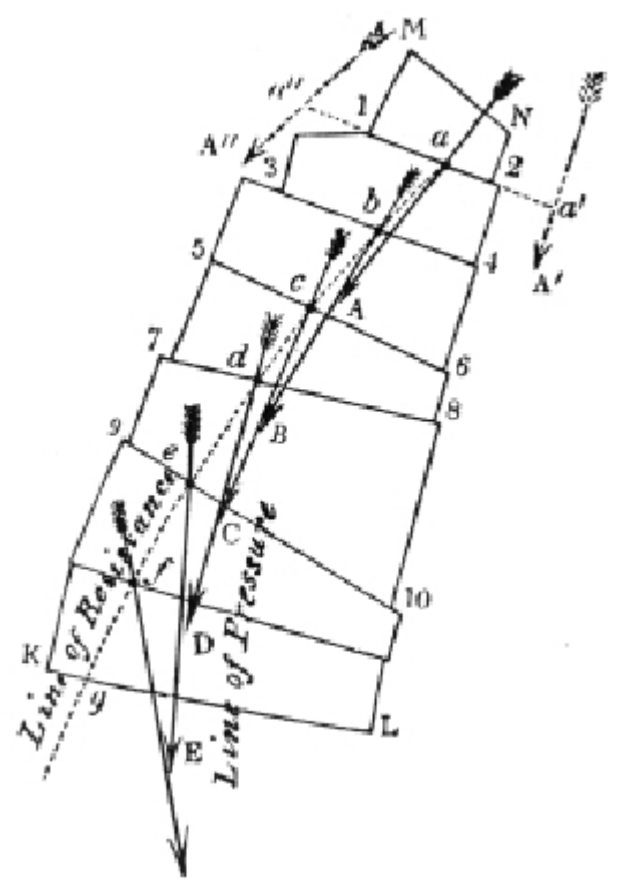

Fig.26 - Definición de línea de empuje dada por Moseley 1835 
"Sea un macizo de fábrica MNLK, [figura anterior], compuesto por un apilamiento de piedras recibidas sin mortero y de cualquier forma. Consideremos ahora un plano 1 a2 que corta a la estructura y llamemos $A$ a la resultante (empuje) de todas las fuerzas situadas por encima de dicho plano (A2y A3 en este caso). Supongamos que esta superficie de corte cambia de forma y posición de manera que coincida con todas las superficies de contacto $3 b 4,5 c 6,7 d 8, \ldots$, de los sólidos que componen la estructura, y sean $B, C, D, E, \ldots$, las resultantes, obtenidas en forma análoga a la $A$, correspondientes a los distintos planos de intersección.

Para cada una de las superficies consideradas la resultante tendrá un punto de aplicación que deberá estar situado dentro de la masa de la estructura. Llamaremos a este punto centro de empuje, los puntos $a, b, c, d$, etc.

Imaginemos ahora la estructura seccionada por una infinidad de planos (que pueden seguir una ley determinada, por ejemplo ser normales a una determinada curva) y consideremos las intersecciones de cada una de las resultantes con su plano, es decir, los centros de empujes correspondientes a cada uno de los planos; el lugar geométrico de estos puntos forma la línea de empujes.

De la anterior definición se deduce fácilmente que la línea de empujes depende de la forma y sistema de cargas de la estructura y, también, de la familia de planos de sección elegidos. Dada una estructura de cualquier forma geométrica, sometida a un determinado sistema de cargas y cuyas partes están en contacto según una serie de superficies definidas geométricamente, los métodos del análisis matemático permiten escribir su ecuación. También puede procederse a la inversa: dada una línea de empujes, podemos deducir la forma geométrica de una estructura compatible con ella."

Se admiten las siguientes tres hipótesis en el análisis en rotura de este tipo de estructura:

1.-La resistencia a compresión es infinita: Se asume que las tensiones son bajas, aunque siempre es necesario realizar una comprobación de resistencia al final.

2.-El colapso por deslizamiento es imposible: Suponemos que el rozamiento en las uniones es suficientemente alto.

3.-La resistencia a tracción es nula: Estamos del lado de la seguridad no considerando la contribución del mortero.

En base a estas hipótesis es posible aplicar los teoremas de análisis plástico de estructuras de acero en el caso de arcos de obra de fábrica:

El primer teorema permite definir estados de carga seguros. Dice que el colapso no se producirá si en cada caso sucesivo de carga que atraviesa la estructura es posible encontrar un estado de equilibrio estáticamente admisible. Esto en los arcos implica que podemos encontrar una línea de empujes estáticamente admisible dentro de la estructura del arco.

El segundo teorema se ocupa de los valores de carga que producen colapso, estableciendo que éste se producirá si se encuentra una configuración de colapso cinemática admisible. Es decir, si desarrolla rótulas suficientes como para convertirse en un mecanismo. Puesto que consideramos nulas las tracciones, las fuerzas interiores siempre serán nulas y, por tanto, siempre que en un desplazamiento virtual, las fuerzas exteriores sean mayores o iguales a cero; es decir, el mecanismo esté en equilibrio inestable, se producirá colapso.

En un arco, se alcanzará un sistema de equilibrio inestable cuando se desarrollen cuatro rótulas. Esto sólo admite dos variaciones: vuelco por riñones, o levantamiento de la clave. Es aquí cuando cobra vital importancia la consideración de la acción del relleno. 
En general es suficiente considerar la acción del relleno como una carga vertical, pero en ocasiones este sistema puede no estar del lado de la seguridad. Es conveniente conocer las hipótesis habituales en su consideración:

1.-Acción vertical: Es la más habitual, considera la acción vertical aplicada sobre la superficie del trasdós del arco. Es correcta para inclinaciones débiles, pero cuando la inclinación supera el ángulo de rozamiento del relleno con el ladrillo empieza a ser errónea.

2.-Acción hidrostática: La segunda opción es considerar que el relleno es un fluido que ejerce una presión normal a la superficie del trasdós. En cada punto se considera la acción de una columna vertical de relleno equivalente.

3.-Acción geostática de Rankine: En este caso se tiene en cuenta el empuje del relleno y la variación de éste con la profundidad y la curva del trasdós.

La mayor o menor seguridad a la hora de considerar estas hipótesis dependerá, como se ha comentado antes de la forma de colapso del arco.

Si se produce vuelco de los riñones el comportamiento del relleno produciendo empujes no verticales tiende a asegurar la estructura, por lo que la hipótesis de acción vertical queda del lado de la seguridad.

Si se produce levantamiento de la clave, los empujes horizontales tienden a levantar la línea de empujes, siendo la hipótesis de acción vertical desfavorable.

En la mayoría de casos prácticos y en los que se emplearán en este trabajo la hipótesis de acción vertical es válida, sólo es preciso tomar algunas precauciones en el caso de arcos muy apuntados o excesivamente rebajados, no siendo este el caso.

Un desarrollo teórico muy completo de esta influencia puede encontrarse en el 'Manual of Applied Mechanics' de 1858 de 'Rankine', donde se hace una discusión completa del problema con relación a las líneas de empujes de los arcos.
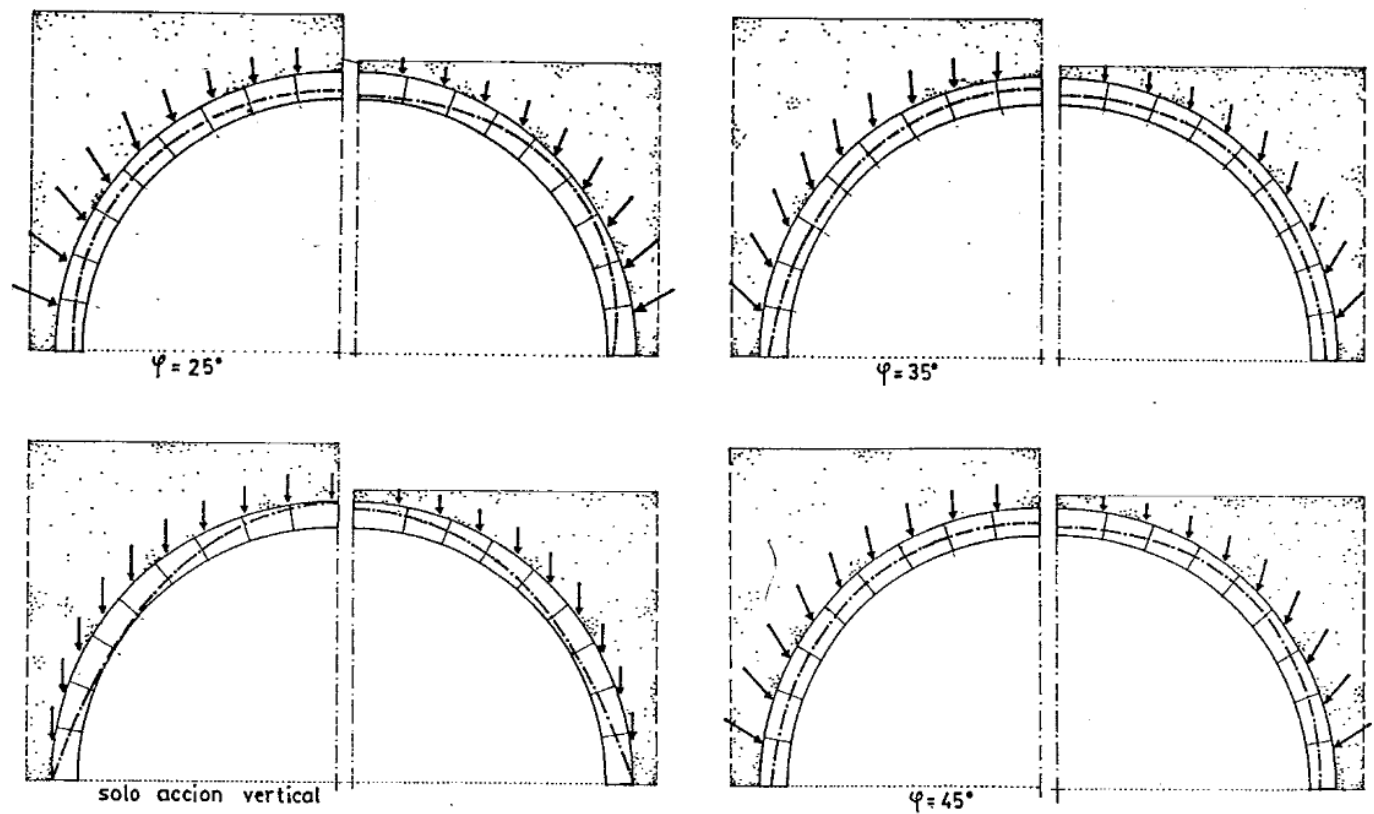

Fig.27 - Influencia de la acción del relleno en la estabilidad (Harvey 1987) 


\section{ANÁLISIS POR NIVELES}

El análisis por niveles, centrado en los arcos de descarga principales tiene un doble objetivo. Por un lado, determinar la línea de empuje de forma gráfica de forma que pueda avanzarse un coeficiente de seguridad geométrico (CSG en figuras) para estos elementos.

En segundo lugar, obtendremos de esta forma las reacciones horizontales con las que hallaremos la línea de empuje de los muros perimetrales en el siguiente apartado.

Como hemos mencionado anteriormente, se ha considerado la hipótesis de acción vertical para la consideración del relleno.

En las siguientes figuras se muestran los resultados obtenidos para cada uno de los arcos de descarga de los diferentes niveles. Comentamos algunos de los aspectos más significativos que se desprenden del análisis:

La bóveda de cañón del nivel 6 encuentra una línea de empuje estable dentro de la franja de coeficiente de seguridad 2. En cambio, en el caso de los arcos de descarga del nivel 5 no es posible hallar una línea de empuje estable con este nivel de seguridad. Sólo cuando llevamos la sección hasta su límite geométrico encontramos una trayectoria estable. El coeficiente de seguridad aquí es poco mayor que la unidad.

Cabe decir que, para este nivel sería importante determinar si los riñones disponen de un relleno apreciable, que podría mejorar el comportamiento derivando en un mayor margen de seguridad.

En el nivel 4, se encuentra una trayectoria estable imponiendo como condiciones de contorno los puntos límite de coeficiente 2, sin embargo no toda la línea de empuje discurre por esta franja, por lo que el nivel de seguridad es algo inferior.

Algo similar ocurre en los niveles 1 y 2 , aunque con empujes en términos globales de mucha menos consideración.

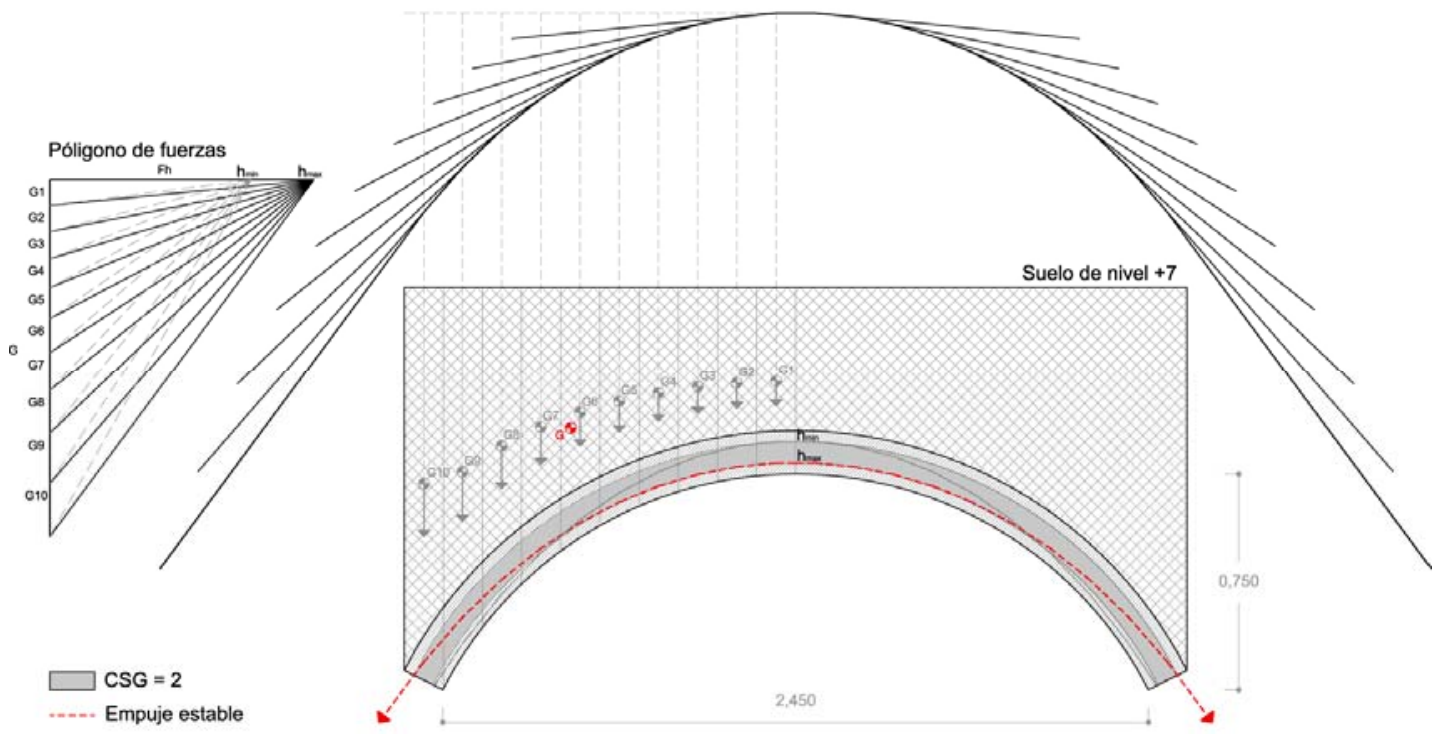

Fig.28 - Líneas de empuje a peso propio de arcos de descarga (Nivel 6) 
El nivel 3 tiene un nivel de seguridad análogo al nivel 5, en el que hay que considerar toda la sección para encontrar una línea estable.

Es necesario hacer varias puntualizaciones en estos análisis. En primer lugar, en todos los casos se ha considerado que el espesor resistente es de unos $15 \mathrm{~cm}$, que es la dimensión aproximada de los ladrillos presentes en la torre, colocados a testa. Nada hace pensar que haya arcos con más de una capa de ladrillo (exceptuando los del nivel 1)

En segundo lugar, las juntas de mortero son muy gruesas en casi todos los casos, dotando de cierta resistencia a tracción al arco, por lo que los coeficientes que se están avanzando aquí son muy conservadores. De hecho, las patologías observadas en el edificio hacen pensar que la capacidad para absorber estos niveles de tracciones es relativamente buena.

Por último, hay dos factores que impiden determinar con más precisión el espesor real del arco. En primer lugar, en muchos casos existe un revestimiento que oculta la sección e impide determinar el estado de las fábricas o si han perdido sección resistente. En segundo lugar, las juntas no abarcan toda la sección del ladrillo, por lo que el área de transferencia eficaz es inferior a la bruta.

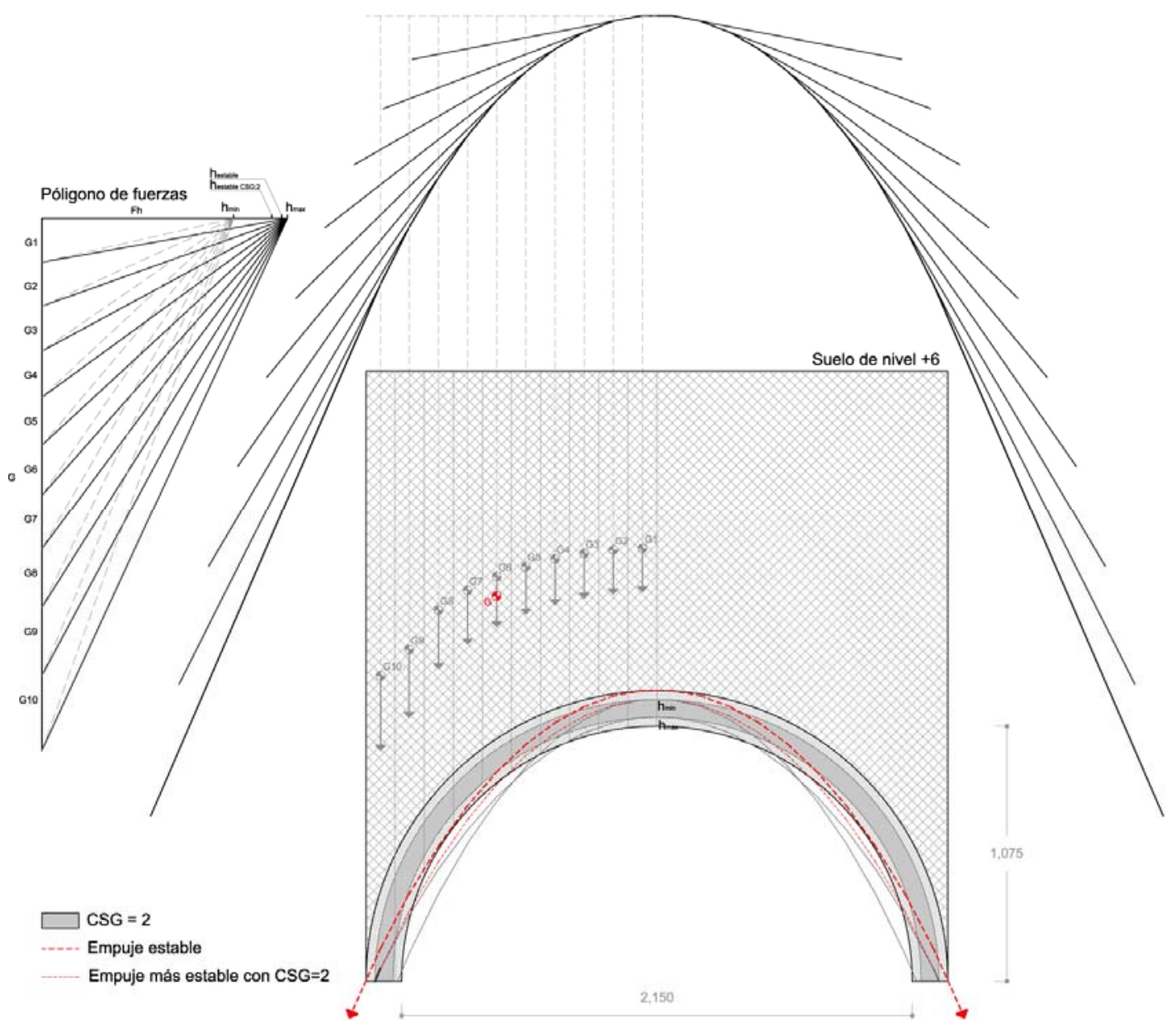

Fig.29 - Líneas de empuje a peso propio de arcos de descarga (Nivel 5) 
Análisis estructural del patrimonio histórico. Torre del Homenaje de la Alhambra

Trabajo Final de Máster. Máster de Estructuras - Universidad de Granada

David Villegas Cerredo [Septiembre 2012]

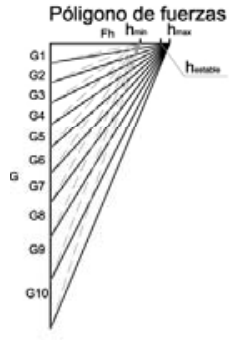

$\square \mathrm{CSG}=2$ -..-. Empuje estable

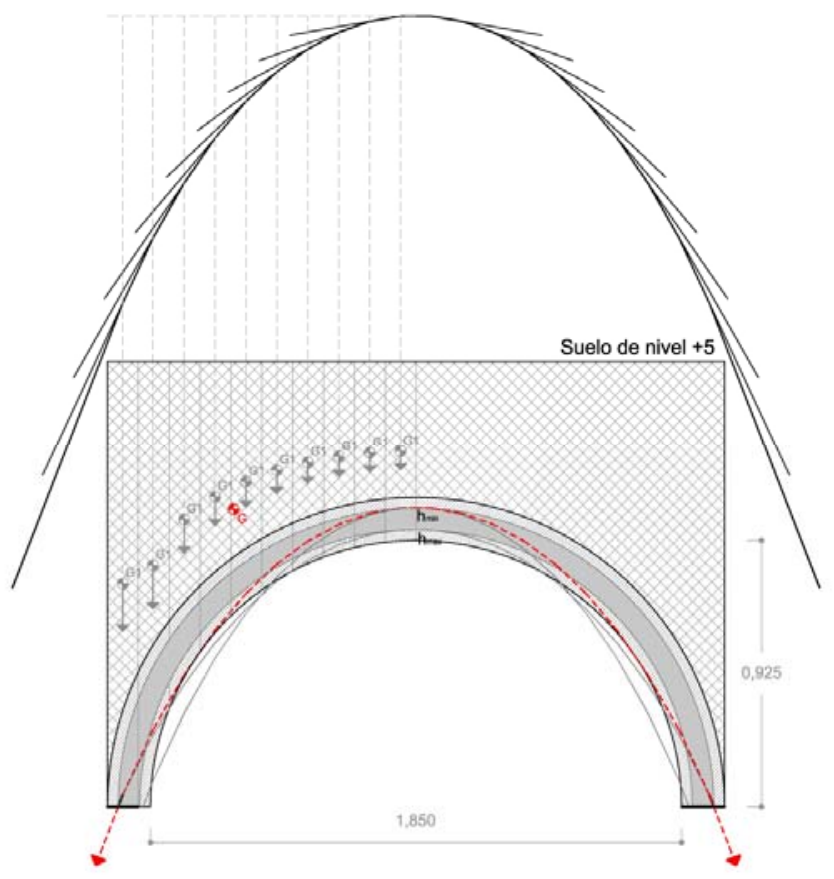

Fig.30 - Líneas de empuje a peso propio de arcos de descarga (Nivel 4)

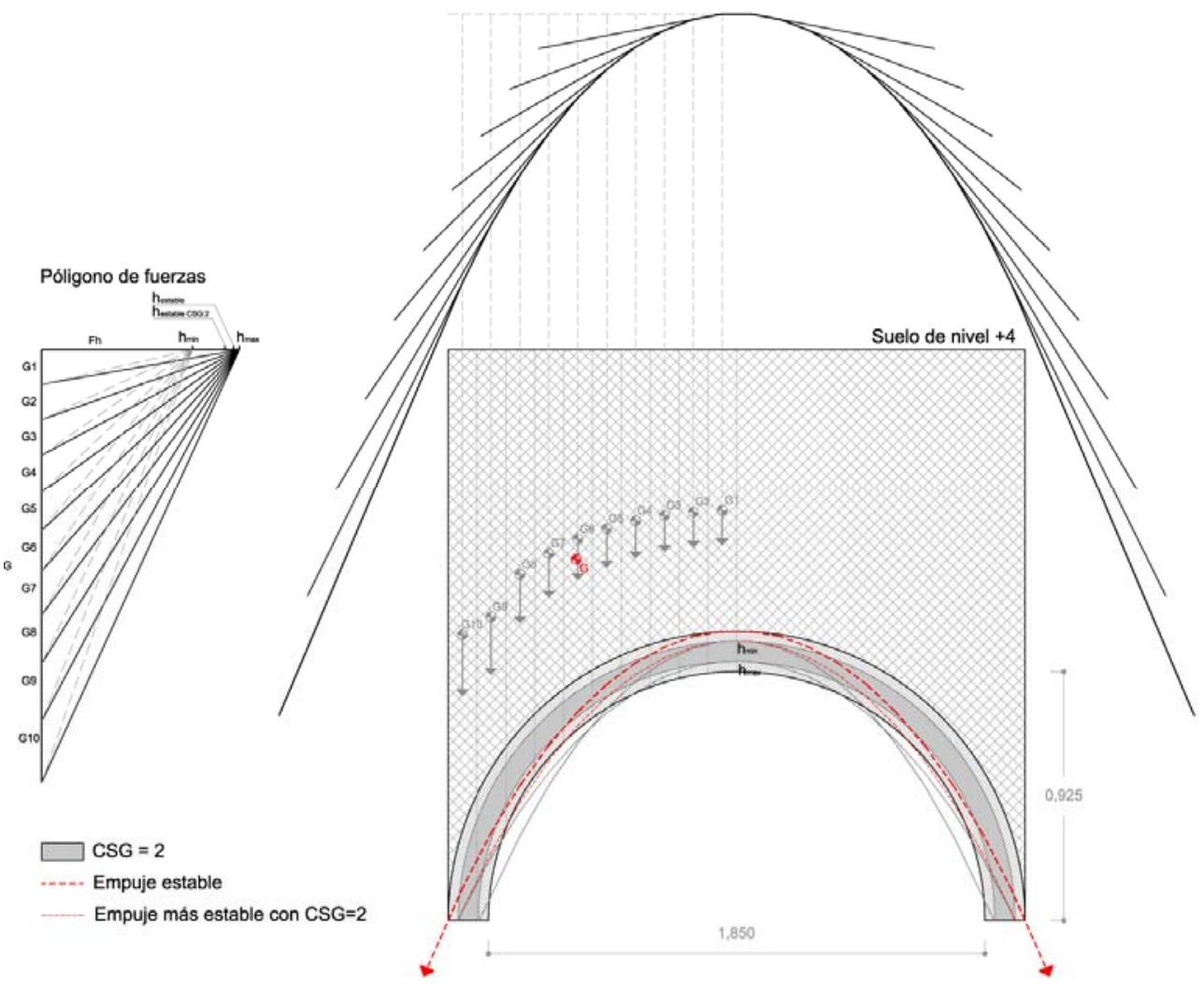

Fig.31 - Líneas de empuje a peso propio de arcos de descarga (Nivel 3) 
El análisis desprende otros datos que conviene señalar: Por un lado, ya sea casual o intencionado, los empujes horizontales mayores se producen en los niveles 3,5 y 6 . Esto no tiene mayor trascendencia en el muro, pero coincide con los niveles (al menos los dos últimos) donde el carácter funcional y el empleo de luces algo mayores prima en el diseño.

Cabe decir que, exceptuando por razones obvias el nivel 1, en el resto de niveles se produce una simetría de empuje casi perfecta cuando se comparan los muros N-S con los E-O, apreciándose diferencia sólo en el nivel 4, donde los empujes son algo mayores en los muros N-S

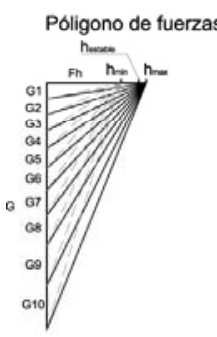

$\square \mathrm{CSG}=2$

-...- Empuje estable

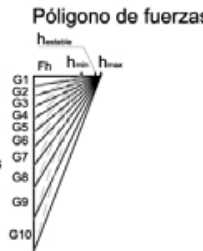

CSG $=2$

-.-- Empuje estable

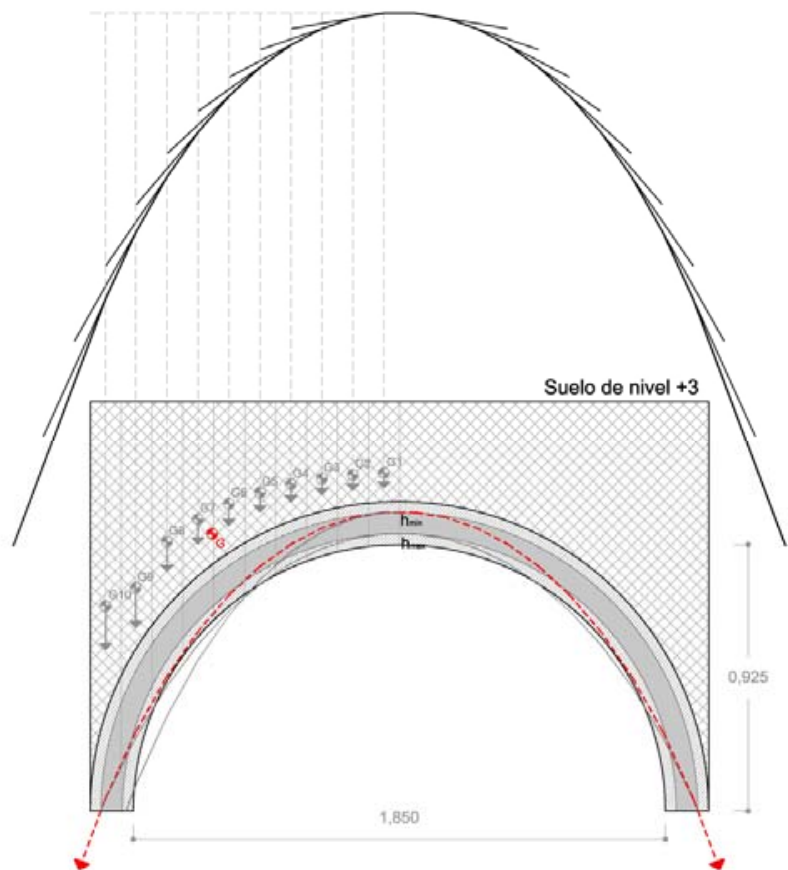

Fig.32 - Líneas de empuje a peso propio de arcos de descarga (Nivel 2)

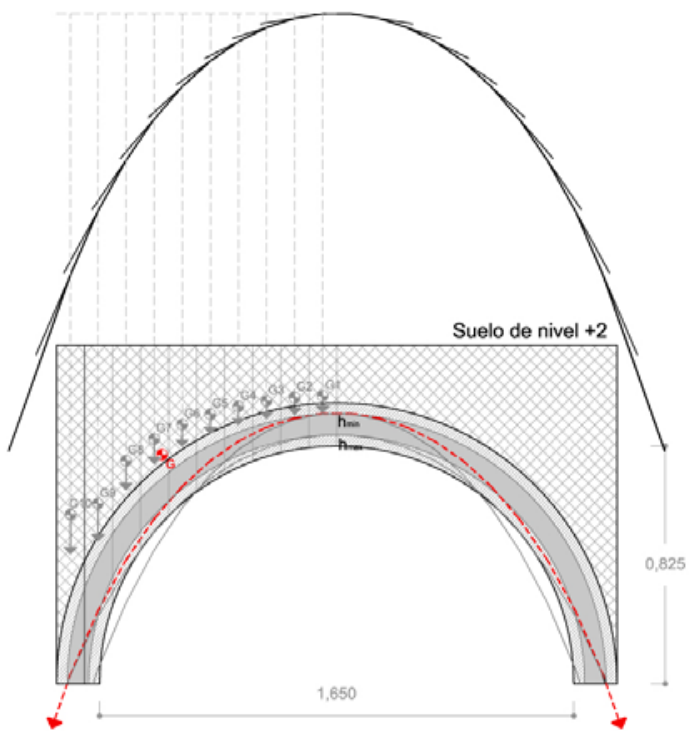

Fig.33 - Líneas de empuje a peso propio de arcos de descarga (Nivel 1) 


\section{ANÁLISIS DE SECCIONES PRINCIPALES}

En este primer análisis cualitativo vamos a hallar la línea de empujes pésima en los muros perimetrales de la torre, considerando que las pilas centrales funcionan de forma dominante a compresión centrada.

La resistencia transversal del muro se calculará aplicando el criterio de rotura de MohrCoulomb al que ya nos hemos referido con anterioridad.

Como ya se ha justificado previamente vamos a centrarnos en una sección de muro coincidente con una pilastra lateral que será donde se produzca el mayor empuje lateral. El efecto de las bóvedas y cúpulas sobre los arcos de descarga principales se ha tenido en cuenta considerando áreas de influencia y columnas de carga equivalentes, de forma que pueda asimilares a un arco de descarga, de forma aproximada, la carga muerta real que soporta.

Uno de los puntos de más incertidumbre en la construcción de la torre es la forma en que se sustentaron las bóvedas de cañón del último nivel. Si el relleno era consistente es muy probable que se apoyaran sobre este directamente asegurando sólo cierto grado de empotramiento. Se han barajado otras hipótesis también, como que existieran algunos arcos de descarga secundarios embebidos en las paredes que sostienen las bóvedas de cañón o que existiera algún sistema de muretes construidos sobre los arcos del nivel inferior que sostuvieran mejor el último nivel.

Todas estas hipótesis han sido descartadas por su grado de complejidad, unido a que este nivel se encuentra casi completamente reconstruido, por lo que podemos hacernos una idea de la vulnerabilidad de la solución inicial.

Para este análisis se considerará que dicho nivel descansa directamente sobre el relleno y se tendrá en cuenta mediante una columna de carga equivalente actuando sobre el nivel inferior. Para un mejor entendimiento hemos considerado el estado probable original de este nivel, compuesto por bóvedas de cañón perimetrales, guardando de esta forma la simetría en sección.

En las siguientes figuras podemos ver el resultado del análisis, que comentamos a continuación:

Como vemos, en el muro Este, la línea de empujes del muro se mantiene dentro de la franja de coeficiente de seguridad geométrico de dos (Para la hipótesis de la reconstrucción del s.XIX, que corresponde al estado actual). Los empujes laterales van descentrando la línea, remarcándose especialmente la influencia de las dos últimas plantas.

En el caso del muro Norte los empujes son algo mayores y llevan a un margen de seguridad menor en la base del muro.

Nótese la influencia en la consideración del nivel 7 en ambos casos. En el muro Este, la hipótesis de que en estado original existían vanos con bóvedas de cañón agota la sección de muro casi en su totalidad, en cambio considerando que en el estado actual la transmisión de esfuerzos sea más cercana a un apoyo simple, el comportamiento general mejora notablemente.

Debe considerarse también que en el muro Este, hemos considerado el vano interior de bóveda cargando sobre el muro exterior, mientras que en el muro norte lo hemos considerado cargando en la pilastra central. Seguramente el comportamiento sea realmente un caso intermedio entre ambas hipótesis, en el que haya una descarga en el relleno que ejerza cierta presión lateral sobre el intradós del muro, pero su influencia se revela de poca importancia. En cualquier caso, no se producen fenómenos de inestabilidad en ninguno de los casos, no siendo preciso hacer más puntualizaciones en este análisis. 
Análisis estructural del patrimonio histórico. Torre del Homenaje de la Alhambra

Trabajo Final de Máster. Máster de Estructuras - Universidad de Granada

David Villegas Cerredo [Septiembre 2012]

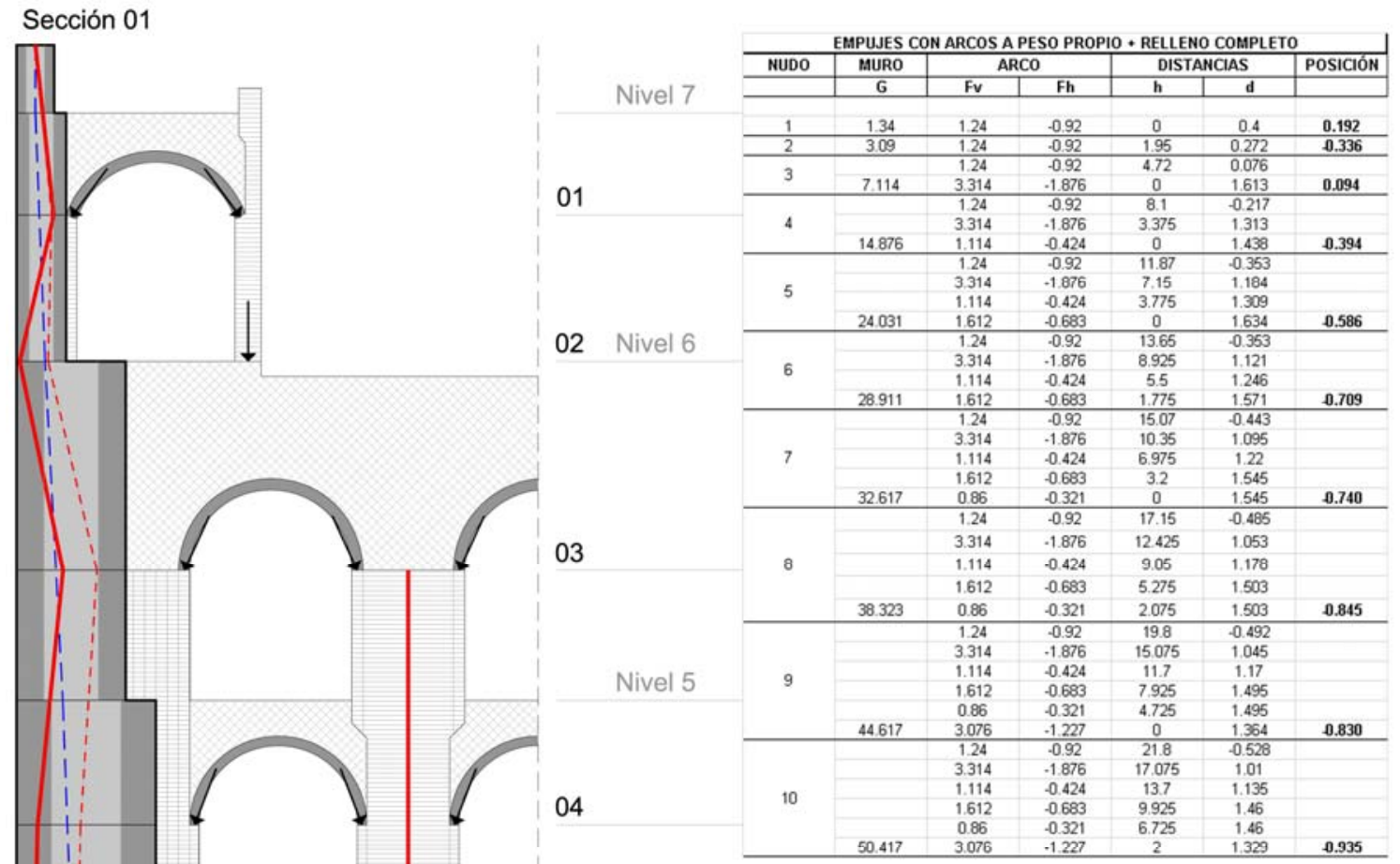

Nivel 4

05

06 Nivel 3

07

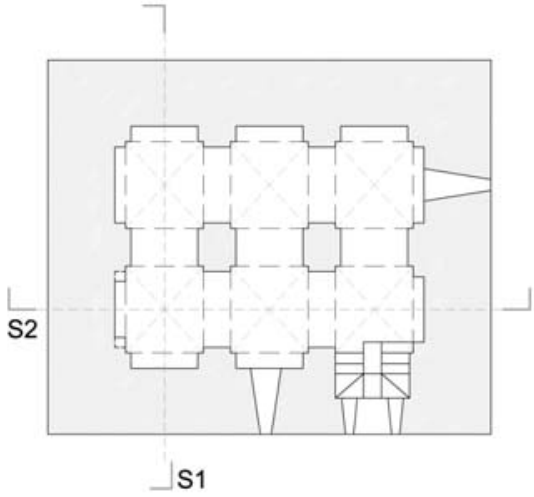

10 Nivel 1

$C S G=2$

- - - - Línea de empujes del muro a peso propio sin empujes laterales - Línea de empujes del muro a peso propio con empujes laterales - Línea de empujes con hipótesis de reconstrucción s.XIX

Fig.34 - Empujes en muro Este 
Análisis estructural del patrimonio histórico. Torre del Homenaje de la Alhambra

Trabajo Final de Máster. Máster de Estructuras - Universidad de Granada

David Villegas Cerredo [Septiembre 2012]

Sección 02
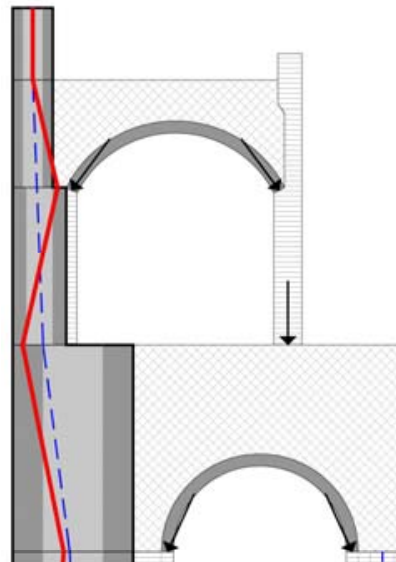

7

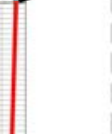

03

04

01

Nivel 7

\begin{tabular}{c|c|c|c|c|c|c|}
\hline EUDO & MURO & \multicolumn{2}{|c|}{ ARCO } & \multicolumn{2}{|c|}{ DISTANCIAS } & POSICIÓN \\
\hline & G & FV & Fh & h & d & \\
\hline
\end{tabular}

\begin{tabular}{ccccccc}
1 & 1.469 & 1.241 & -0.802 & 0 & 0.446 & 0.204 \\
\hline 2 & 3.09 & 1.241 & -0.802 & 2.027 & 0.422 & 0.254 \\
\hline 3 & & 1.241 & -0.802 & 4.6 & 0.09 &
\end{tabular}

\begin{tabular}{|c|c|c|c|c|c|c|}
\hline & 7.854 & 2.247 & -0.926 & 0 & 1.215 & -0.075 \\
\hline \multirow{3}{*}{4} & & 1.241 & .0 .802 & 6.527 & .0 .005 & \\
\hline & 11.704 & 2.247 & -0.926 & 1.925 & 1.12 & 0.297 \\
\hline & & 1.241 & .0 .802 & 8.077 & .0 .065 & \\
\hline \multirow[t]{2}{*}{5} & & 2.247 & .0 .926 & 3.475 & 1.06 & \\
\hline & 15.036 & 0.994 & -0.363 & 0 & 1.36 & 0.310 \\
\hline \multirow{3}{*}{6} & & 1.241 & .0 .802 & 9.827 & -0.125 & \\
\hline & & 2.247 & .0 .926 & 5.225 & 1 & \\
\hline & 19.061 & 0.994 & -0.363 & 1.75 & 1.3 & 0.424 \\
\hline \multirow{4}{*}{7} & & 1.241 & .0 .802 & 11.952 & 0.139 & \\
\hline & & 2.247 & .0 .926 & 7.35 & 0.906 & \\
\hline & & 0.994 & .0 .363 & 3.875 & 1.286 & \\
\hline & 23.311 & 1.612 & .0 .648 & 0 & 1.136 & 0.430 \\
\hline \multirow{4}{*}{8} & & 1.241 & .0 .802 & 13.727 & 0.158 & \\
\hline & & 2.247 & .0 .926 & 9.125 & 0.967 & \\
\hline & & 0.994 & -0.363 & 5.65 & 1.267 & \\
\hline & 27.127 & 1.612 & .0 .648 & 1.775 & 1.117 & -0.530 \\
\hline \multirow{5}{*}{9} & & 1.241 & .0 .802 & 15.152 & 0.162 & \\
\hline & & 2.247 & .0 .926 & 10.55 & 0.963 & \\
\hline & & 0.994 & .0 .363 & 7.075 & 1.263 & \\
\hline & & 1.612 & .0 .648 & 3.2 & 1.113 & \\
\hline & 29.977 & 0.86 & -0.3 & 0 & 1.113 & 0.558 \\
\hline \multirow{6}{*}{10} & & 1.241 & 0.802 & 18.402 & 0.183 & \\
\hline & & 2.247 & .0 .926 & 13.8 & 0.942 & \\
\hline & & 0.994 & .0 .363 & 10.325 & 1.242 & \\
\hline & & 1.612 & -0.648 & 6.45 & 1.092 & \\
\hline & & 0.86 & .0 .3 & 3.25 & 1.092 & \\
\hline & 36.965 & 0.611 & .0 .198 & 0 & 1.292 & -0.670 \\
\hline \multirow{6}{*}{11} & & 1.241 & -0.802 & 21.877 & -0.217 & \\
\hline & & 2.247 & .0 .926 & 17.275 & 0.908 & \\
\hline & & 0.994 & -0.363 & 13.8 & 1.208 & \\
\hline & & 1.612 & .0 .648 & 9.925 & 1.058 & \\
\hline & & 0.86 & .0 .3 & 6.725 & 1.058 & \\
\hline & 45.131 & 0.611 & -0.198 & 3.475 & 1.258 & 0.784 \\
\hline
\end{tabular}

06 Nivel 4

07

\begin{tabular}{|c|c|c|c|c|c|c|}
\hline \multirow[t]{2}{*}{ NUDO } & \multirow{2}{*}{$\begin{array}{c}\text { MURO } \\
\text { G }\end{array}$} & \multicolumn{2}{|c|}{ ARCO } & \multicolumn{2}{|c|}{ DISTANCIAS } & \multirow[t]{2}{*}{ POSICIÓN } \\
\hline & & Fv & Fh & $\mathrm{h}$ & d & \\
\hline 1 & 0.407 & 1.241 & -0.802 & 0 & 0.165 & 0.124 \\
\hline 2 & 1.067 & 1.241 & 0.002 & 1.9 & 0.129 & 0.591 \\
\hline 1 & 5.919 & 2.308 & 0 & 0 & 1.175 & 0.330 \\
\hline$\frac{1}{2}$ & 7.651 & 2.308 & 0 & 0 & 1.175 & 0.272 \\
\hline 3 & 10.569 & 2.308 & 0 & 0 & 1.175 & 0.211 \\
\hline 4 & 12.144 & 2.308 & 0 & 0 & 1.175 & 0.188 \\
\hline 5 & 17.28 & 2.308 & 0 & 0 & 1.175 & 0.138 \\
\hline 6 & 19.41 & 2.308 & 0 & 0 & 1.175 & 0.125 \\
\hline 7 & 22.412 & 2.308 & 0 & 0 & 1.175 & 0.110 \\
\hline 8 & 24.902 & 2.308 & 0 & 0 & 1.175 & 0.100 \\
\hline 9 & 27.181 & 2.308 & 0 & 0 & 1.175 & 0.092 \\
\hline 10 & 31.351 & 2.308 & 0 & 0 & 1.175 & 0.081 \\
\hline
\end{tabular}

09

Nivel 2

10

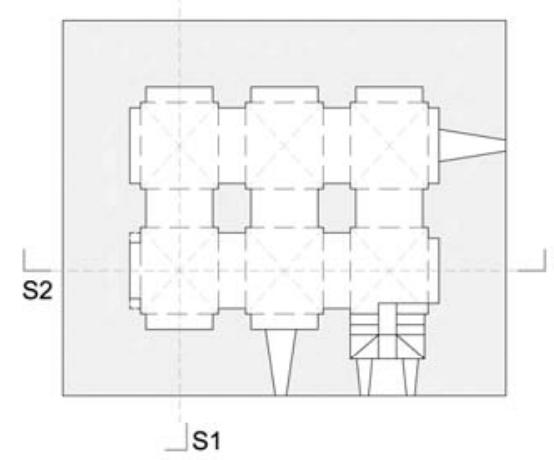

11 Nivel 1

$\mathrm{CSG}=2$ 


\section{ESTIMACIÓN DE LA RESISTENCIA}

A partir de los parámetros para caracterizar los materiales que discutimos en apartados anteriores $\mathrm{y}$, conociendo a nivel bidimensional el estado tensional a axil del muro podemos evaluar con suficiente certeza el margen de seguridad a peso propio que dispone el muro frente a las acciones, sobre todo de cortante, que lo solicitan.

Evaluaremos la resistencia a cortante como:

$$
f_{v k}=f_{v k 0}+0.36 \sigma_{d} \leq 0.065 f_{c k}
$$

Aunque el valor inicial de cortante puede llegar a ser relevante en este tipo de muros, tomaremos un valor nulo para este estudio, considerando sólo el término que depende de la tensión axial.

Obsérvese que la disminución de sección en el muro con la altura implica que la resistencia a cortante no sea monótonamente creciente.

En las siguientes figuras puede verse el resultado del análisis, que comentamos a continuación:

En ambos muros, el cortante basal cuenta con un coeficiente de seguridad geométrico de aproximadamente dos. No obstante, en el desarrollo en altura del muro encontramos determinados tramos más desfavorables.

En el muro Este, la solicitación casi agota la resistencia desde el nivel 3, en cambio en el muro norte, sólo están más ajustadas las dos últimas plantas.

En cuanto a la solicitación a axil, los niveles tensionales son bajos y, en ambos casos manejamos coeficientes de seguridad por encima de 4 . 
Análisis estructural del patrimonio histórico. Torre del Homenaje de la Alhambra

Trabajo Final de Máster. Máster de Estructuras - Universidad de Granada

David Villegas Cerredo [Septiembre 2012]

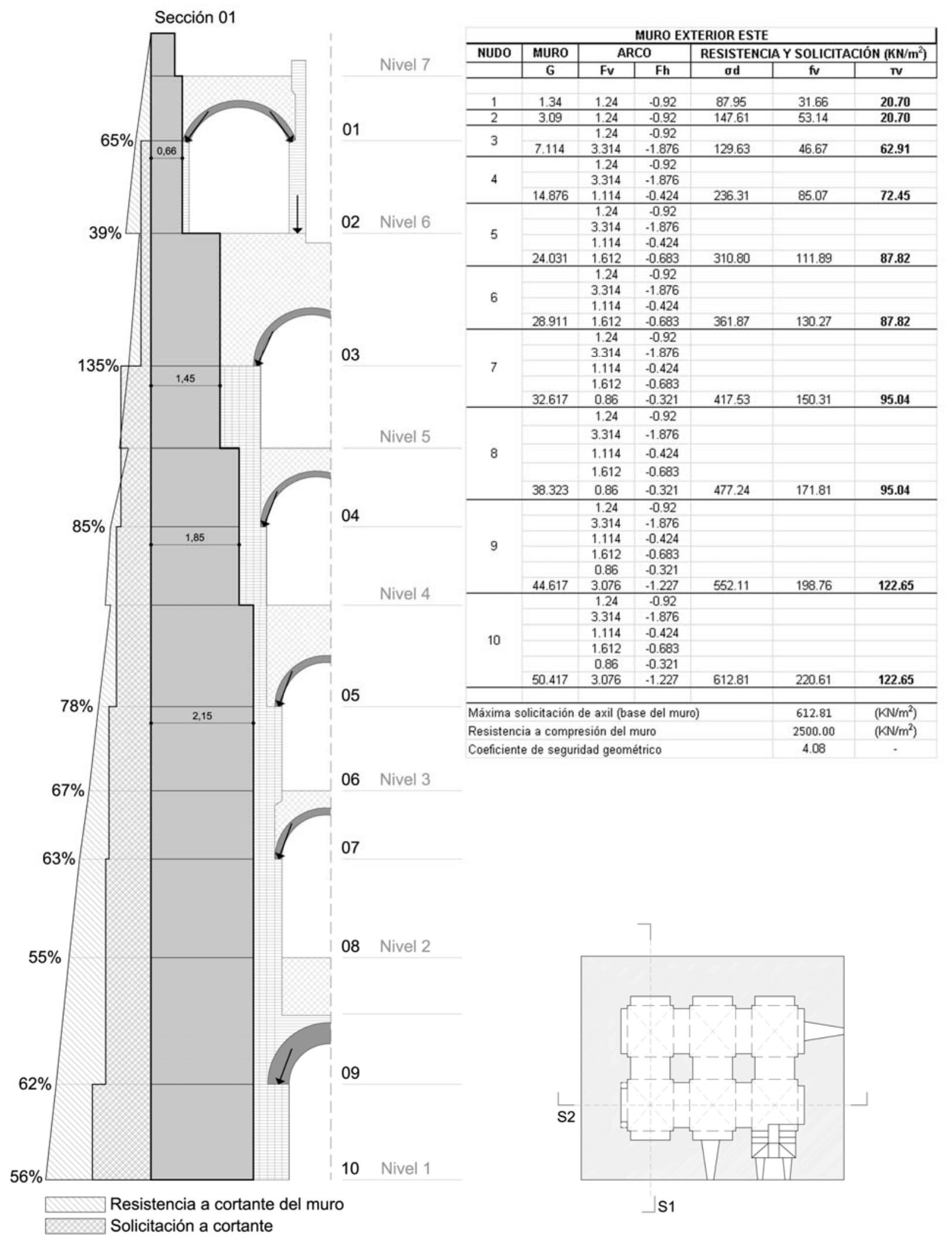

Fig.36 - Solicitación de cortante del muro exterior Este 
Análisis estructural del patrimonio histórico. Torre del Homenaje de la Alhambra

Trabajo Final de Máster. Máster de Estructuras - Universidad de Granada

David Villegas Cerredo [Septiembre 2012]

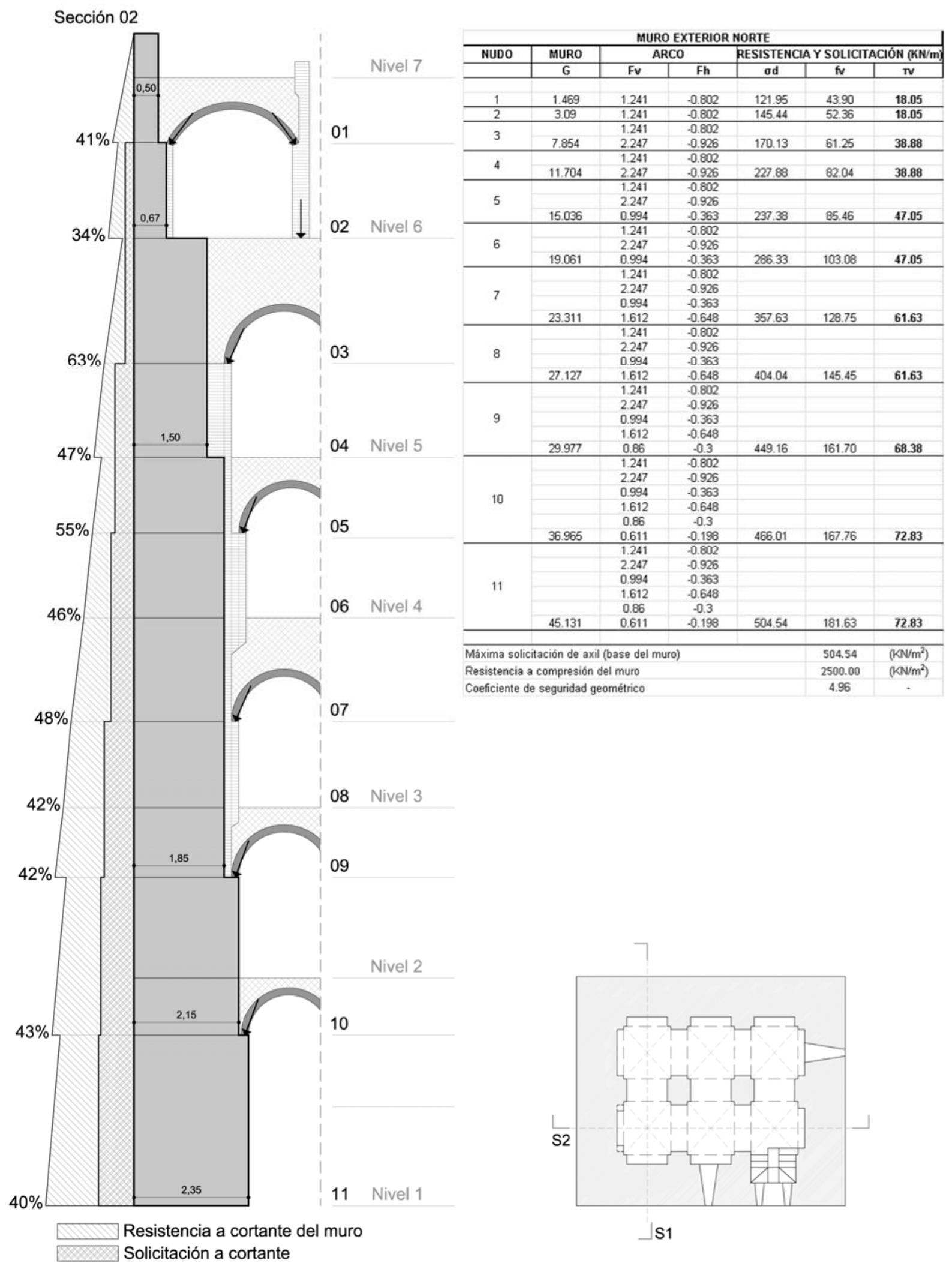

Fig.37 - Solicitación de cortante del muro exterior Norte 



\section{ANÁLISIS ESTÁTICO}

En este apartado, vamos a discutir y ampliar los resultados obtenidos en apartados anteriores, mediante modelos sólidos de elementos finitos.

Se han modelado, de un lado, todos los niveles de la torre con objeto de comprobar el estado tensional de los elementos bóveda y cúpula.

Por otro lado, se han modelado varios modelos globales donde chequearemos el muro perimetral y realizaremos un análisis modal del conjunto.

\section{DESCRIPCIÓN DE LOS MODELOS EMPLEADOS}

Para el estudio estático de la torre se han empleado dos modelos con propósitos bien distintos.

Por un lado se han empleado modelos de elementos finitos compuestos de elementos tridimensioanles de mallado fino para la estimación del estado tensional de las bóvedas y cúpulas de los distintos niveles de la torre, atendiendo exclusivamente a peso propio.

Se ha realizado un modelo de este tipo para cada nivel de la torre, aplicando como condiciones de contorno, las cargas verticales estimadas que recibe cada planta de las superiores, simulando de esta forma el incremento de rigidez transversal del muro perimetral por rigidización axial.

Se ha realizado otro modelo para cada nivel donde aparecen las bóvedas y cúpulas desconectadas del muro, de forma que no se ven presionadas por éste. No es sencillo determinar qué modelo representa mejor la realidad construida, ya que es difícil determinar con precisión las condiciones de trabado con que están ejecutados los distintos niveles.

A efectos prácticos, se ha observado que esta particularización de modelos sólo afecta significativamente a las zonas de contacto, mientras que en las zonas interiores las tensiones obtenidas son algo mayores en el modelo con influencia de muro. Analizaremos este modelo con influencia de muros, aunque tendremos en cuenta que los valores en las zonas de contorno pueden resultar demasiado conservadores, siendo de gran interés efectuar una comparación con patologías encontradas.

Por otro lado, se ha realizado otro modelo de elementos finitos principalmente tridimensionales con un mallado más tosco general, refinado en el muro perimetral, con el fin de estimar las tensiones en el muro considerando las condiciones de distribución de pesos por niveles real. A este modelo, además, se le ha incorporado una carga de viento, que comentaremos en los próximos apartados para considerar una situación pésima de dimensionado.

\section{ANÁLISIS POR NIVELES}

En las siguientes páginas se discuten los resultados obtenidos por planta, centrándonos en los elementos de cubrición (bóvedas y cúpulas). Las cargas de rellenos son importantes en este análisis, se han modelado incluyendo su geometría en el modelo de elementos finitos, de forma que la distribución de masas sea la real. Las propiedades son similares a las del muro perimetral (según informe CEDEX), por lo que se han modelado con la misma densidad, aunque con un módulo longitudinal muy inferior, considerando que no aportan de forma significativa rigidez al conjunto. 
Análisis estructural del patrimonio histórico. Torre del Homenaje de la Alhambra

Trabajo Final de Máster. Máster de Estructuras - Universidad de Granada

David Villegas Cerredo [Septiembre 2012]

NIVEL 1

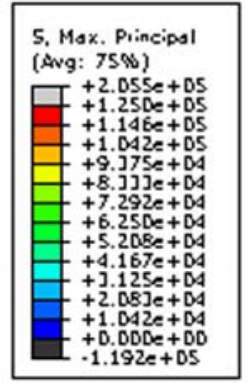

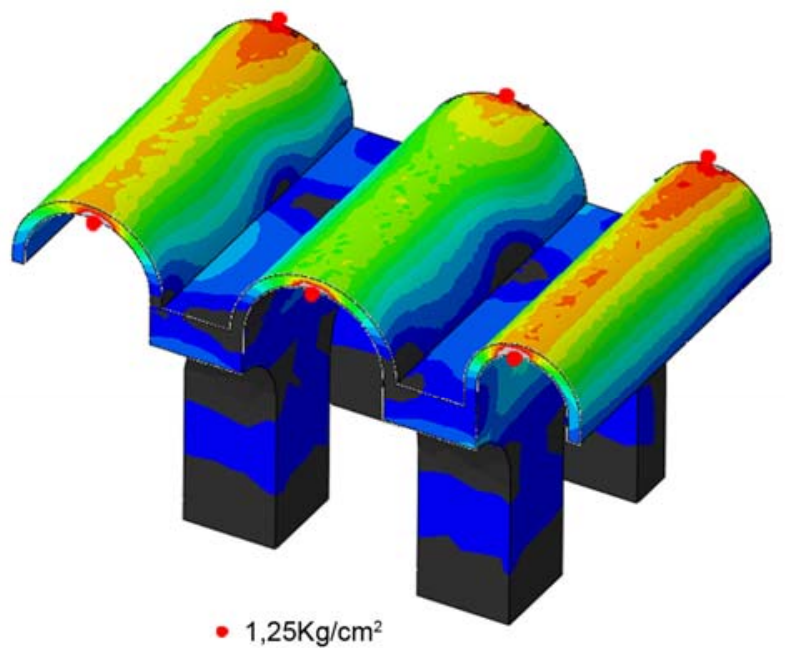

Máximas tensiones de tracción
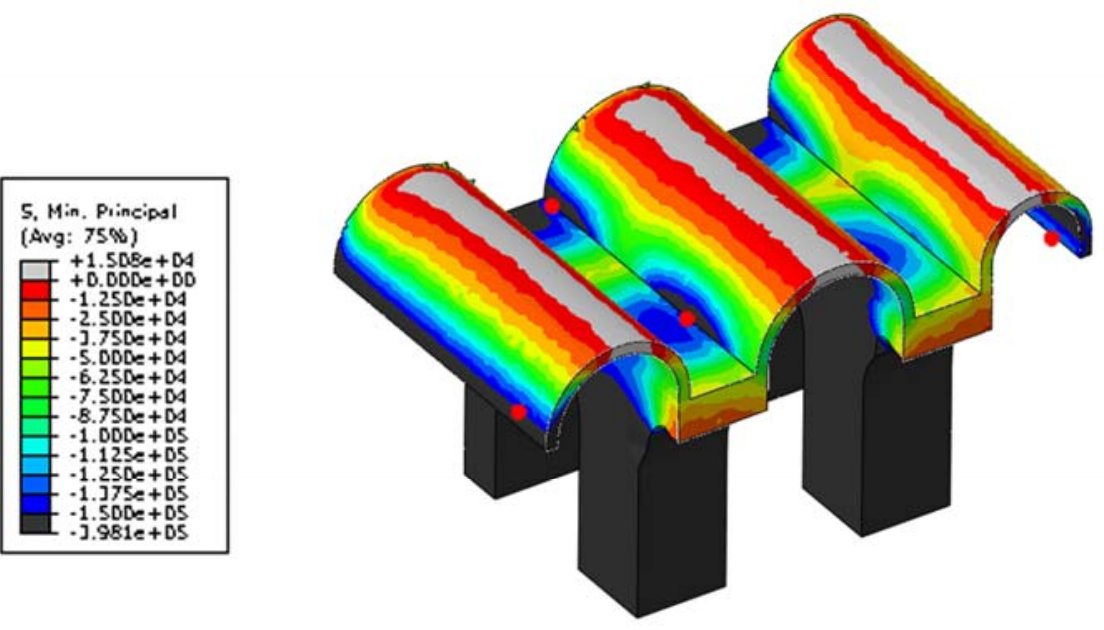

$-1,50 \mathrm{Kg} / \mathrm{cm}^{2}$

Máximas tensiones de compresión

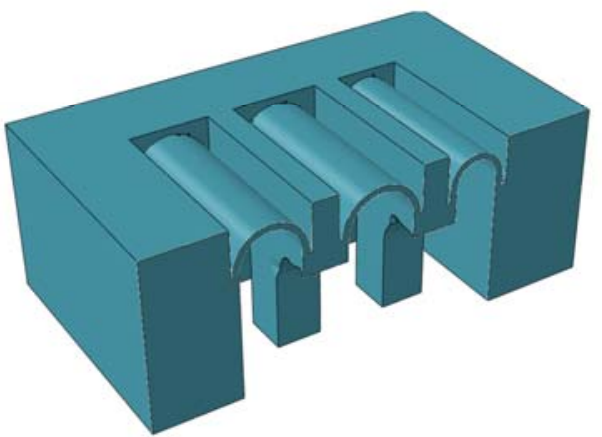

Modelo empleado

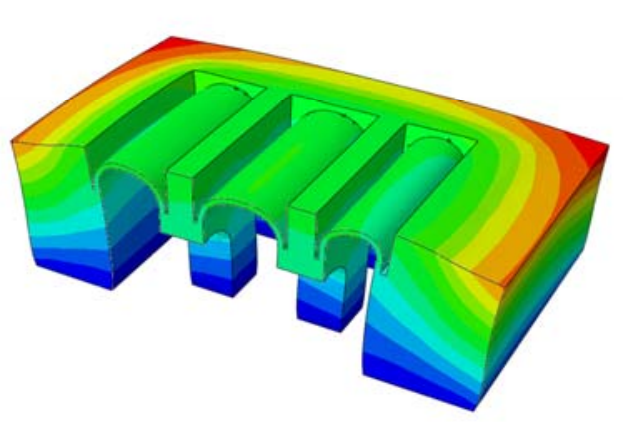

Magnitud de la deformación (0 a 5,2e-4)

Fig.38 - Esquemas de comportamiento a peso propio (nivel 1) 
Análisis estructural del patrimonio histórico. Torre del Homenaje de la Alhambra

Trabajo Final de Máster. Máster de Estructuras - Universidad de Granada

David Villegas Cerredo [Septiembre 2012]

NIVEL 2
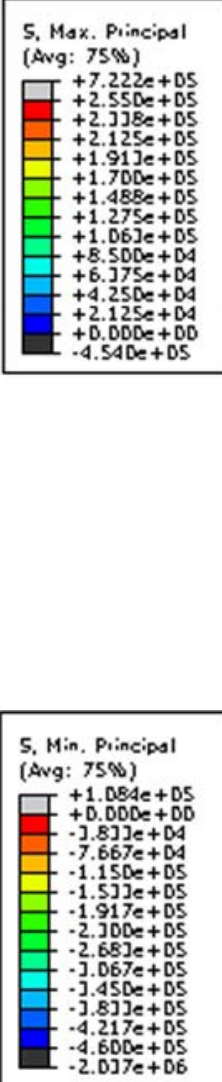

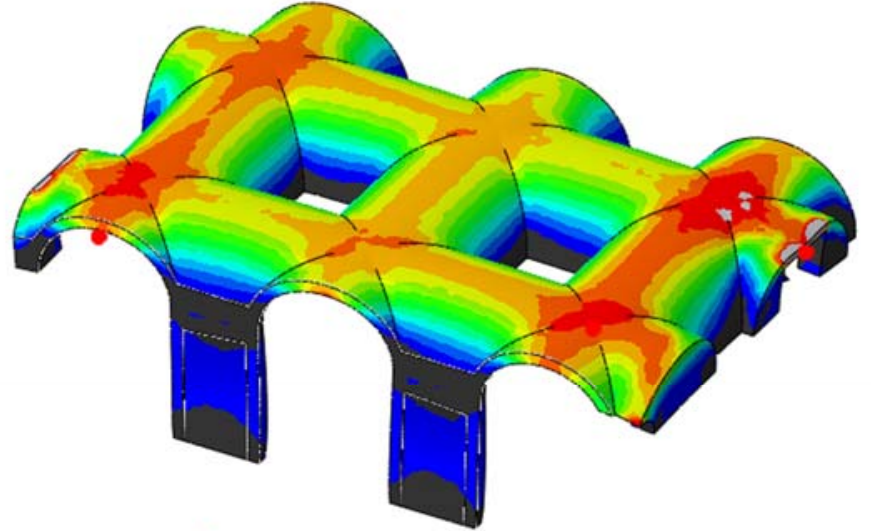

- $2,55 \mathrm{Kg} / \mathrm{cm}^{2}$

Máximas tensiones de tracción

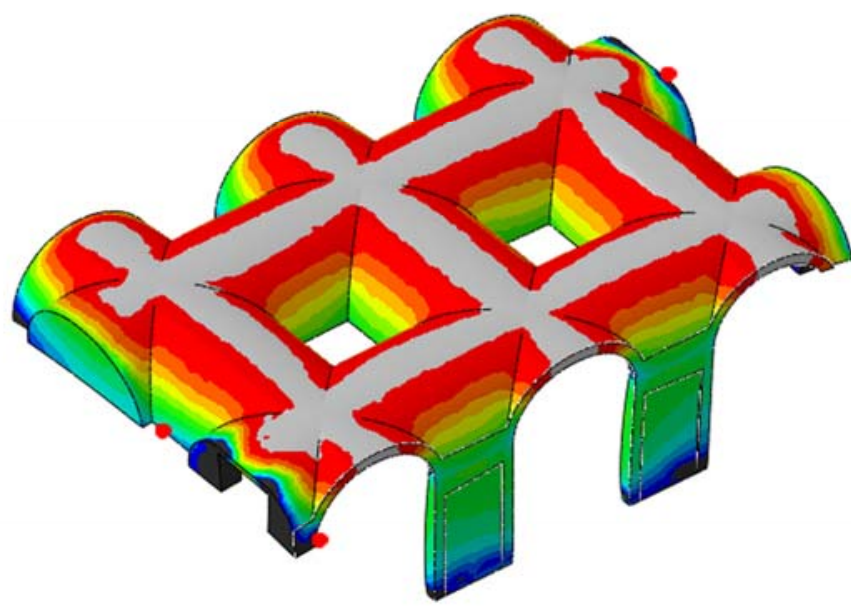

$-4,60 \mathrm{Kg} / \mathrm{cm}^{2}$

Máximas tensiones de compresión

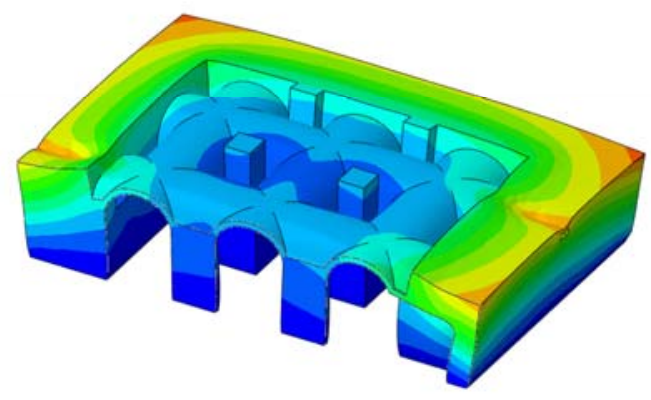

Magnitud de la deformación (0 a 1,4e-3)

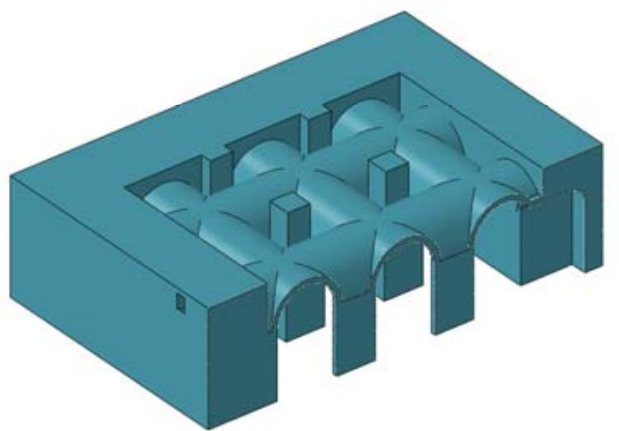

Modelo empleado

Fig.39 - Esquemas de comportamiento a peso propio (nivel 2) 
Análisis estructural del patrimonio histórico. Torre del Homenaje de la Alhambra

Trabajo Final de Máster. Máster de Estructuras - Universidad de Granada

David Villegas Cerredo [Septiembre 2012]

NIVEL 3
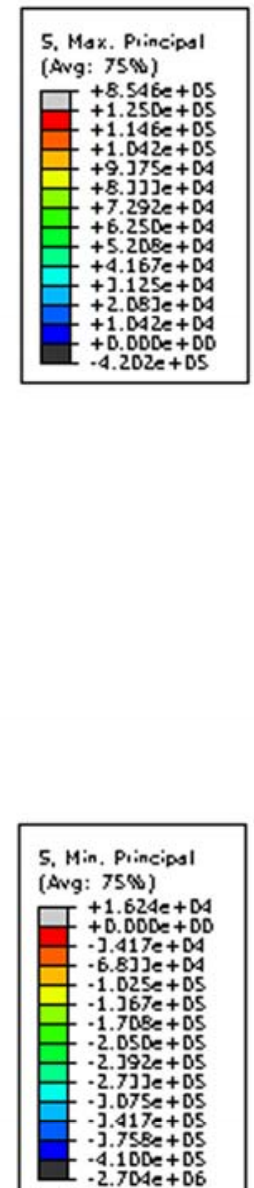

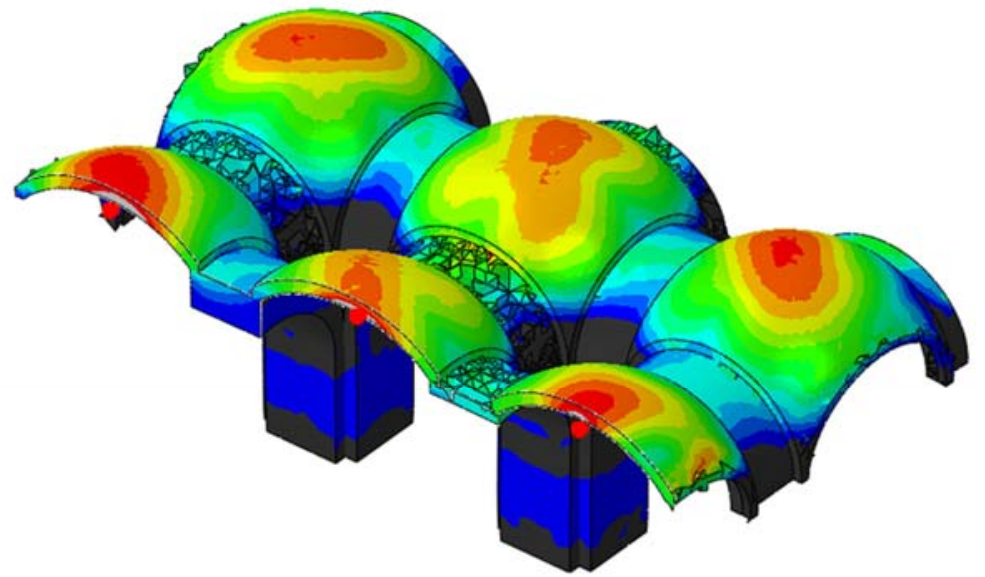

- $1,25 \mathrm{Kg} / \mathrm{cm}^{2}$

Máximas tensiones de tracción

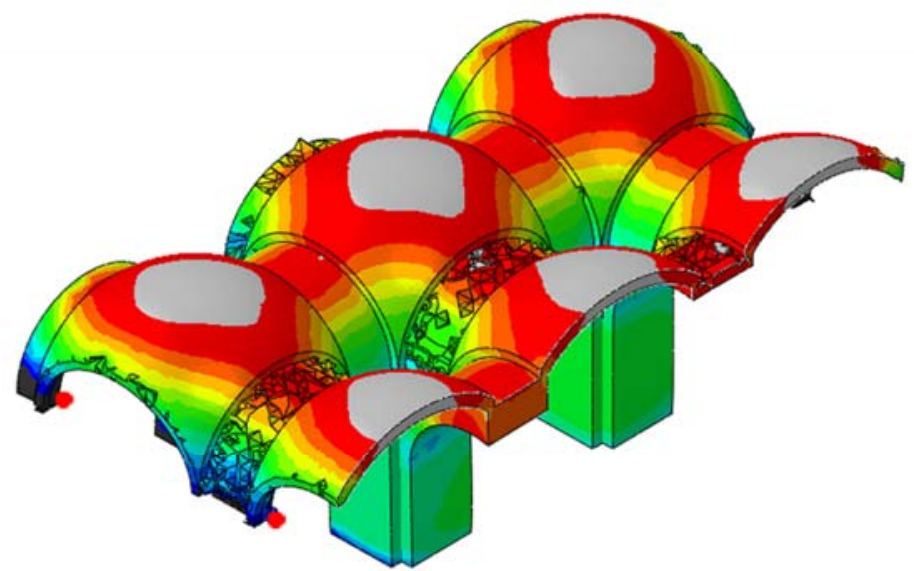

$-4,10 \mathrm{Kg} / \mathrm{cm}^{2}$

Máximas tensiones de compresión

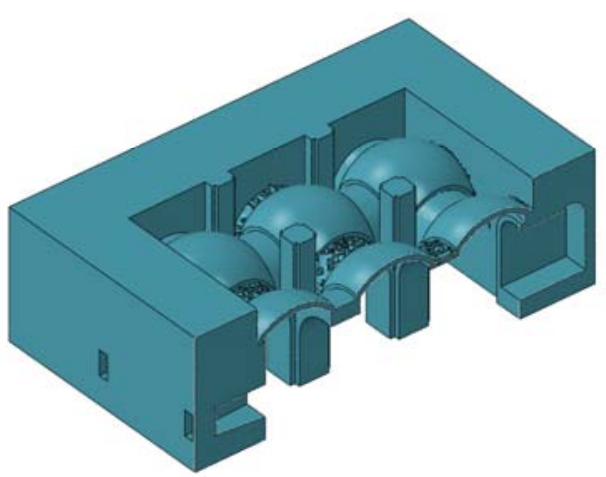

Modelo empleado

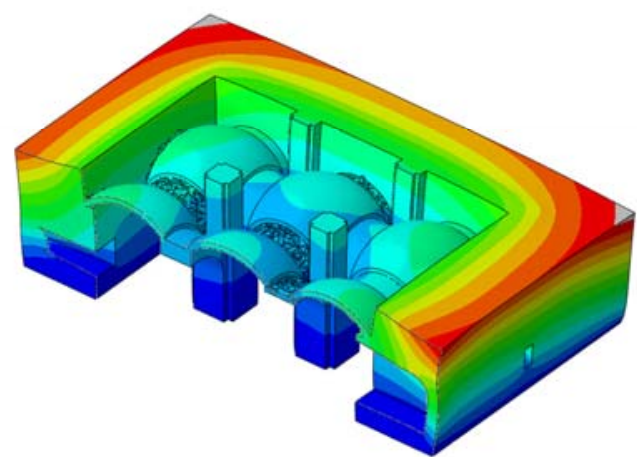

Magnitud de la deformación (0 a 1,1e-3)

Fig.40 - Esquemas de comportamiento a peso propio (nivel 3) 
Análisis estructural del patrimonio histórico. Torre del Homenaje de la Alhambra

Trabajo Final de Máster. Máster de Estructuras - Universidad de Granada

David Villegas Cerredo [Septiembre 2012]

NIVEL 4

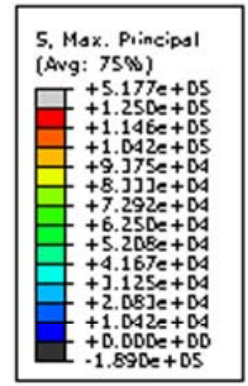

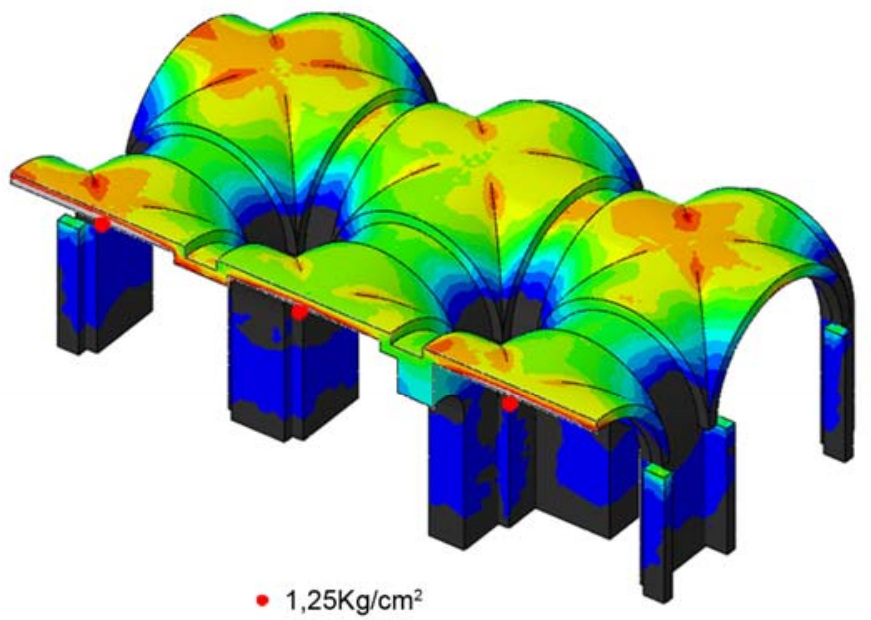

Máximas tensiones de tracción

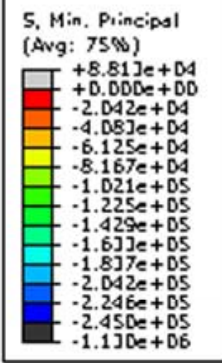

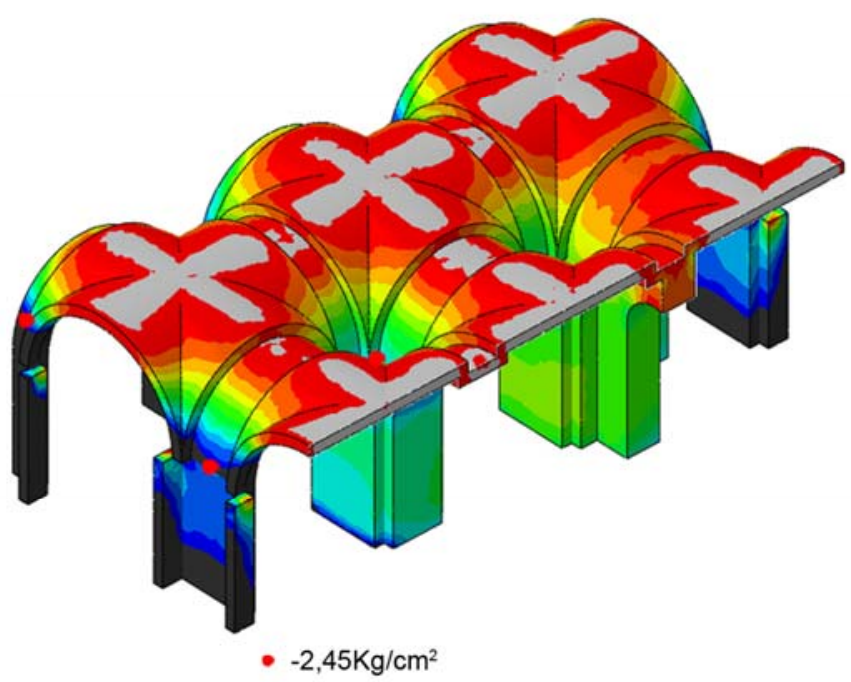

Máximas tensiones de compresión

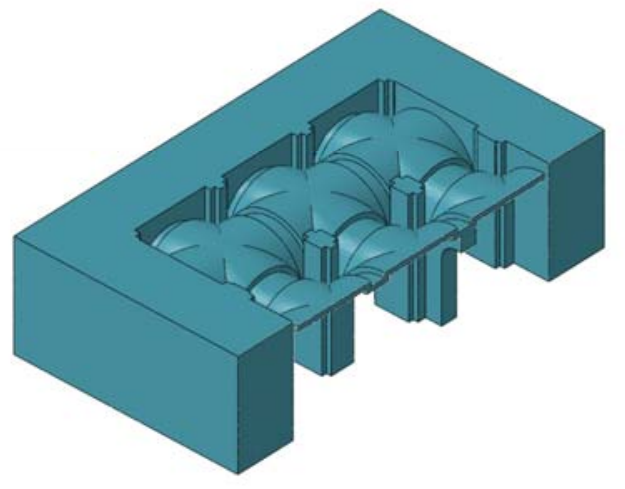

Modelo empleado

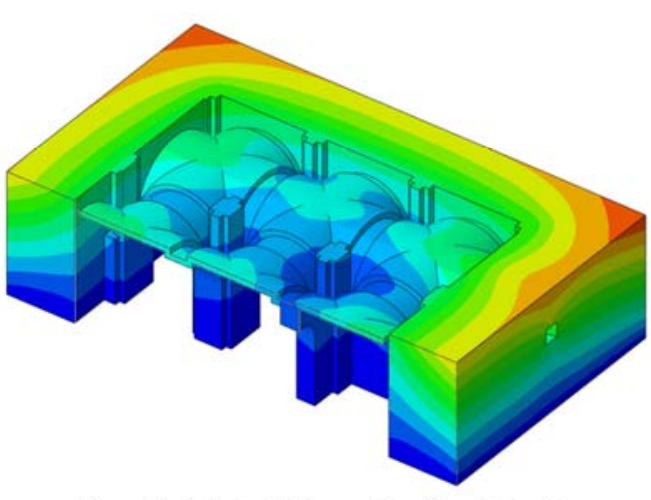

Magnitud de la deformación (0 a 7,5e-4)

Fig.41 - Esquemas de comportamiento a peso propio (nivel 4) 
Análisis estructural del patrimonio histórico. Torre del Homenaje de la Alhambra

Trabajo Final de Máster. Máster de Estructuras - Universidad de Granada

David Villegas Cerredo [Septiembre 2012]

NIVEL 5
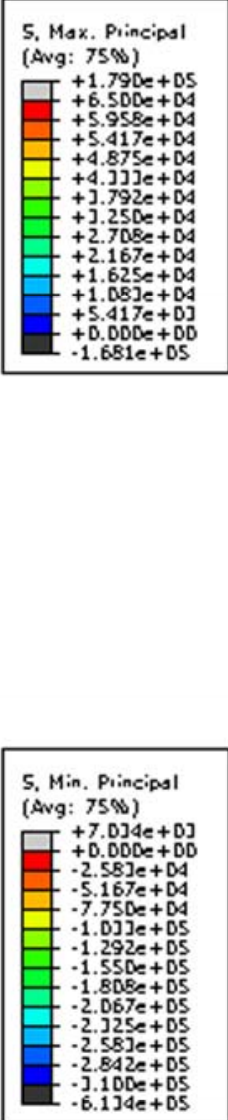

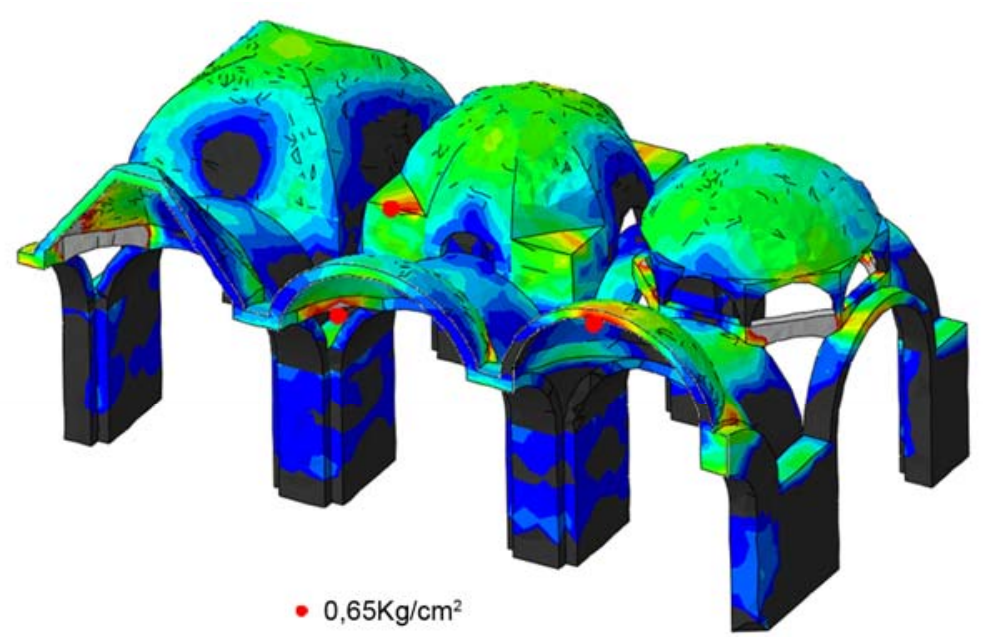

Máximas tensiones de traccion

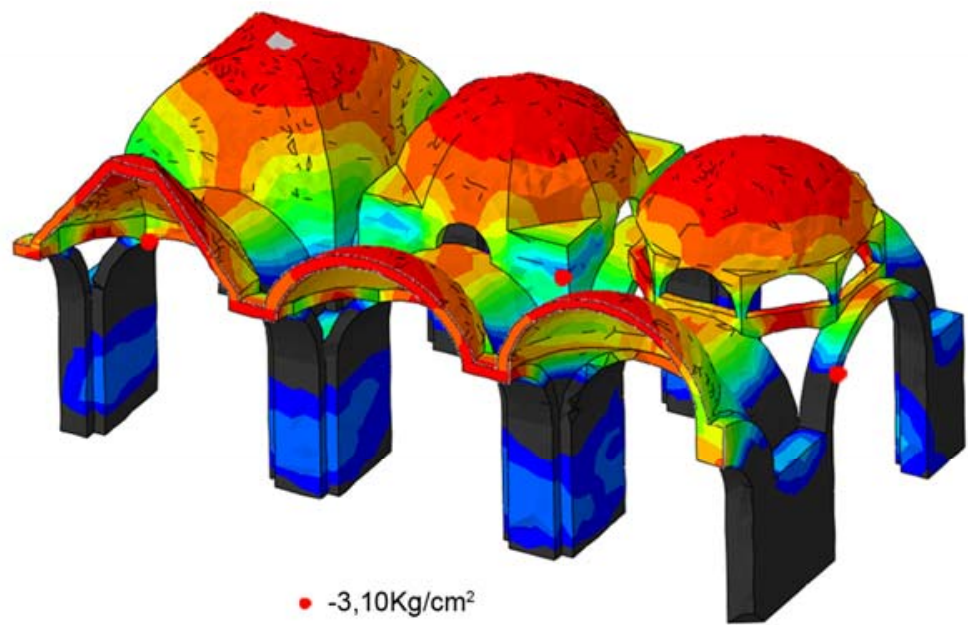

Máximas tensiones de compresión

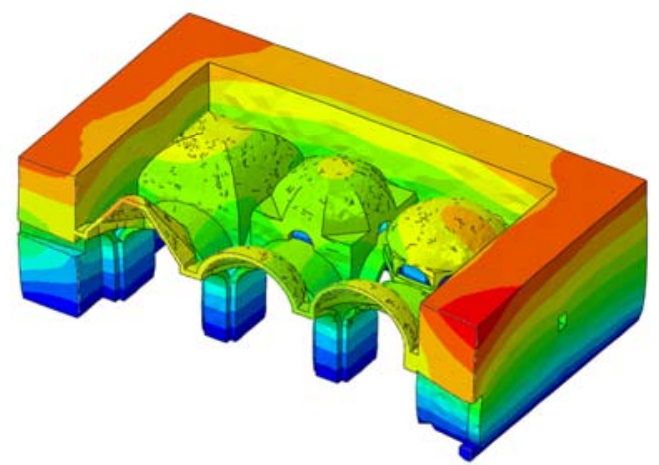

Magnitud de la deformación (0 a 5,2e-4m)

Modelo empleado

Fig.42 - Esquemas de comportamiento a peso propio (nivel 5) 


\section{CONCLUSIONES DEL ANÁLISIS POR NIVELES}

Como podemos ver, en general, el estado tensional de compresión es bastante bajo en comparación con la resistencia que estimamos para la fábrica, sin embargo, los esfuerzos de tracción están más ajustados.

$\begin{array}{cccc}\text { NIVEL } & \text { MÁXIMA TENSIÓN DE } \\ \text { TRACCIÓN }\left(\mathrm{Kg} / \mathrm{cm}^{2}\right) & \text { RESISTENCIA A } & \text { COEFICIENTE DE } \\ \text { TRACCIÓN }\left(\mathrm{Kg} / \mathrm{cm}^{2}\right) & \text { SEGURIDAD }\end{array}$

$\begin{array}{llll}\text { Nivel 1 } & 1,25 & 3 & 2,40 \\ \text { Nivel 2 } & 2,55 & 3 & 1,17 \\ \text { Nivel 3 } & 1,25 & 3 & 2,40 \\ \text { Nivel 4 } & 1,25 & 3 & 2,40 \\ \text { Nivel 5 } & 0,65 & 3 & 4,60\end{array}$

\section{NIVEL MÁXIMA TENSIÓN DE RESISTENCIA A COEFICIENTE DE COMPRESIÓN $\left(\mathrm{Kg} / \mathrm{cm}^{2}\right)$ COMPRESIÓN $\left(\mathrm{Kg} / \mathrm{cm}^{2}\right)$ SEGURIDAD}

$\begin{array}{cccc}\text { Nivel } 1 & -1,50 & 40 & 26,65 \\ \text { Nivel 2 } & -4,60 & 40 & 8,70 \\ \text { Nivel 3 } & -4,10 & 40 & 9,75 \\ \text { Nivel 4 } & -2,45 & 40 & 16,32 \\ \text { Nivel } 5 & -3,10 & 40 & 12,90\end{array}$

Dado que el valor limitante es el de tracción, deducimos que los entrepisos están dentro de los márgenes de seguridad adecuados.

Por otro lado, no se han observado fenómenos de concentración de tensiones o zonas especialmente débiles, donde fuera preciso efectuar una intervención de mejora.

En comparación con otros estudios similares, en los ensayos realizados con gato plano en la torre de Comares revelan un estado tensional en la fábrica de ladrillo de $3,86 \mathrm{Kg} / \mathrm{cm}^{2}$, aunque estos resultados no son representativos, nos dan un orden de magnitud de las tensiones, siendo las presentes en esta torre algo inferiores a aquellas. Por otro lado esto es fácilmente explicable si se tiene en cuenta la geometría de la Torre de Comares, donde las luces salvadas son mayores.

Estos valores deben tomarse con una precaución que ya se ha comentado con anterioridad. En los modelos se ha considerado una transmisión perfecta, con un espesor de lámina de $15 \mathrm{~cm}$, que es el tamaño del ladrillo empleado en la construcción, no obstante, no puede afirmarse que la transmisión real disponga de este espesor de forma homogénea (especialmente por la trabazón entre elementos), por lo que podrían existir estados de tensión diferentes a los aquí contemplados en el edificio real en algunas zonas específicas. 


\section{ANÁLISIS GLOBAL DE LA TORRE}

En este apartado, tratamos de estimar los esfuerzos actuantes sobre el muro perimetral de la torre. Como ya se ha comentado, se ha empleado un modelo de elementos finitos de elementos de mallado sólidos.

En cuanto a cargas se ha considerado el peso propio más una carga de viento de acuerdo al CTE-DB-AE de edificación:

$$
q_{e}=q_{b} \cdot c_{e} \cdot c_{p}=1320 \mathrm{~N} / \mathrm{m}^{2}
$$

Se ha considerado una ley triangular con el valor máximo de $1320 \mathrm{~N} / \mathrm{m}^{2}$ aplicado sobre el nivel del suelo de cubierta.

Un primer acercamiento es el desplazamiento que se produce a peso propio por efecto del empuje de las murallas laterales. Se ampliará posteriormente, aunque podemos observar en la imagen al pie como modifica deformada esperada.

En cuanto al nivel tensional del muro perimetral y de las pilastras, se obtienen los siguientes resultados para la hipótesis de peso propio + viento: (la influencia de las cargas de viento es del entorno del $10 \%)$.

Se han medido las compresiones que se producen en la base del muro, así como el cortante basal.
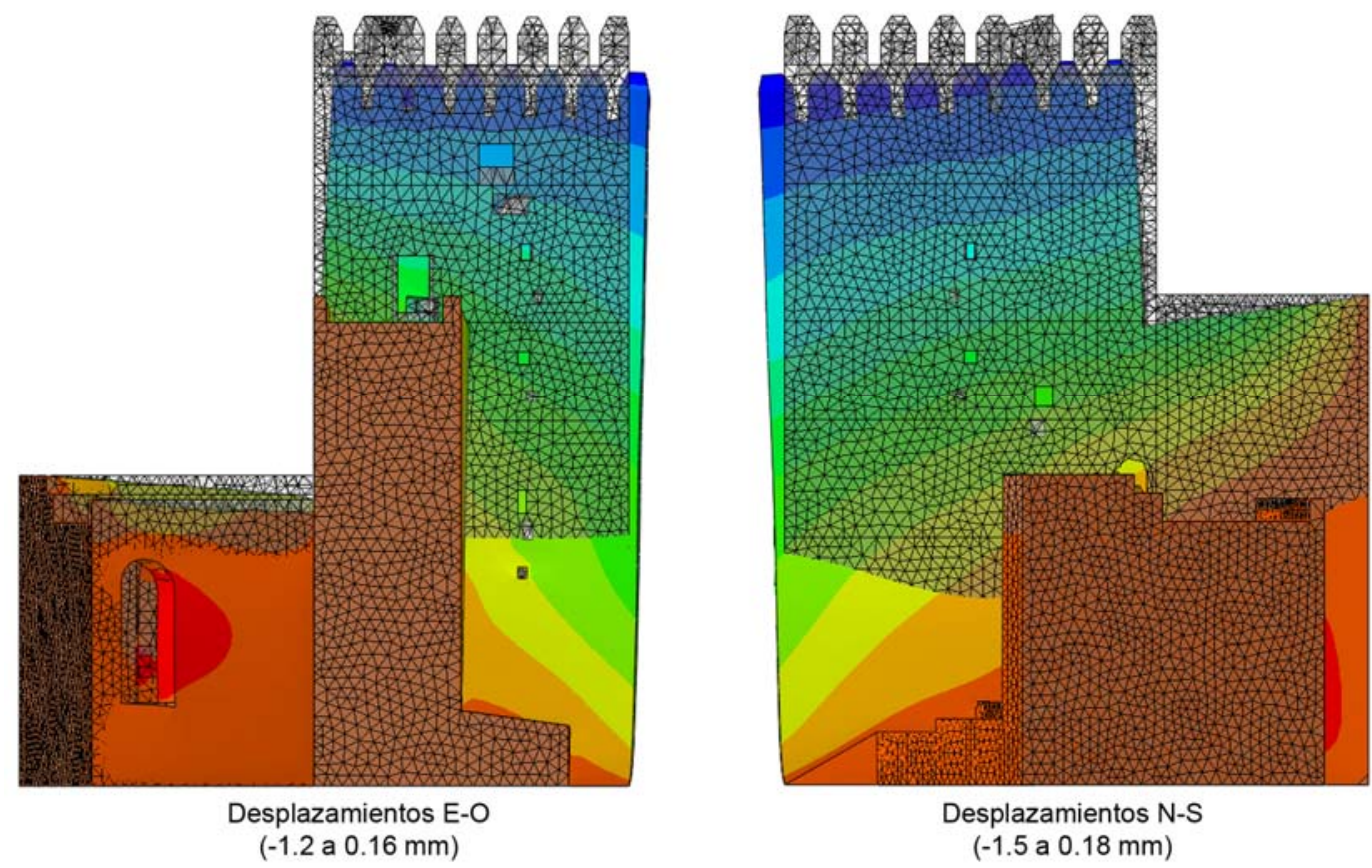

Fig.43 - Desplazamientos generales de la torre 

DE SEGURIDAD

\section{Compresiones}

Base del muro en E-O (Ladrillo) Base del muro en E-O (Tapial)

Pilastra central en E-O (Ladrillo)

Base del muro en N-S (Ladrillo) Base del muro en N-S (Tapial)

Pilastra central en N-S (Ladrillo)

\section{Cortante}

Base del muro en E-O (Ladrillo)

Base del muro en E-O (Tapial)

Pilastra central en E-O (Ladrillo)

Base del muro en N-S (Ladrillo)

Base del muro en N-S (Tapial)

Pilastra central en N-S (Ladrillo)
6,20

40

25

40

4,58

7,14

7,15

40

25

5,40

6,60

1,85

2,23

1,20

1,22

1,65

1,35

1,53

2,57

1,68

1,75

2,57

1,47

1,43

1,35

1,94

2,36
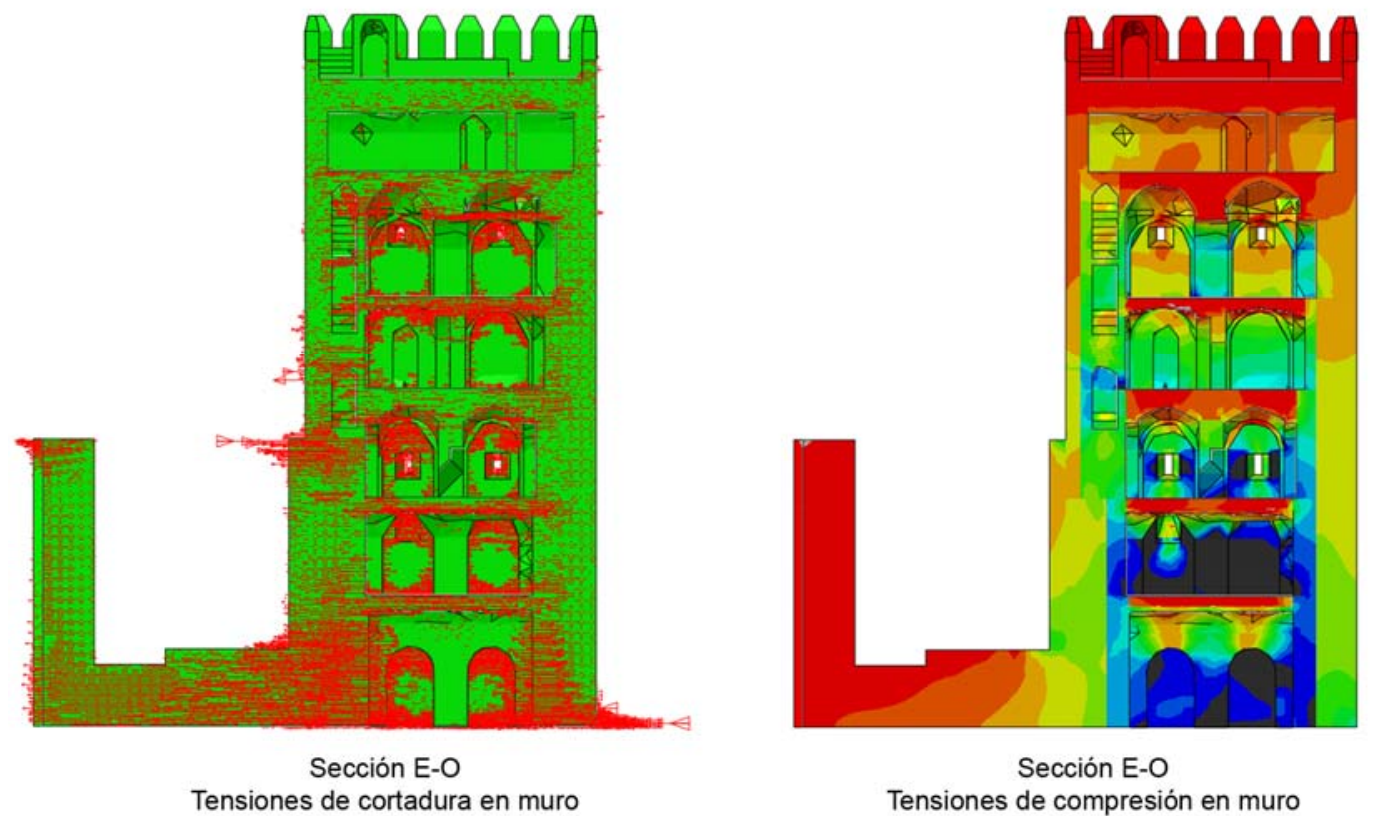

Fig.44 - Estado tensional del muro perimetral (E-O) 
Como vemos, las tensiones de cortante no son para nada despreciables, siendo el coeficiente de seguridad obtenido escaso.

Si se compara con el análisis estático realizado mediante líneas de empuje, vemos que aunque aquel ya predecía con bastante fidelidad la distribución tensional (ver imágenes de distribución de la magnitud de cortadura), los valores no contemplaban el esfuerzo inducido por las murallas, sin duda de mucha consideración, por lo que los valores que se obtuvieron anteriormente quedan por debajo de los obtenidos aquí.

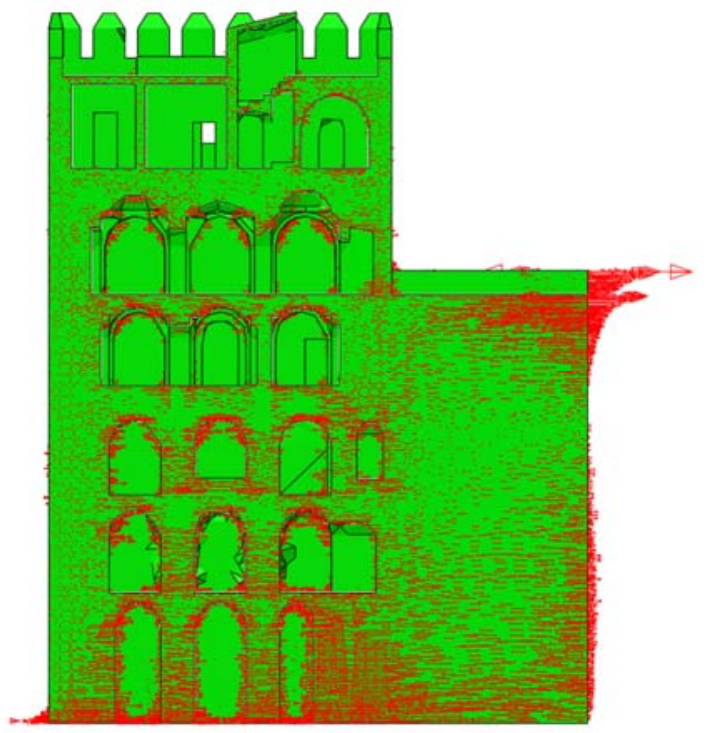

Sección N-S

Tensiones de cortadura en muro

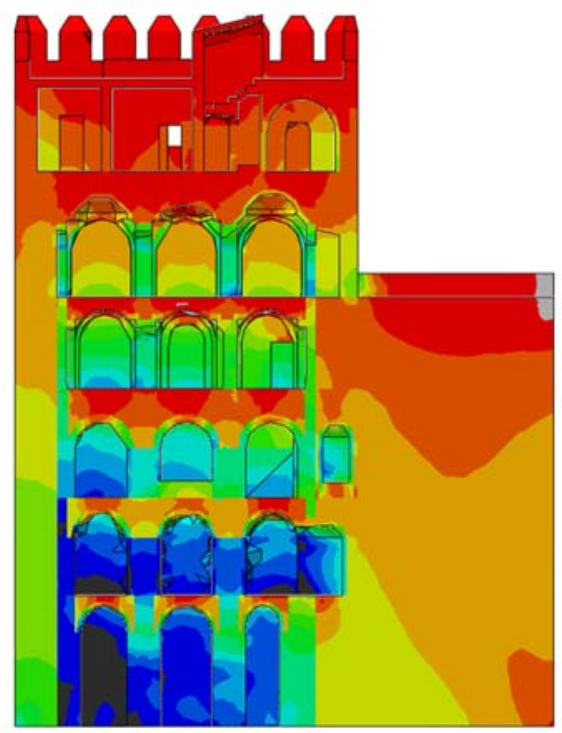

Sección N-S

Tensiones de compresión en muro

Fig.45 - Estado tensional del muro perimetral (N-S) 


\section{INFLUENCIA DE LAS CONDICIONES DE CONTORNO EN LA TORRE}

Existen varios factores que debemos tener en cuenta en el análisis de las condiciones de contorno del edificio.

En primer lugar, aunque estamos considerando la base del edificio como empotrada en la base conviene recordar que el primer nivel discurre en parte de su perímetro en semisótano y que no es posible saber con certeza cuando termina el muro, cuando empieza la cimentación y cuando empieza el terreno natural. Esto es debido, además de por la ausencia de catas en el muro, por el enorme parecido entre materiales. Esto, unido a algunos escritos y descripciones que afirman que la cimentación era pobre y se mejoró en el siglo XIV-XV hacen que sea muy difícil reproducir a nivel analítico las condiciones reales de apoyo del edificio, siendo aún más difícil estimar qué patologías están directamente relacionadas con la geometría del edificio y su funcionamiento y cuales están relacionadas con un determinado comportamiento en la base o con unos determinados asientos en el terreno.

Por otro lado, no está muy claro que exista una trabazón uniforme con las murallas norte y este. Vamos a ampliar un poco esta apreciación:

Si nos fijamos en el lienzo norte de la muralla, observamos que existe una zona ejecutada claramente en tapial que, probablemente sea original (S.XI), en cambio, la mayor parte de ésta está claramente reconstruida con ladrillo. En la entrada en recodo se aprecia con especial claridad que el ladrillo de la puerta está independizado del muro de tapial de la torre. Así mismo, una vez hemos pasado el umbral y estamos bajo la bóveda de cañón del muro norte podemos apreciar que, de nuevo parece que esta estructura es independiente de la torre.
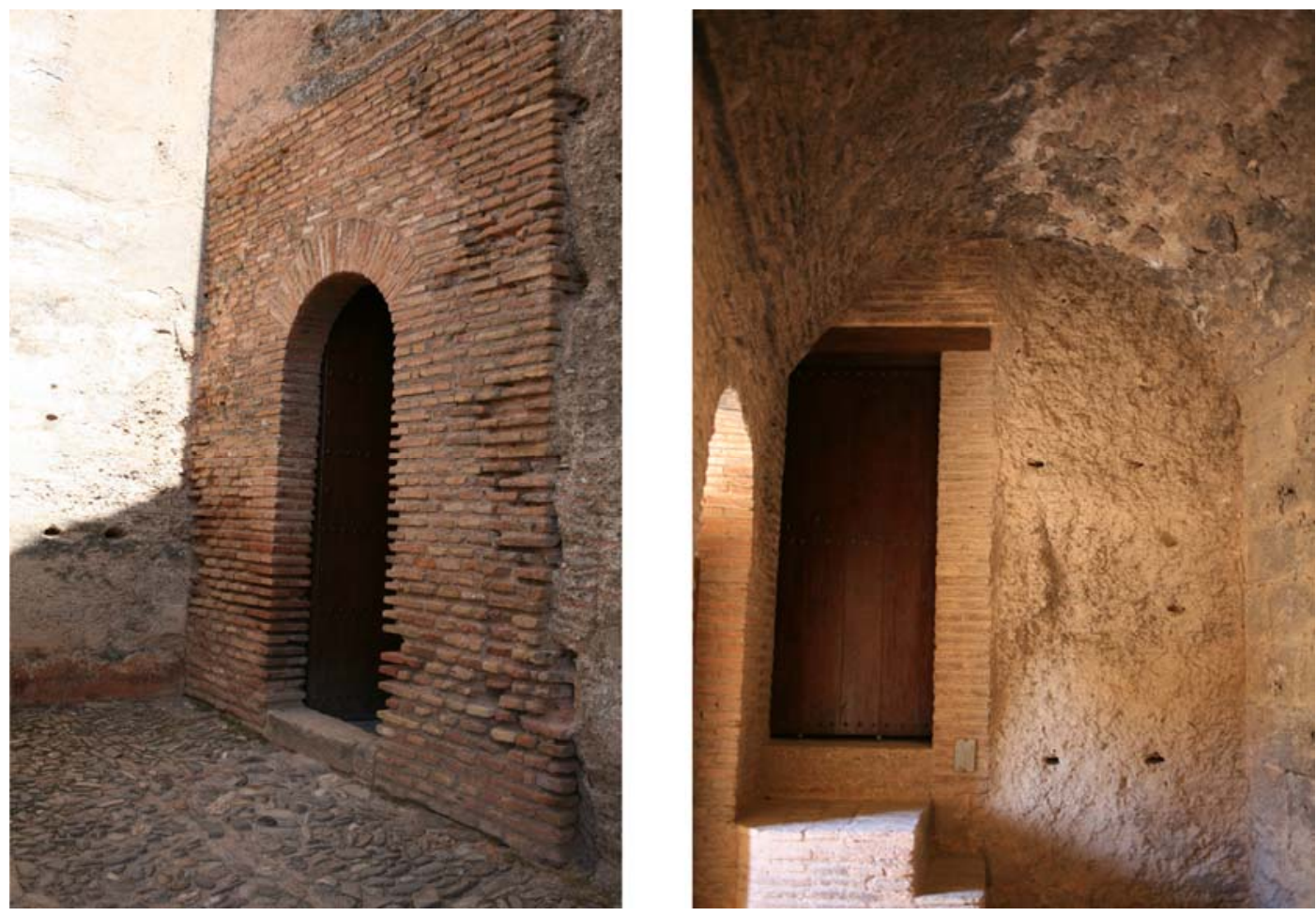

Fig.46 - Contacto entre muralla Norte y lateral Oeste de la torre 
En cuanto a la muralla Este, sabemos que fue reconstruida en el siglo XIV y sabemos también que la esquina S-O de la torre ha sido reconstruida en algún momento de la historia, ya que su despiece en ladrillo es claramente de una época posterior al resto del muro perimetral; más aún en esa esquina no se sigue la tendencia troncopiramidal del perímetro, lo que hace pensar que fue una reconstrucción que no tuvo en cuenta esa geometría original.

Aquí la trabazón parece clara con la torre, pero es debida a una zona reconstruida, lo que hace del todo imposible afirmar o desmentir que en las partes ocultas y originales exista tal trabazón.

Otro punto de especial atención es el refuerzo bajo que presenta la muralla Este en la barbacana entre la torre y el antemuro. Ésta es de guijarros de piedra de dimensión mediana que nada tienen que ver con la muralla ni con la torre, lo que descarta casi con toda seguridad que estén trabados.

Esto nos lleva a considerar otra posible influencia entre torre y contorno y es que es muy probable que el relleno en las murallas y adarves esté presionando los laterales del muro de la torre en la esquina S-O Esto sólo puede discutirse como posibilidad, pero trataremos que estimar mediante modelos de elementos finitos qué hipótesis se ajusta mejor al estado actual de la estructura.
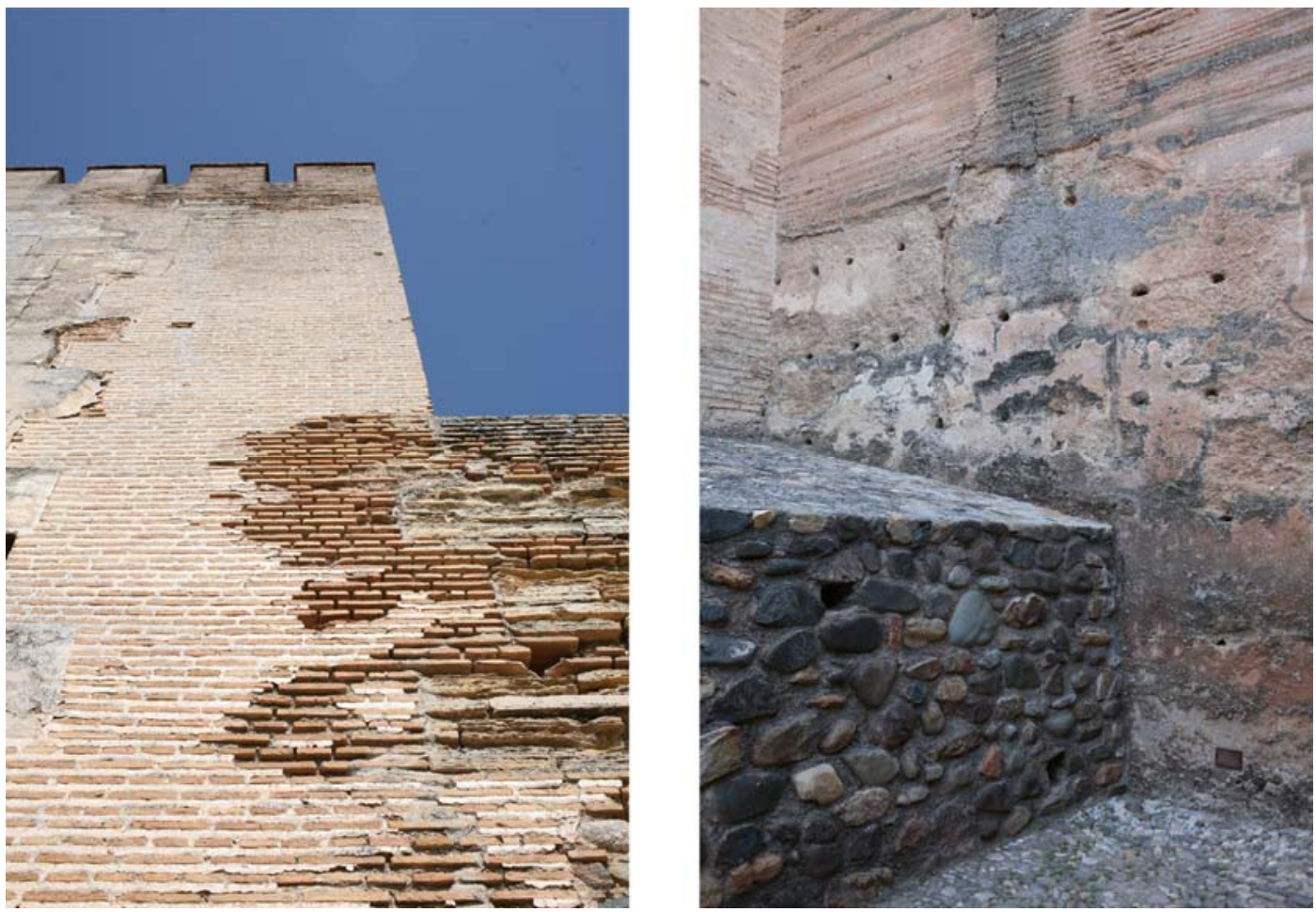

Fig.47 - A la izquierda, esquina S-O reconstruida. A la derecha contacto de la muralla E con la torre 
Si analizamos la estructura a peso propio podemos observar la diferencia de comportamiento que existe cuando modelamos el edificio aislado y cuando consideramos el empuje de las murallas.

Como puede apreciarse en la imagen al pie, la muralla Este ejerce un empuje sobre la cara sur de la torre que, por ser esta muralla de gran altura, acaba por desplazar hacia el lado Norte todo el conjunto.

La muralla Norte, de menor entidad, hace lo propio con la cara Oeste, provocando un desplazamiento del conjunto hacia la barbacana del lienzo Este.

Como vemos, la esquina S-O es la que sufre de manera más significativa el empuje de ambos muros, lo que podría explicar el hecho de que fuera necesaria una importante reparación a lo largo de su historia.

Probablemente, el estado real de empujes corresponda a un estado intermedio en el que ambas murallas presionan sólo parcialmente a la torre, no obstante, no tiene demasiado interés discutir este modelo dado que no tenemos datos más fiables a los ya expuestos acerca de la construcción de las murallas.

Cuando sometemos al modelo a cargas laterales, considerando la muralla, e independizándola obtenemos los desplazamientos que vemos en las figuras de la siguiente página.

Podemos apreciar que, para una misma carga, los desplazamientos laterales se reducen notablemente por la influencia de la muralla. Si nos centramos en la imagen de desplazamientos N-S, considerando la muralla vemos como el empuje del relleno de la muralla Este hace incluso que haya desplazamientos negativos en la parte inferior de la torre (zona en gris). Como vimos en el apartado anterior, este esfuerzo de cortante adicional tiene su influencia en las tensiones de cortante del muro perimetral.

Este efecto hace que la esquina S-O tenga un empuje puntual importante que la debilita enormemente respecto al resto del conjunto.

\section{HIPÓTESIS DE PESO PROPIO}

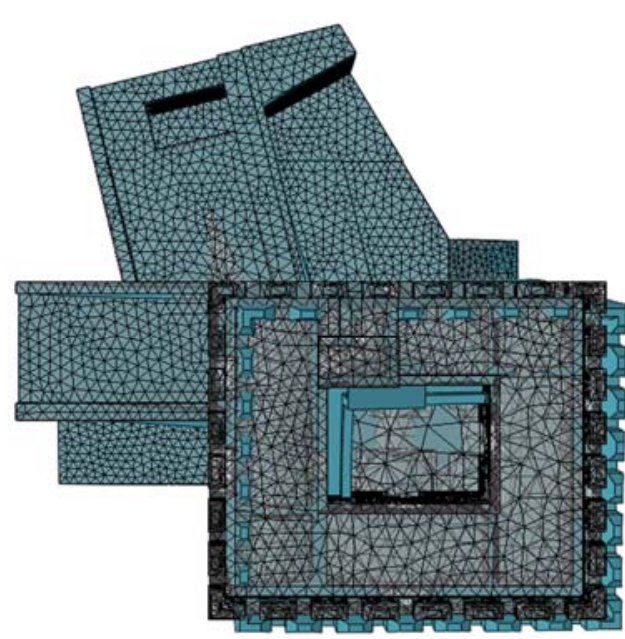

Desplazamientos con empuje de murallas

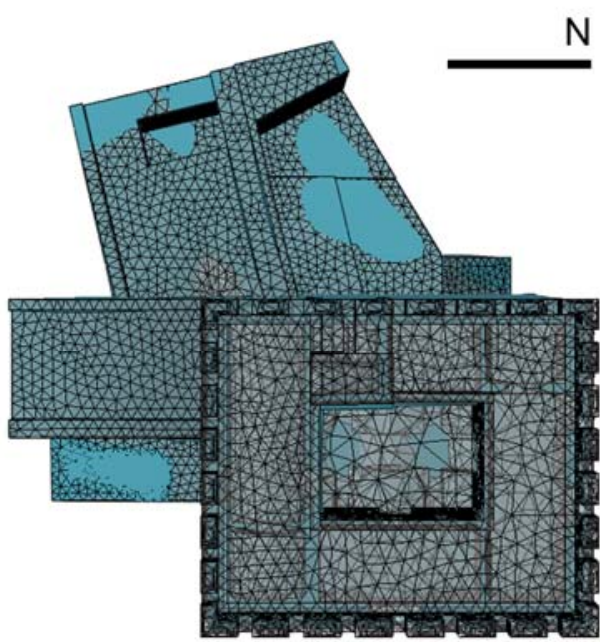

Desplazamientos sin empuje de murallas

Fig.48 - Desplazamientos a peso propio con y sin efecto de las murallas anexas 

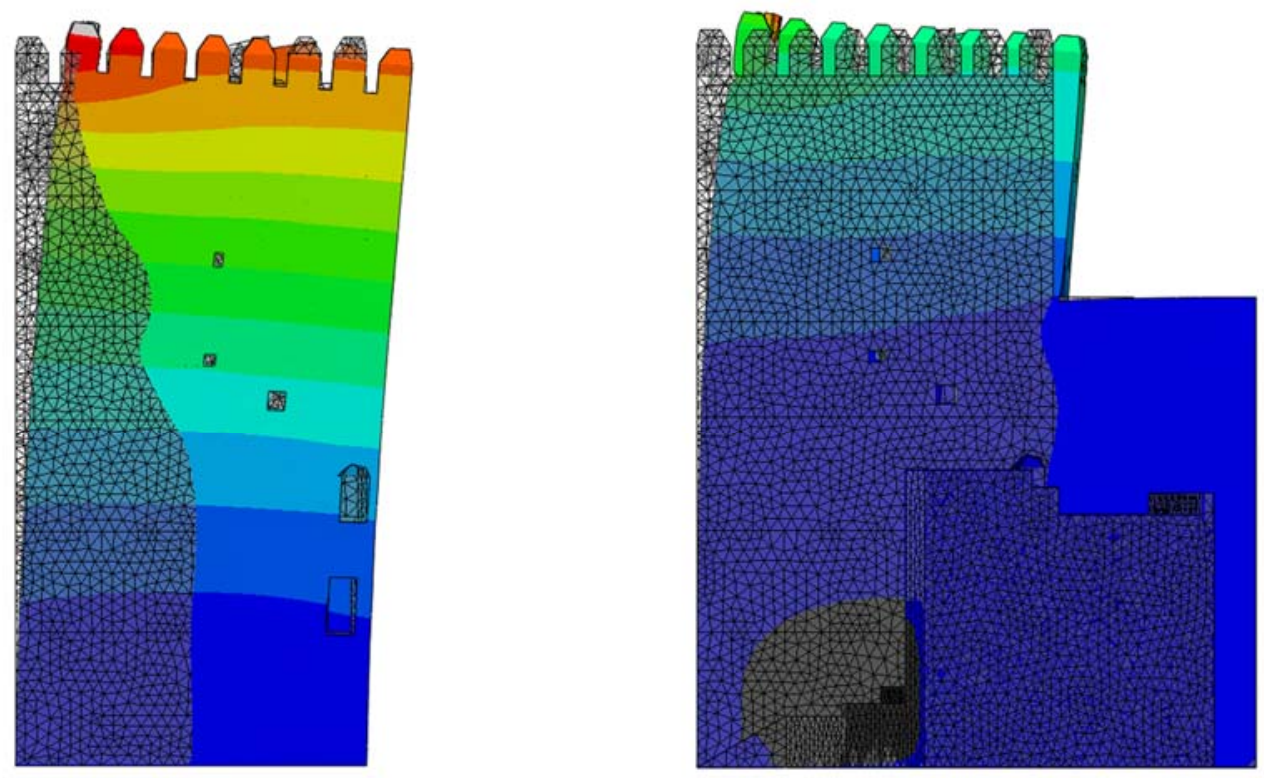

Desplazamientos N-S con carga lateral

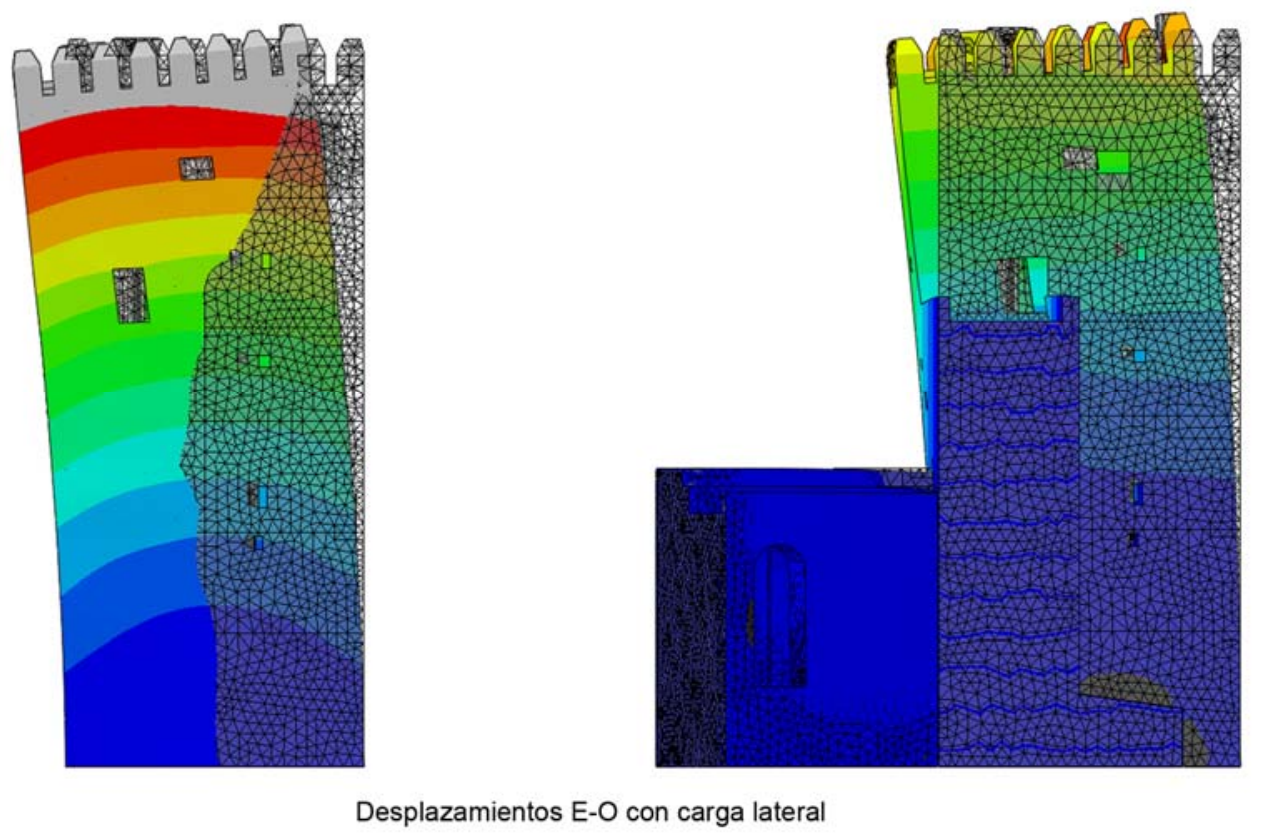

Fig.49 - Desplazamientos laterales con y sin efecto de las murallas laterales 


\section{ANÁLISIS MODAL}

\section{DESCRIPCIÓN DEL MODELO EMPLEADO}

Para el análisis modal del edificio, se ha empleado un modelo de elementos finitos basado fundamentalmente en elementos tridimensionales de geometría tetraédrica.

Las distribuciones de masa son las reales del edificio, ya que se ha empleado un modelo fiel a la geometría del conjunto.

A fin de no capturar modos de vibración de bajas frecuencias que pudieran derivarse de elementos débiles se han simplificado algunos encuentros y se ha empleado un mallado más tosco en los elementos de entrepiso y bóvedas, entendiendo que su único interés en el comportamiento modal del edificio es la rigidización horizontal por planta que aportan y la distribución de masas, particularmente singular.

También se han tenido en cuenta las murallas Este y Norte como condiciones de contorno de la torre, si bien con las cautelas que describimos en apartados anteriores.

\section{OBTENCIÓN DE LAS FRECUENCIAS FUNDAMENTALES DEL EDIFICIO}

Previo al cálculo mediante elementos finitos, para contar con un orden de magnitud aproximado, se ha recurrido a la norma NCSE-02 que en su artículo 3.7.2.2 permite estimar el período fundamental de un edificio en altura de estructura de fábrica de ladrillo mediante la siguiente expresión:

$$
T_{f}=\frac{0.06 H \sqrt{H /(2 L+H)}}{\sqrt{L}}
$$

$H$ : Altura de la torre

\section{$L$ :Ancho en planta en la dirección considerada}

Operando, obtenemos:

$\begin{array}{ll}T_{f 1}=0.3234(s) & \text { Según dirección } E-O \\ T_{f 2}=0.2864(s) & \text { Según dirección } N-S\end{array}$

Los resultados que obtenemos mediante la resolución del problema de elementos finitos son los que se listan a continuación:

\begin{tabular}{l|c|c|c|c}
\multirow{2}{*}{ MODO } & \multicolumn{2}{c}{ VALOR DE REFERENCIA } & \multicolumn{2}{c}{ VALOR OBTENIDO } \\
\cline { 2 - 5 } & $\mathbf{( s )}$ & $\mathbf{( H z )}$ & $\mathbf{( s )}$ & $\mathbf{( H z )}$ \\
\hline & & & & \\
Primer modo de flexión (E-O) & 0.323 & 3.092 & 0.318 & 3.145 \\
Primer modo de flexión (N-S) & 0.286 & 3.492 & 0.204 & 4.907 \\
Primer modo de torsión & - & - & 0.151 & 6.633
\end{tabular}

En estos modos se ha tenido en cuenta el efecto que producen las murallas Norte y Este sobre la torre, en las siguientes páginas se muestra gráficamente los 3 primeros modos de vibración de la estructura. 

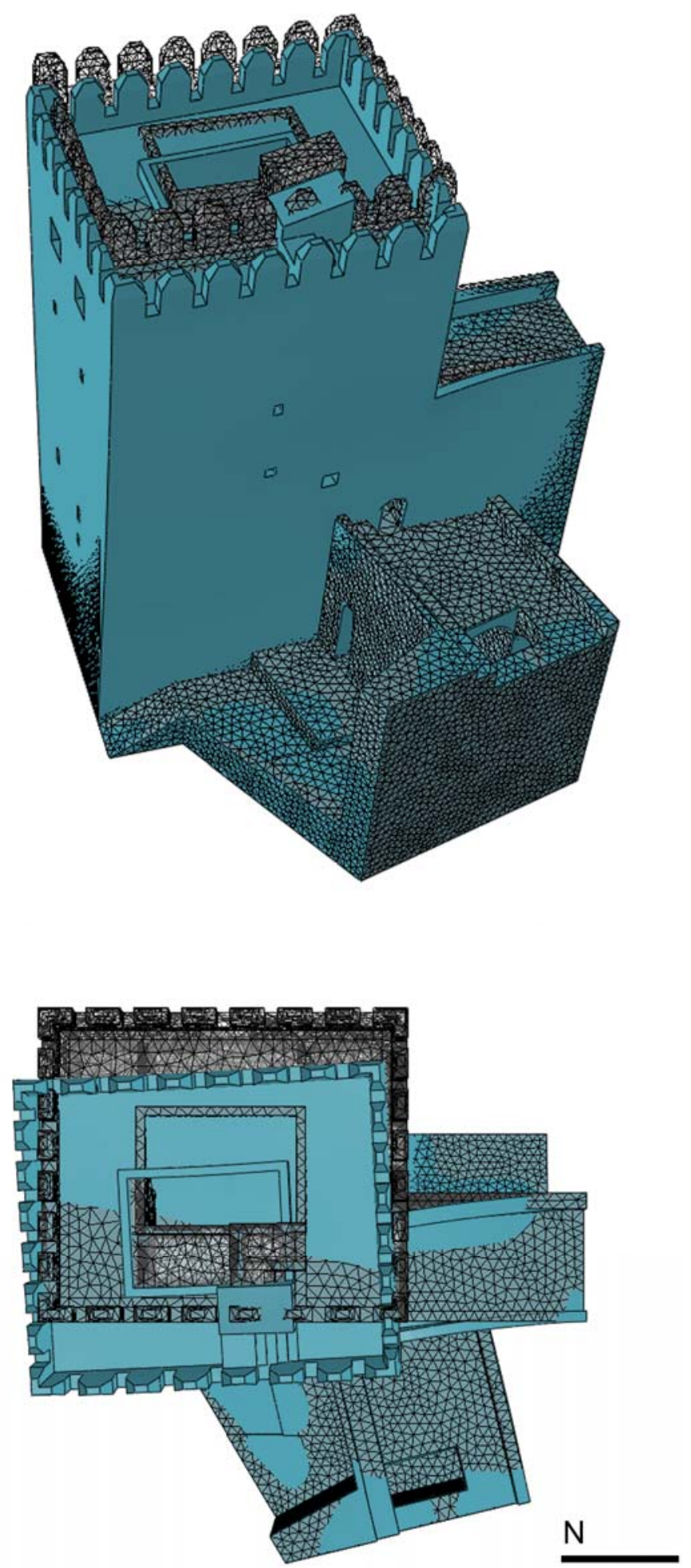

Fig.50 - $1^{\circ}$ Modo de vibración $T=0.318 \mathrm{~s}$ 

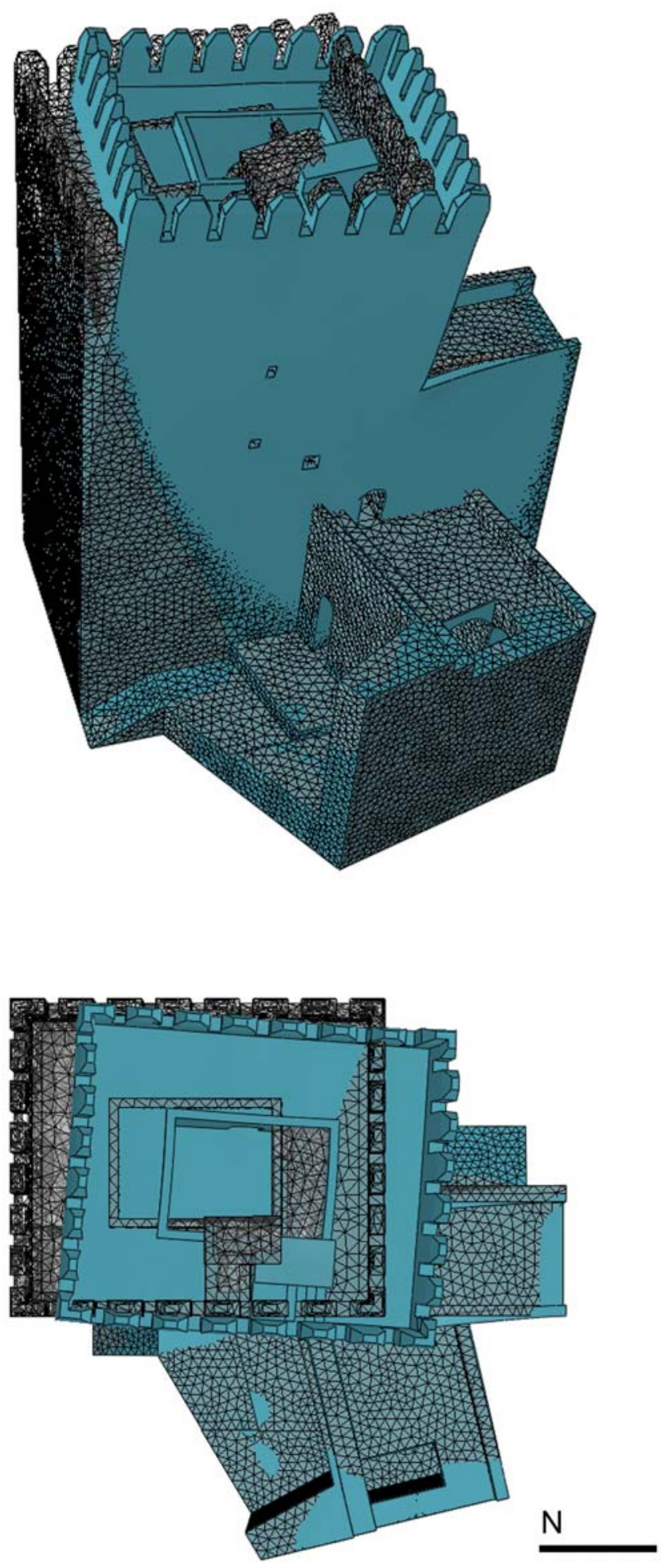

Fig.51 - 20 Modo de vibración T=0.204s 

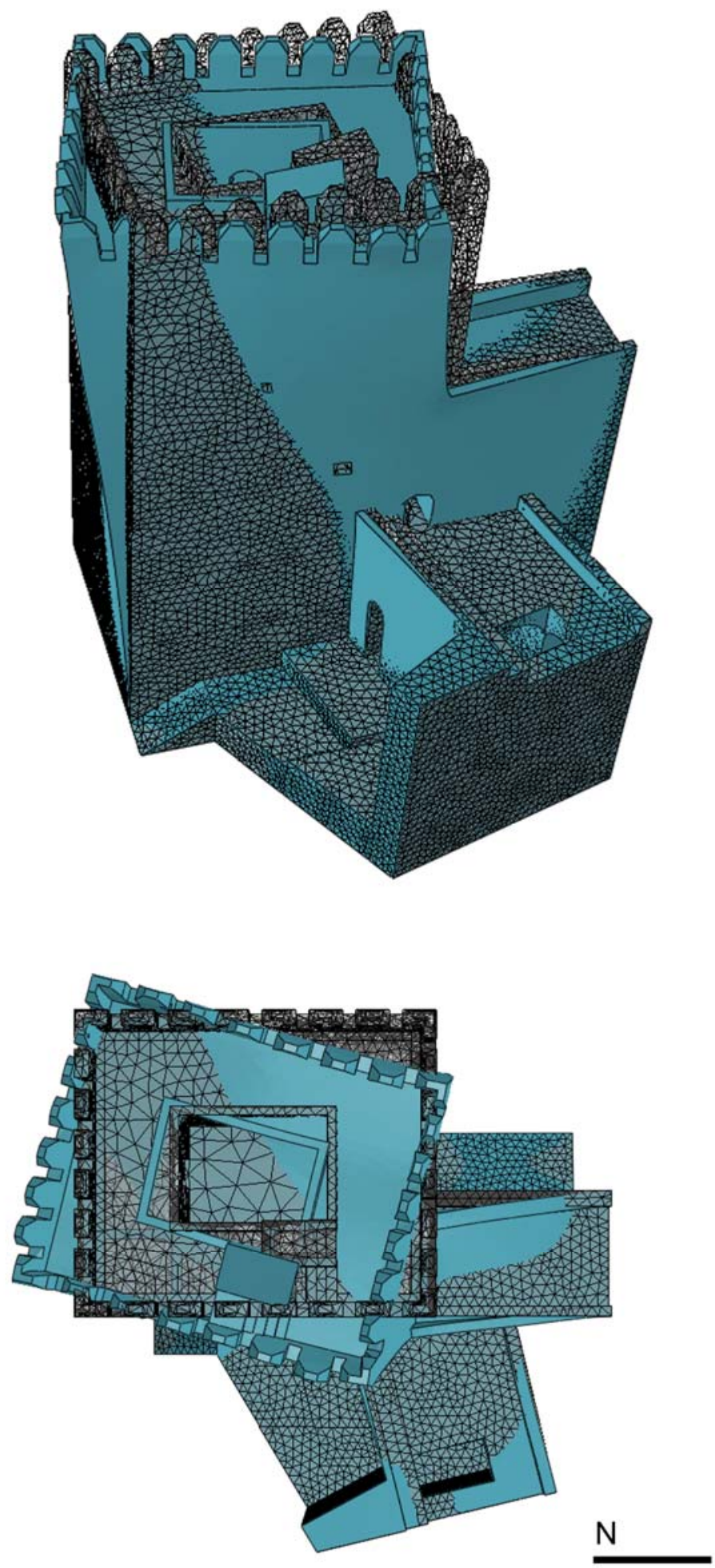

Fig.52 - 3० Modo de vibración T=0.151s 


\section{DISCUSIÓN DE RESULTADOS}

Uno de los aspectos más interesantes que podemos destacar de este análisis es la influencia de los muros Norte y Este en el comportamiento de la torre. Como ya vimos en el apartado de análisis estático, ambas murallas ejercen un empuje sobre la torre de bastante consideración y su efecto se refleja también notablemente en el análisis modal. Son varios los aspectos que pueden ser comentados:

Por un lado, la existencia de estas murallas rompe decididamente la simetría de planta que, casi con toda limpieza, guarda el edificio. Esto lleva a una modificación clara en la forma de vibrar de la torre, como podemos ver en la imagen al pie.

La muralla Este obliga a la torre a moverse sensiblemente hacia la cara norte, mientras que la muralla Norte descompensa el movimiento hacia el Oeste de parte de la torre, induciendo ambas un cierto grado de torsión en planta.

Los períodos de vibración varían de forma considerable, aunque de forma diferente:

\begin{tabular}{|c|c|c|c|c|c|}
\hline \multirow[t]{2}{*}{ MODO } & \multicolumn{2}{|c|}{ SIN MURALLA } & \multicolumn{2}{|c|}{ CON MURALLA } & VARIACIÓN* \\
\hline & (s) & $(\mathrm{Hz})$ & (s) & $(\mathrm{Hz})$ & (\%) \\
\hline Primer modo de flexión (E-O) & 0.391 & 2.558 & 0.318 & 3.145 & $-18.7 \%$ \\
\hline Primer modo de flexión (N-S) & 0.348 & 2.876 & 0.204 & 4.907 & $-41.4 \%$ \\
\hline Primer modo de torsión & 0.193 & 5.183 & 0.151 & 6.633 & $-21.8 \%$ \\
\hline
\end{tabular}

*Variación en el período de vibración (s) al incorporar en el análisis las murallas

Como es lógico, la influencia de la muralla Este, de mayor altura, condiciona mucho más el modo fundamental en la dirección N-S de lo que condiciona la muralla Norte el modo E-O.

Si bien es cierto que los valores calculados mediante el método simplificado de la NCSE-02 son meramente orientativos, nos dan pie a preguntarnos si el modelo habitual de masas concentradas tiene validez en un edificio donde el peso del muro es tan signifícativo.

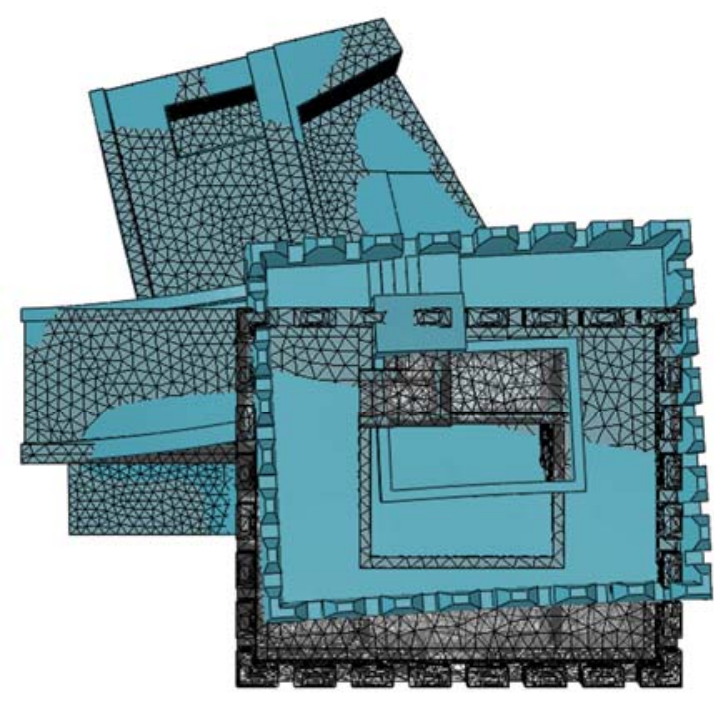

$1^{\circ}$ Modo de vibración con murallas $\mathrm{T}=0.318 \mathrm{~s}$

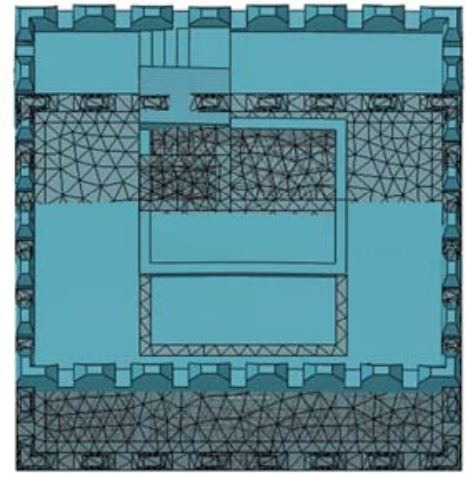

$1^{\circ}$ Modo de vibración sin murallas $\mathrm{T}=0.391 \mathrm{~s}$

Fig.53 - Comparación del primer modo de vibración para el modelo con y sin muralla 
Estudiar la vibración de la torre desde un modelo de viga continua de sección variable es, probablemente más ajustado. Para estudiar hasta qué punto las masas concentradas por plantas que representan los entrepisos influyen en la respuesta global del edificio se ha realizado un modelo complementario donde hemos modelado exclusivamente el muro perimetral.

Como vemos en la siguiente tabla, en cuanto a pesos, los elementos que forman los entrepisos son poco significativos frente al peso total por planta:

\begin{tabular}{lcc|c}
\cline { 2 - 4 } & \multirow{2}{*}{ NIVEL } & PESO TOTAL & \multicolumn{2}{c}{ PESO DE ENTREPISO } \\
\cline { 2 - 4 } & $\mathbf{( K N )}$ & $\mathbf{( K N )}$ & $\mathbf{( \% )}$ \\
\hline \multirow{2}{*}{ NIVEL +1 } & \multicolumn{3}{|c}{} \\
NIVEL +2 & 8788 & 504 & $6 \%$ \\
NIVEL +3 & 6179 & 748 & $12 \%$ \\
NIVEL +4 & 7045 & 1258 & $18 \%$ \\
NIVEL +5 & 5607 & 767 & $14 \%$ \\
NIVEL +6 & 7750 & 2094 & $27 \%$ \\
TOTAL & 4167 & 895 & $21 \%$ \\
& $\mathbf{3 9 5 3 8}$ & $\mathbf{6 2 6 6}$ & $\mathbf{1 6 \%}$
\end{tabular}

Si analizamos los valores que obtenemos en el modelo, considerando sólo el muro perimetral tenemos:

\begin{tabular}{l|c|c|c|c|c}
\multirow{2}{*}{ MODO } & \multicolumn{2}{c}{ CON ENTREPISOS } & \multicolumn{2}{c}{ SIN ENTREPISOS } & \multicolumn{1}{c}{ VARIACIÓN* } \\
\cline { 2 - 6 } & $\mathbf{( s )}$ & $\mathbf{( H z )}$ & $\mathbf{( s )}$ & $\mathbf{( H z )}$ & $\mathbf{( \% )}$ \\
\hline & & & & \\
Primer modo de flexión (E-O) & 0.391 & 2.558 & 0.431 & 2.319 & $+10.2 \%$ \\
Primer modo de flexión (N-S) & 0.348 & 2.876 & 0.371 & 2.696 & $+6.6 \%$
\end{tabular}

*Variación en el período de vibración (s) al eliminar en el análisis los entrepisos

**No se ha considerado el primer modo de torsión, ya que no existir diafragmas de planta, el modo varía sustancialmente y no resulta comparable.

Como es de esperar, los períodos de vibración disminuyen (fundamentalmente por la reducción de masas), pero los modos son prácticamente idénticos, no siendo significativa la rigidez aportada en los primeros modos por los entrepisos. 


\section{CONCLUSIONES GENERALES Y TRABAJO FUTURO}

\section{CONCLUSIONES GENERALES}

1.-Por su contexto, por su construcción y por su diseño, la Torre del Homenaje es uno de los edificios paradigmáticos de la arquitectura defensiva del medievo hispanomusulmán. Su monótono aspecto exterior contrasta con la rica diversidad interior, planteando diferentes soluciones técnicas en los distintos niveles que suponen un catálogo de soluciones constructivas y estilísticas, elegidas y determinadas por los espacios en los que se encuentran.

2.-Junto con la Torre de la Vela, la del Homenaje es una de las edificaciones más antiguas de la Alhambra; siendo ésta además el punto más elevado de todo el conjunto monumental.

3.-La construcción en tapial calicostrado, usada habitualmente con posterioridad en otros edificios del conjunto, se muestra como un ingenio técnico de gran eficacia, durabilidad y economía de medios, sin una merma en la resistencia importante.

4-Las principales incertidumbres en lo concerniente al a construcción de la torre son:

-Interfaz ladrillo-Tapial: No es posible averiguar, en la mayoría de casos la secuencia lógica de construcción determinando dónde empieza y dónde acaba uno y otro material.

-Consecución de piso horizontal: Tanto la teoría de aligeramiento como la de relleno en masa cuentan con argumentos suficientemente sólidos, sin que sea posible decantarse por ninguna.

-Ejecución cimbrada: Parece muy probable que no fuera necesario el empleo de cimbras provisionales para la ejecución de la mayor parte de los elementos estructurales interiores.

5.-La concepción de la torre, organizada en planta en seis vanos prácticamente cuadrados, buscaba una minimización de las cargas de cortante en el muro perimetral, de forma que la carga principal recayera sobre los pilares centrales que, por condición de simetría trabajan fundamentalmente a compresión centrada. Un mayor esfuerzo axil en estos pilares, compensado con un módulo de deformación mayor en el ladrillo que en el tapial permiten que la compatibilidad de deformaciones entre los elementos sustentantes externos e internos sea muy alta y no se produzcan cortantes verticales en las bóvedas y arcos principales.

6.-El estudio del edificio mediante líneas de empuje nos acerca a un orden de magnitud bastante fiable del estado estructural de la torre; tanto a nivel de estabilidad como a nivel de resistencia.

7.-El análisis mediante elementos finitos revela que las cargas presentes en el edificio llevan a un coeficiente de seguridad escaso en la base del muro, estando las cúpulas y bóvedas en general en un estado tensional mucho menor.

-En cuanto a las tensiones de tracción en los elementos de entrepiso van de 0,65 a $2,55 \mathrm{~kg} / \mathrm{cm}^{2}$, mientras que las tensiones de compresión están entre $-1,50$ y $-4,60 \mathrm{~kg} / \mathrm{cm}^{2}$

-En cuanto al muro perimetral, las compresiones están entre 4,50 y $7,15 \mathrm{~kg} / \mathrm{cm}^{2}$, mientras que las tensiones de cortante están por debajo de $\mathrm{kg} / \mathrm{cm}^{2}$

8.-Por niveles, el entrepiso del nivel dos es el que se encuentra más solicitado, tanto a tracción como a compresión. Por el contrario, el nivel 5 es el que encuentra menor solicitación a tracción; seguramente por la mayor esbeltez de sus bóvedas y cúpulas y por la 
presencia de importantes tambores que absorben las tracciones que pudieran producirse en los arranques de cúpulas y bóvedas.

9.-La influencia de las murallas exteriores sobre el edificio se torna de suma importancia. Propician un desplome del edificio hacia la esquina N-E y modifican los estados tensionales del muro perimetral en los niveles inferiores, incrementando el cortante y estableciendo una discontinuidad en la esquina S-O que probablemente condujera a un derrumbe parcial (del que puede observarse la reparación) en épocas anteriores. Conduce a una ruptura de la simetría de planta, llevando además a un modo de torsión, donde la torre no torsiona siguiendo el esquema habitual de diafragma por planta.

10.-El análisis modal se encuentra muy influencia por la consideración o no de las murallas, en cambio, casi no se ve afectado por la distribución de masas cambiante presente en los distintos niveles. La rigidez del muro perimetral es tal, que la geometría de los entrepisos no condiciona la rigidez transversal total en términos considerables.

\section{TRABAJOS FUTUROS}

Como trabajo futuro se plantean las siguientes líneas de investigación:

1.-Medición in situ de la torre, mediante acelerómetros, aplicando un análisis modal operaciones, de forma que puedan discutirse de forma más amplia los resultados obtenidos aquí.

2.-Análisis de la estructura mediante modelos de comportamiento de materiales no-lineales, de forma que puedan estudiarse, fisuraciones, grietas y se establezcan otras hipótesis de estado tensional.

3.-Respuesta del edificio ante una carga dinámica sobrevenida, como un terremoto. Comportamiento esperable y seguridad frente a acciones sísmicas del edificio. 


\section{BIBLIOGRAFÍA}

ALMAGRO CORBEA, A. Un aspecto constructivo de las bóvedas en Al-Andalus.

AROCA, R. Tamaño y proporción de las estructuras. Rankine.W. Manual of applied mechanics. Thompson, D. Sobre el crecimiento y la forma.

ASTIZ, M.A. Estudio de la seguridad estructural de la Torre de Comares.

AZKARATE, A. Aparejos constructivos medievales en el Mediterráneo Occidental : estudio arqueológico de las técnicas constructivas

BASILIO PAVÓN, M. La ALcazaba de la ALhambra

BERMÚDEZ LÓPEZ, J. La Alhambra y el Generalife

BERMÚDEZ PAREJA, J. La Alcazaba y Torres de la Alhambra

COBREROS, M. La concepción estática de la obra de fábrica en el renacimiento. Tesis doctoral.

CUELLAR MIRASOL, V. Caracterización dinámica de los materiales

DE LA TORRE LÓPEZ M. J. Estudio de los materiales de construcción en la Alhambra. Universidad de Granada, Tesis doctoral, 1995

DE LAS CASAS GÓMEZ, A. Algunos aspectos constructivos de la arquitectura islámica

ESCRIG, F. Las grandes estructuras de los edificios históricos: desde la antigüedad hasta el gótico

ESLAVA GALÁN, J. Materiales y técnicas en la fortificación Bajomedieval.

FERNÁNDEZ PUERTAS, A. The Alhambra T.I

FERNÁNDEZ PUERTAS, A. El Arte hispanomusulmán

GALLEGO BURÍN, A. La Alhambra, Granada; Patronato de la Alhambra 1963

GÓMEZ-MORENO CALERA, J.M. Estructuras defensivas de la Alhambra

GÓMEZ MORENO MARTÍNEZ, M. Granada en el siglo XIII

HEYMAN, J. Teoría, historia y restauración de estructuras de fábrica : colección de ensayos

HUERTA FERNÁNDEZ, S. Arcos, bóvedas y cúpulas. Geometría y equilibrio en el cálculo tradicional de estructuras de fábrica. (2004)

MALPICA CUELLO, A. Las técnicas constructivas en Al-Aldalus

TORRES BALBÁS, L. Arte almohade, arte nazarí.

VITRUVIO. Tratado de Arquitectura

VV.AA. Informe técnico. CEDEX - "Caracterización Geotécnica de las Condiciones de Cimentación del Conjunto Monumental de la Alhambra y el Generalife", 1995

VV.AA. Comportamiento mecánico de la obra de fábrica. (2001) 

Análisis estructural del patrimonio histórico. Torre del Homenaje de la Alhambra

Trabajo Final de Máster. Máster de Estructuras - Universidad de Granada

David Villegas Cerredo [Septiembre 2012]

ANEXO I. PLANIMETRÍA DEL EDIFICIO 


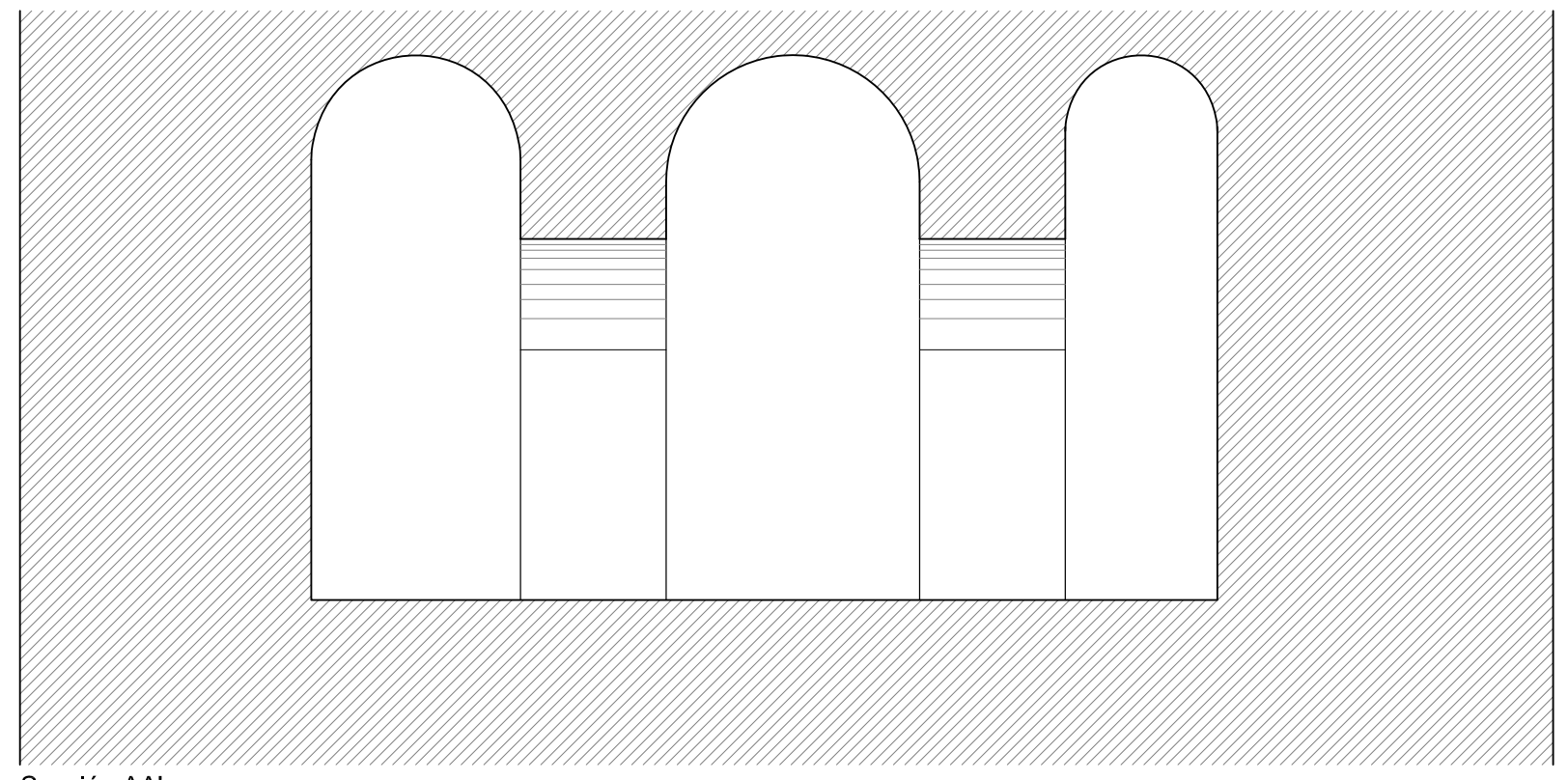

Sección AA'

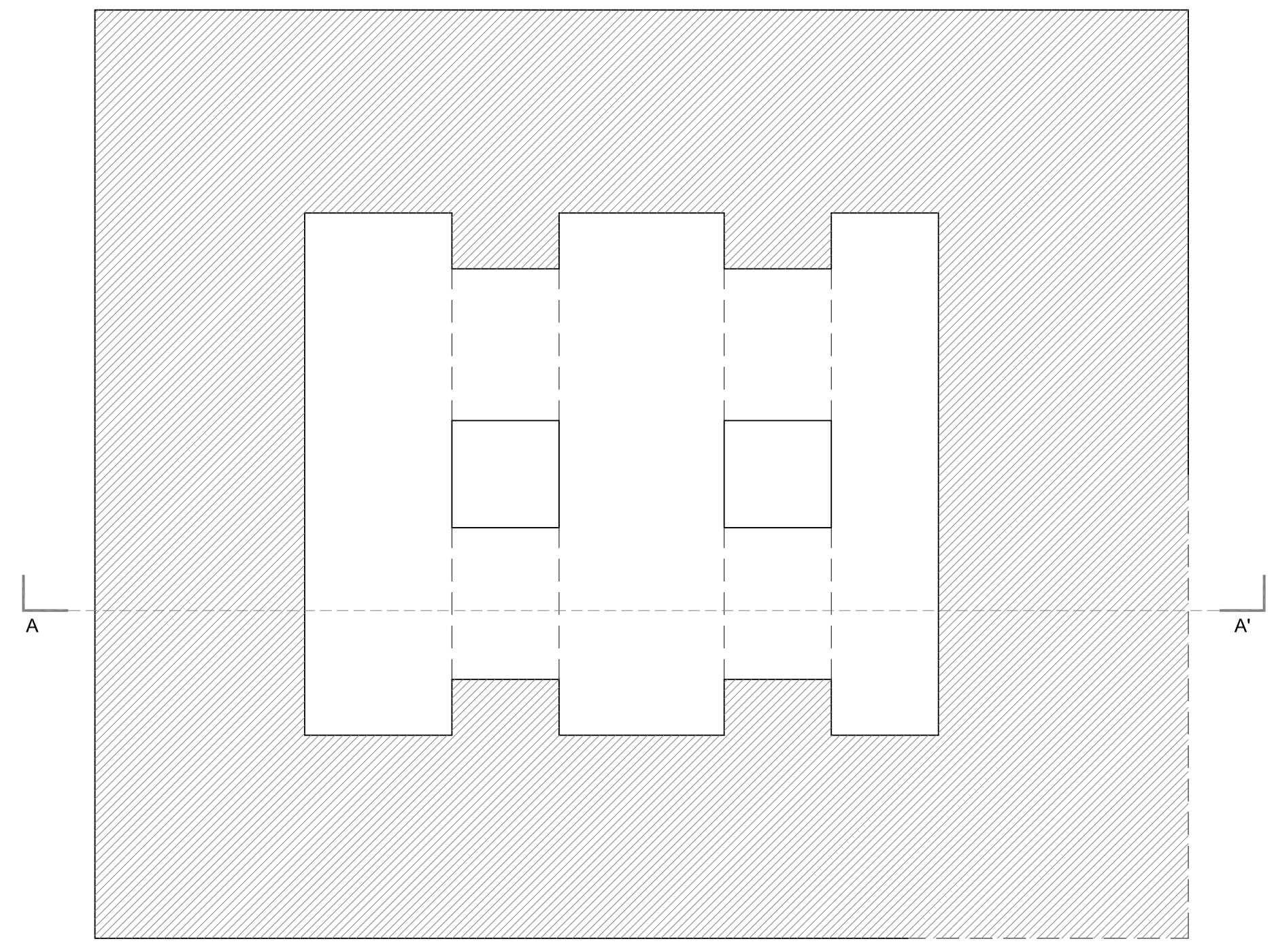

Planta Nivel 1

TRABAJO FIN DE MÁSTER

TORRE DEL HOMENAJE DE LA ALHAMBRA PLANIMETRIÁA DEL EDIFICIO

Plano: Nivel 1

$\begin{array}{llllll}0 & 1 & 2 & 3 & 4 & 5 \mathrm{~m} \\ 1 & 1 & 1 & 1 & 1\end{array}$




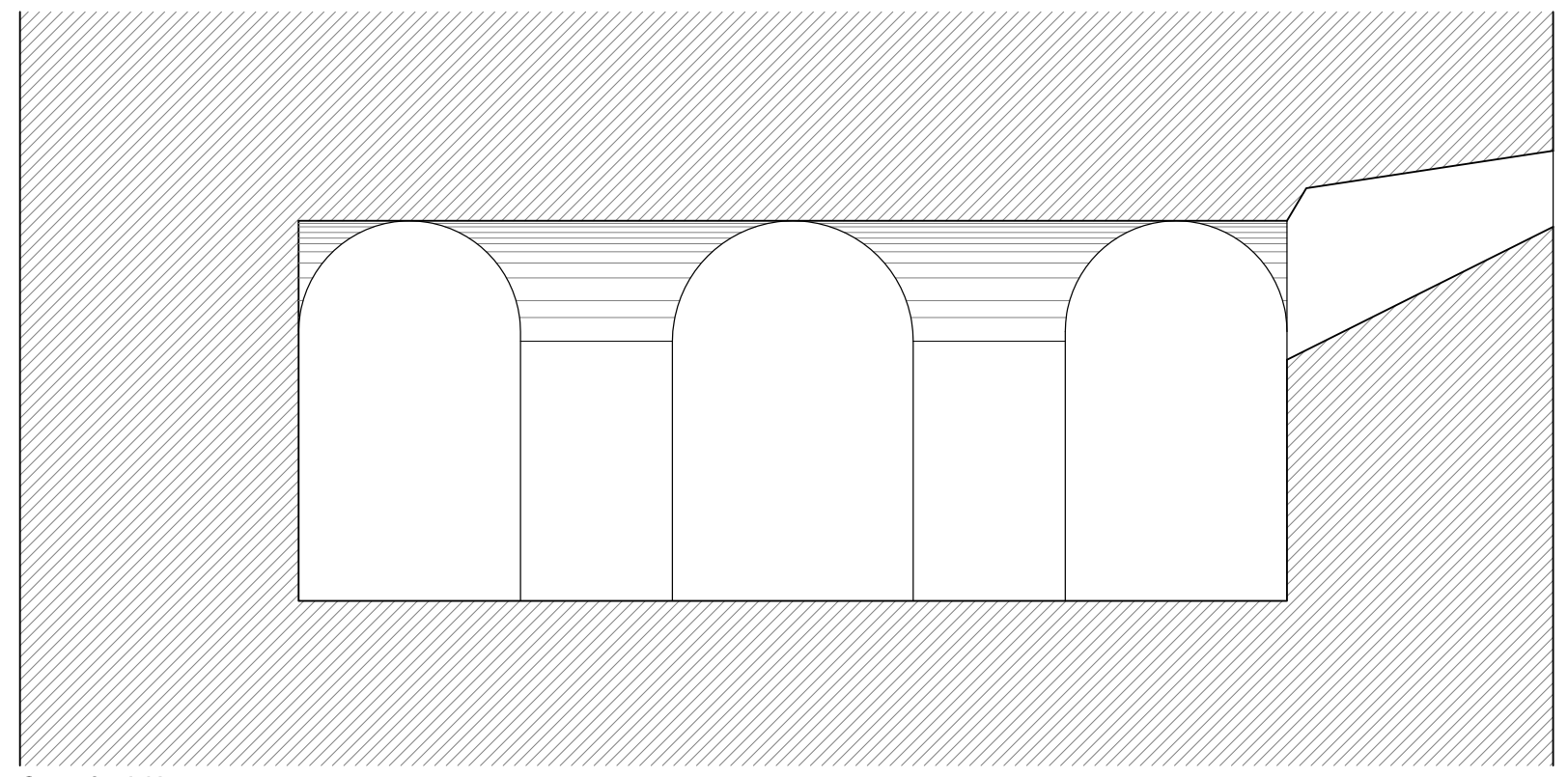

Sección $A^{\prime}$

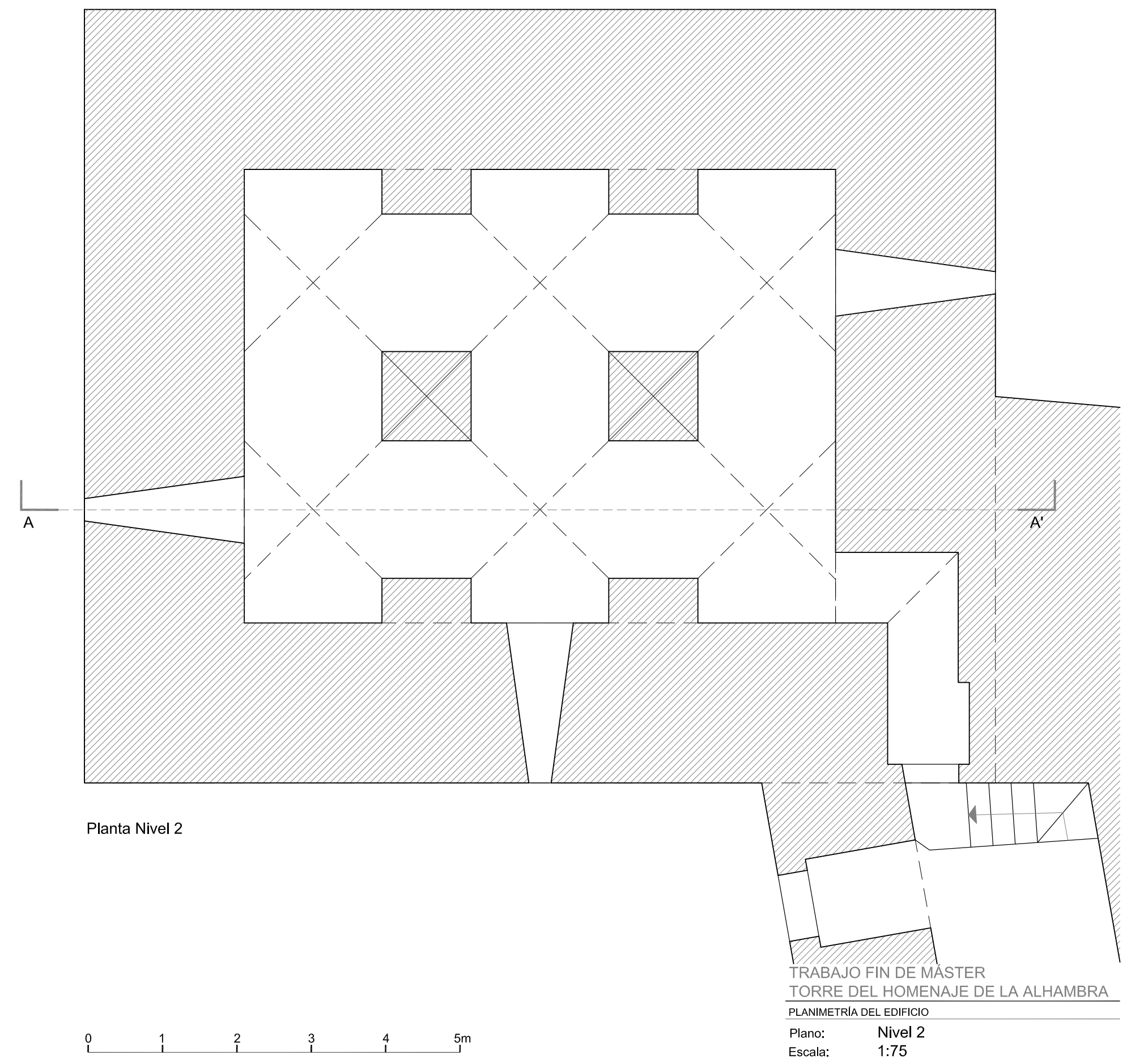



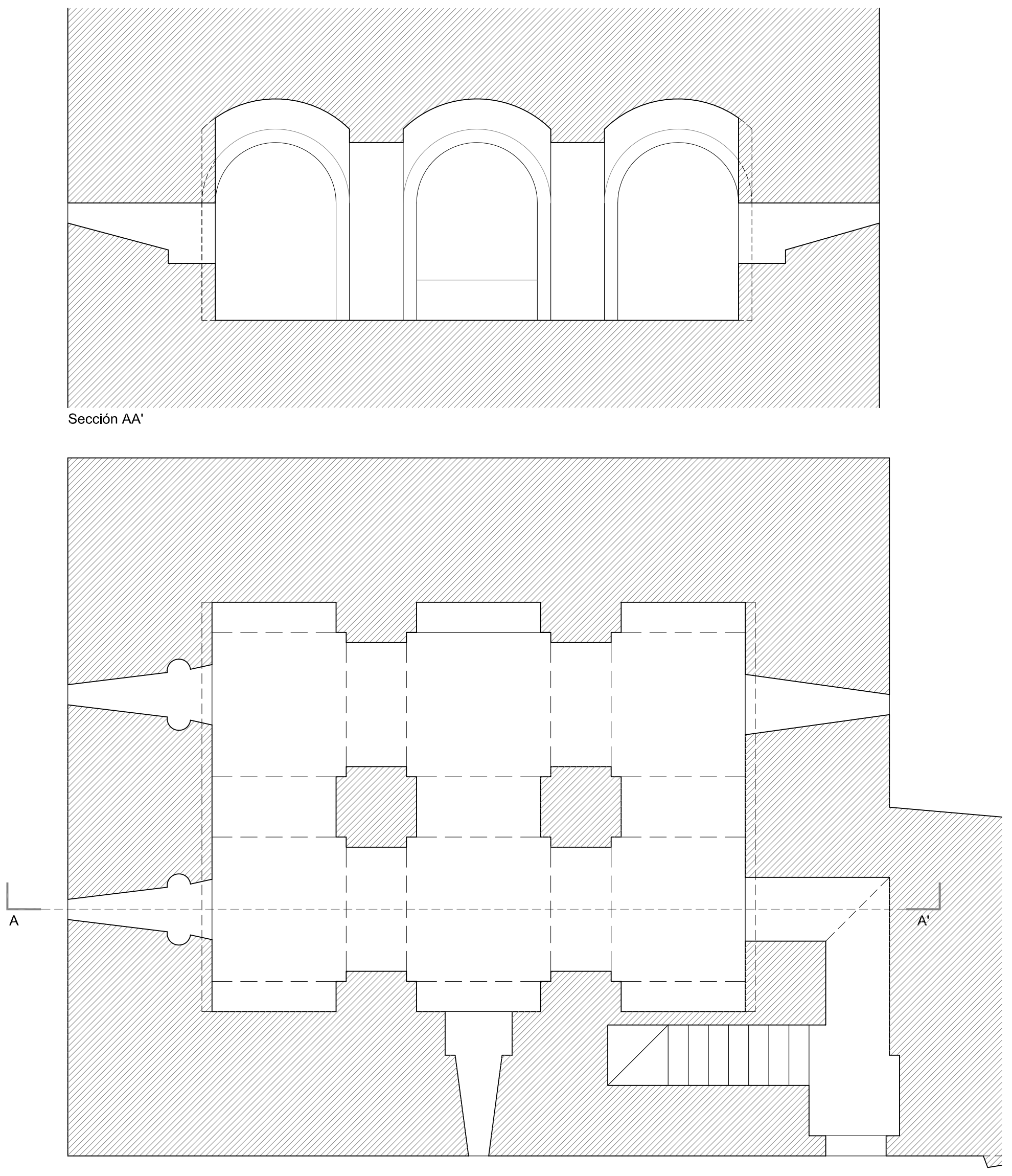

Planta Nivel 3

TRABAJO FIN DE MÁSTER

TORRE DEL HOMENAJE DE LA ALHAMBRA

PLANIMETRIA DEL EDIFICIO

$\begin{array}{llllll}0 & 1 & 2 & 3 & 4 & 5 \mathrm{~m} \\ 1 & 1 & 1 & 1 & 1 & 1\end{array}$

Plano:

Nivel 3
$1: 75$ 


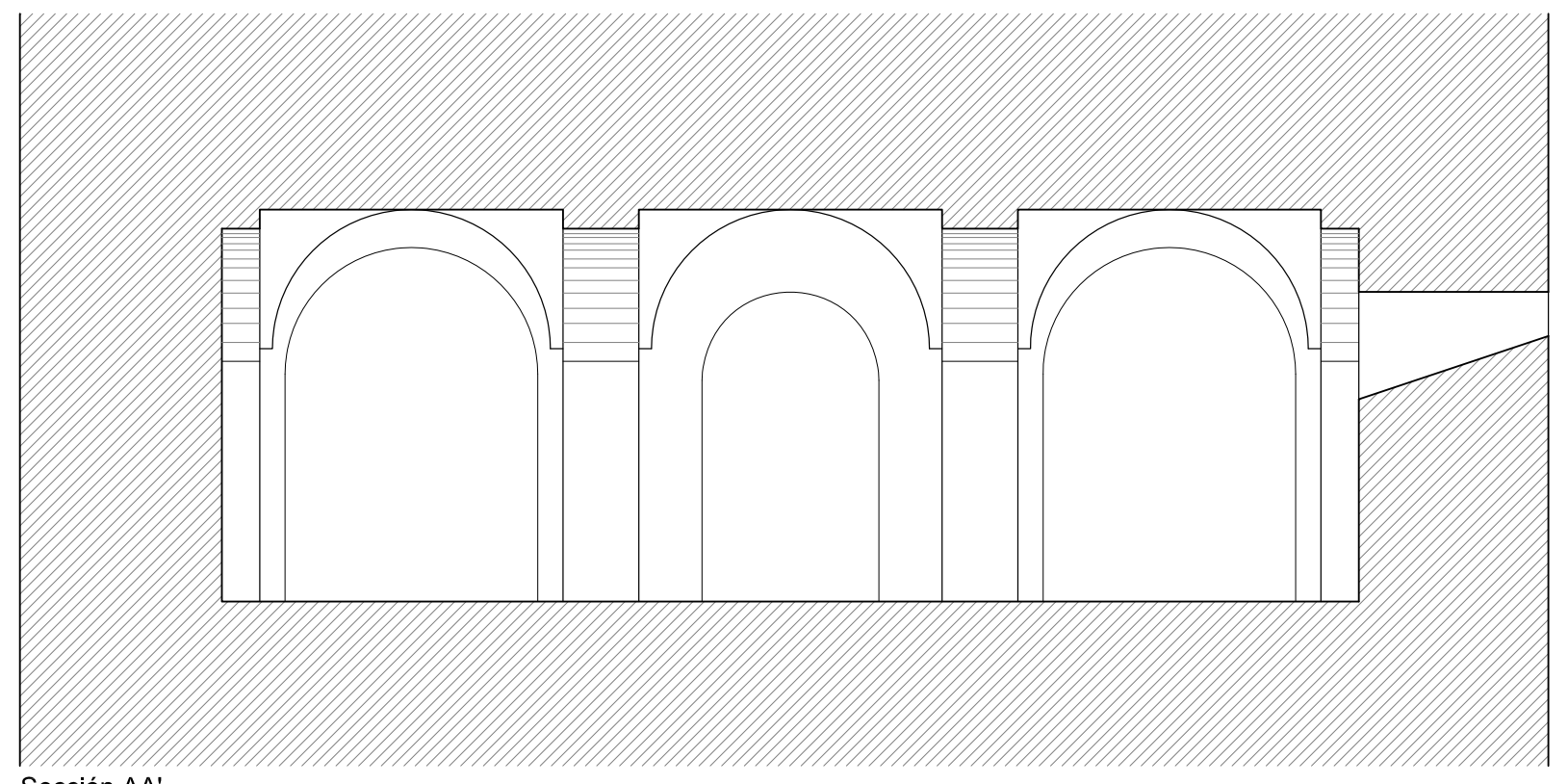

Sección AA'

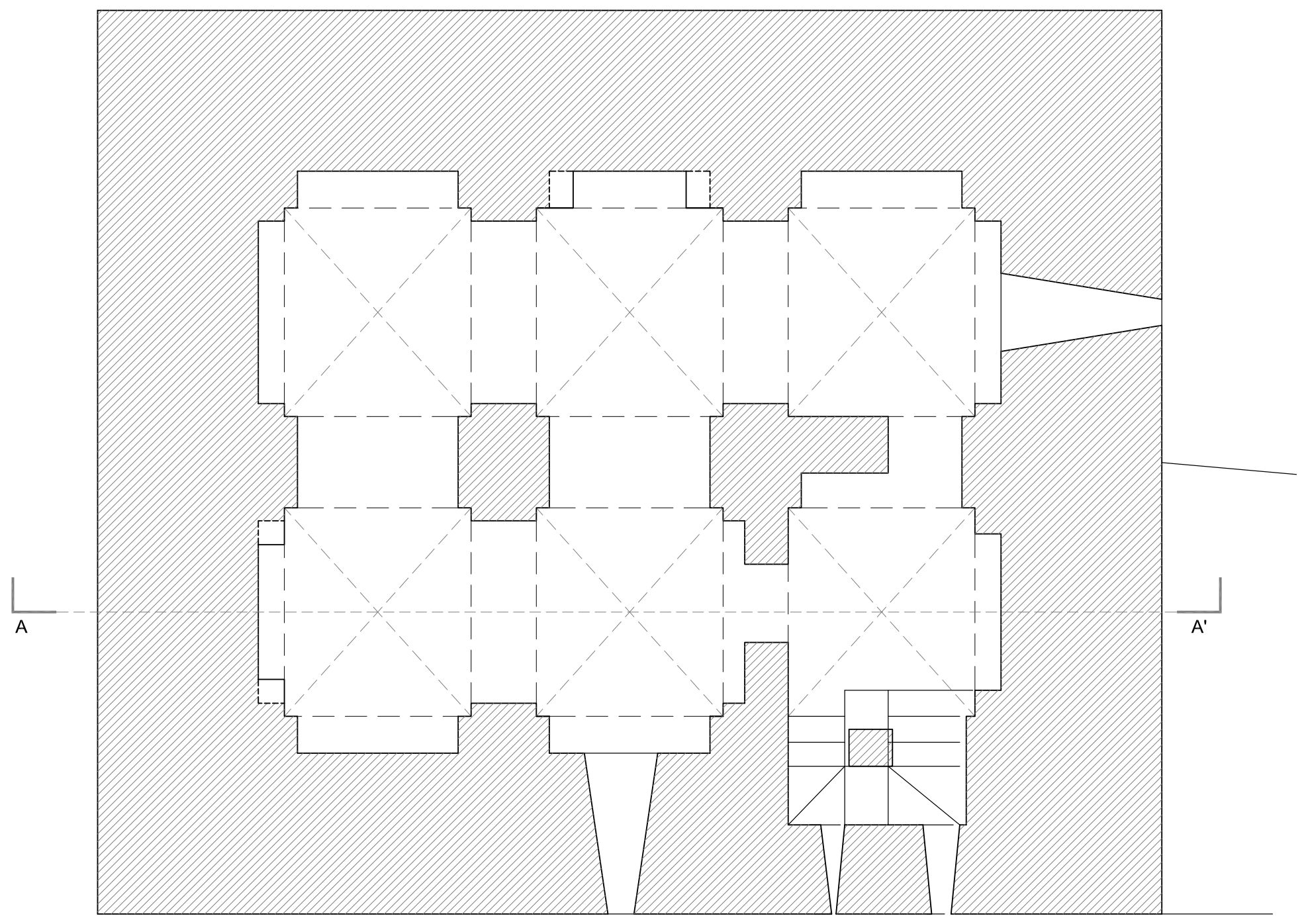

Planta Nivel 4

TRABAJO FIN DE MÁSTER

TORRE DEL HOMENAJE DE LA ALHAMBRA PLANIMETRIA DEL EDIFICIO

$\begin{array}{llllll}0 & 1 & 2 & 3 & 4 & 5 \mathrm{~m} \\ 1 & 1 & 1 & 1\end{array}$

Plano: Nivel 4

Escala: $\quad 1: 75$ 


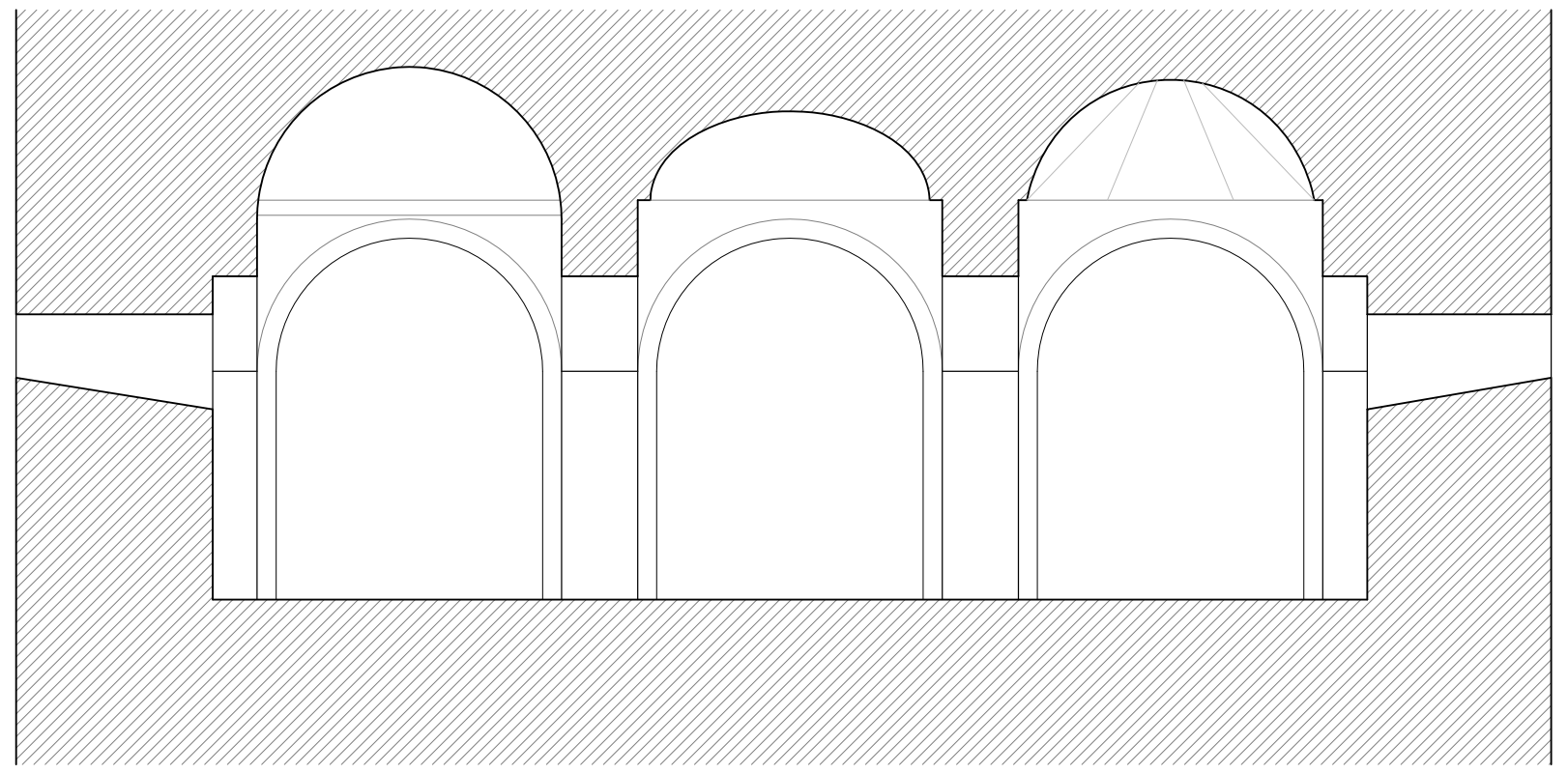

Sección AA'

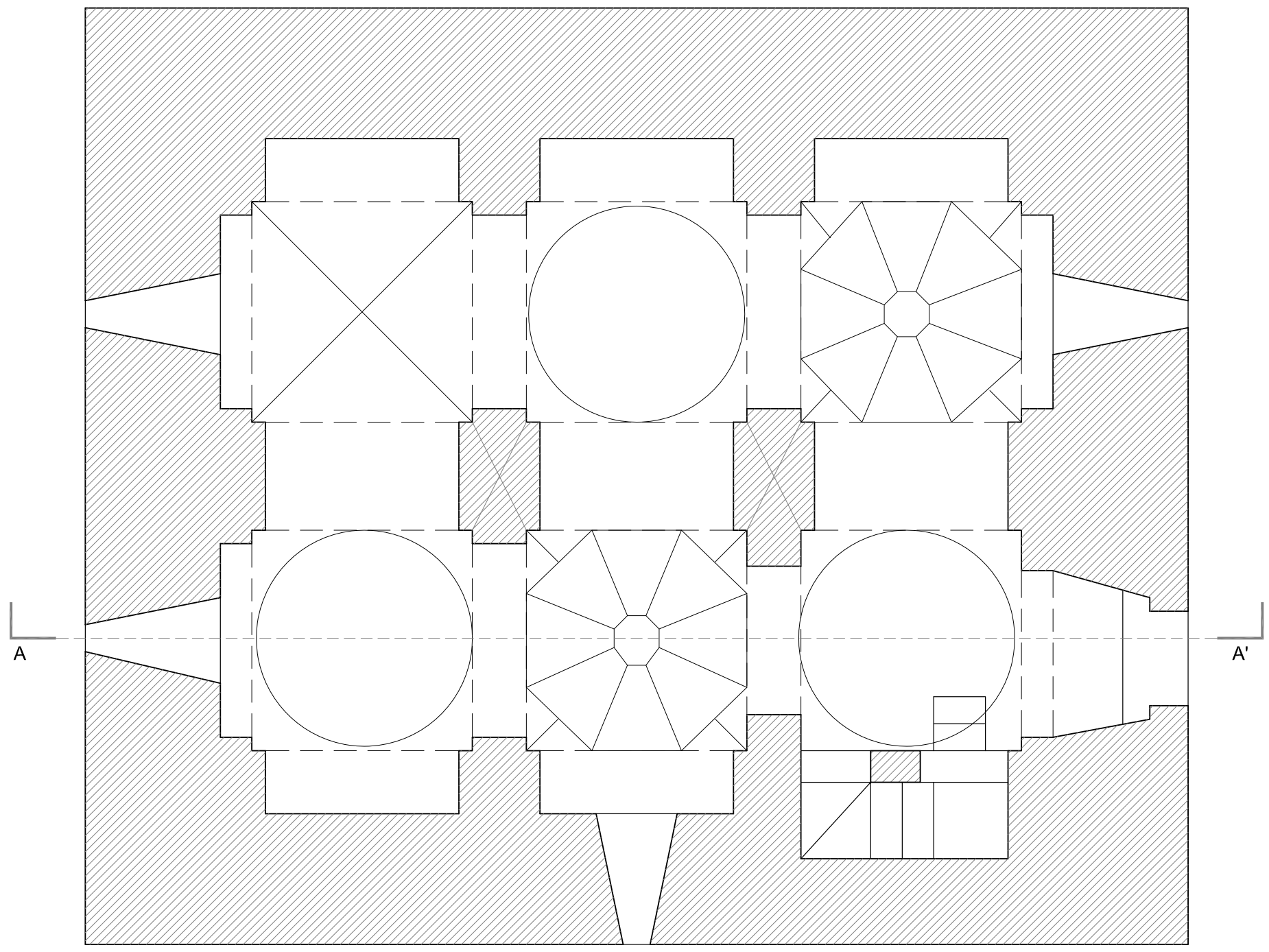

Planta Nivel 5

TRABAJO FIN DE MÁSTER

TORRE DEL HOMENAJE DE LA ALHAMBRA 


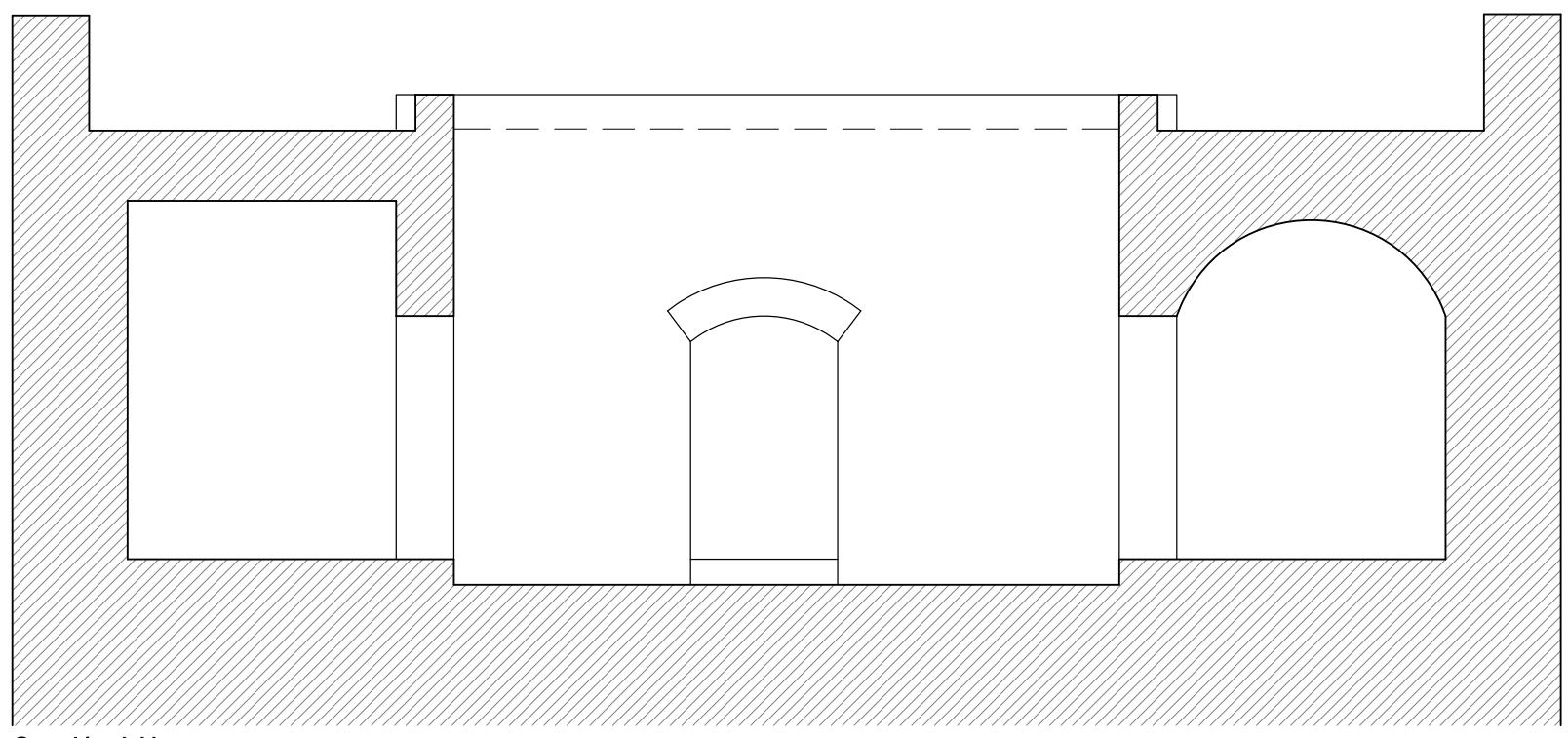

Sección AA'

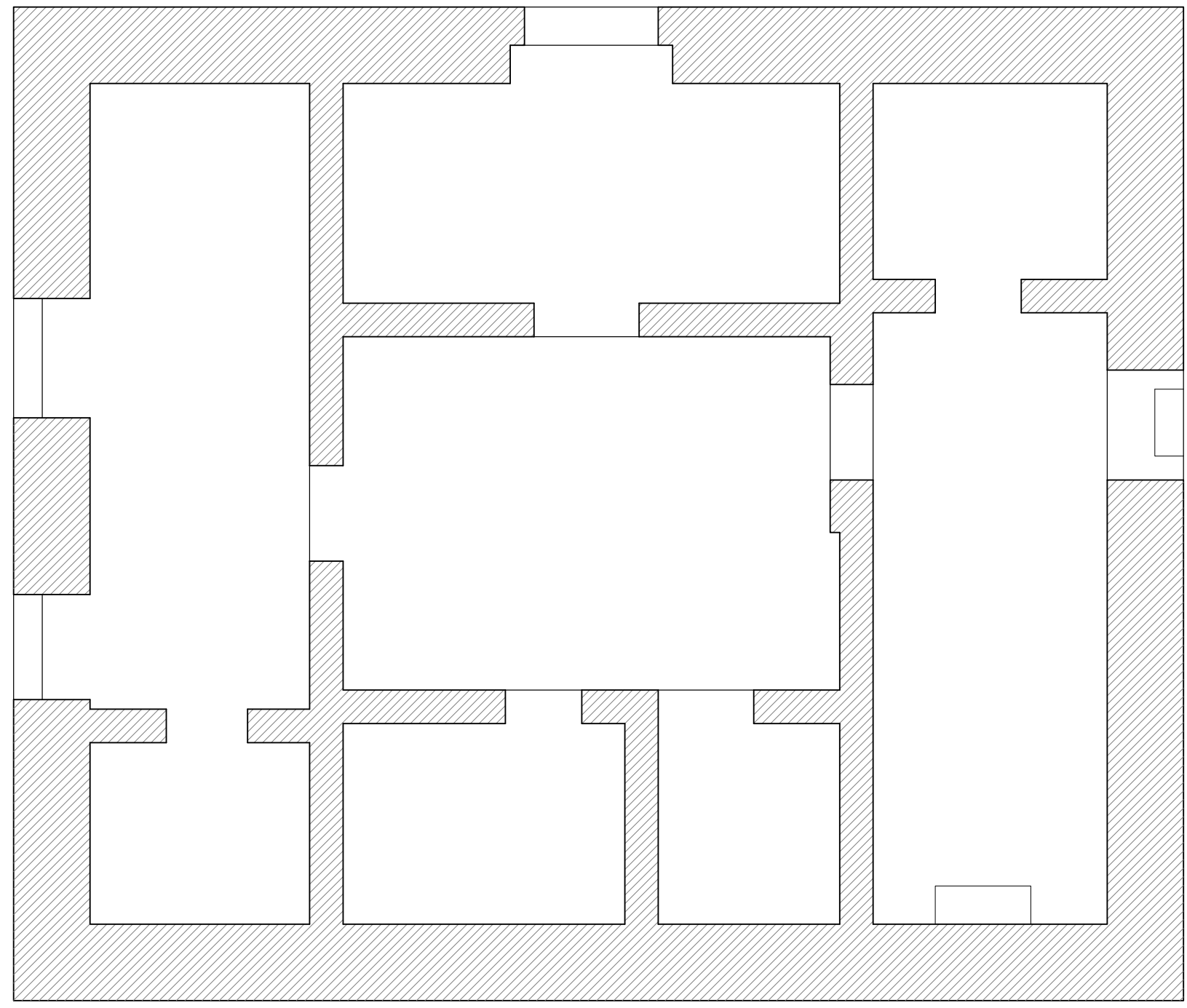

Planta Nivel 6

TRABAJO FIN DE MÁSTER

TORRE DEL HOMENAJE DE LA ALHAMBRA PLANIMETRÍA DEL EDIFICIO 


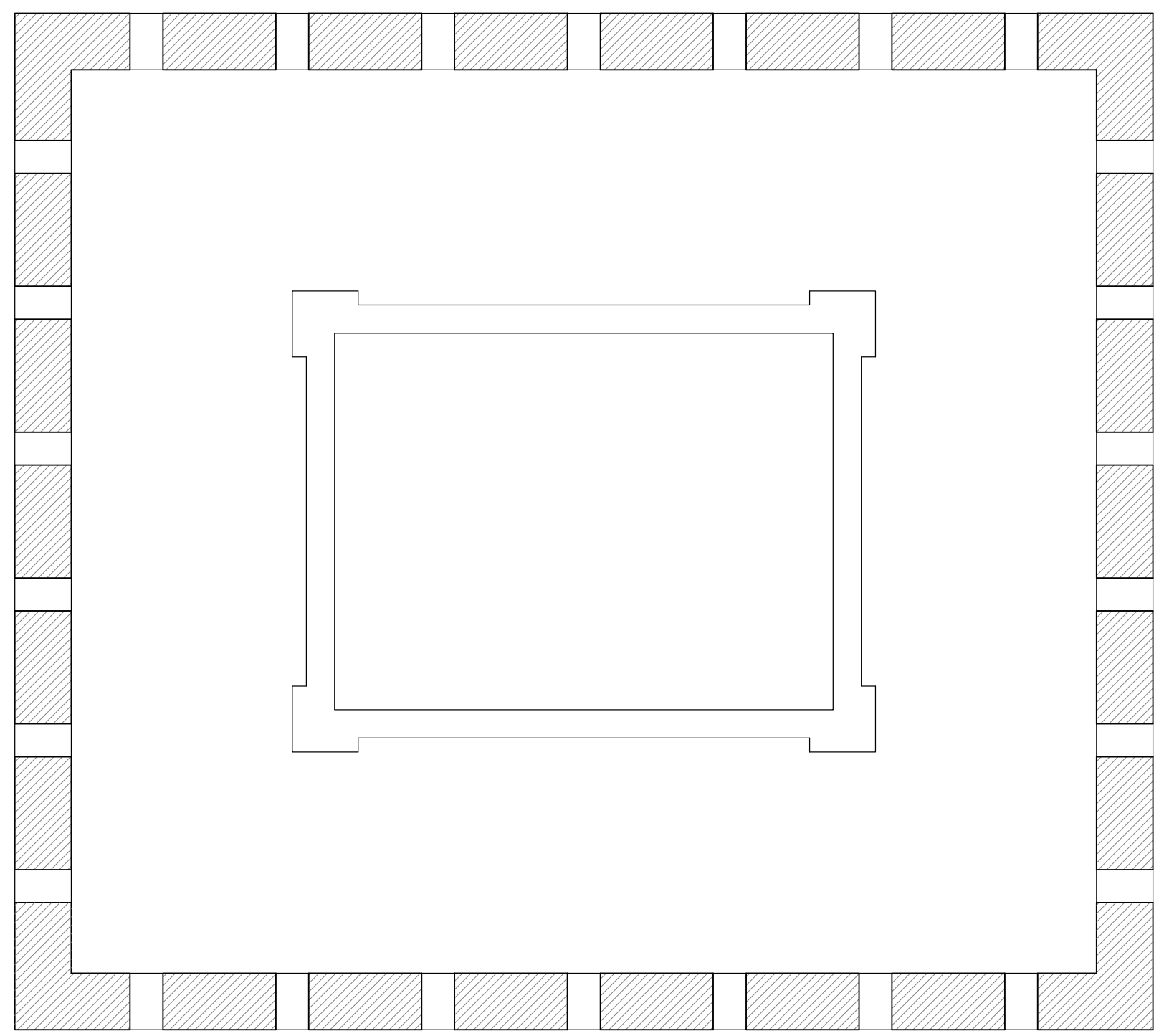

Planta Nivel 7

TRABAJO FIN DE MÁSTER

TORRE DEL HOMENAJE DE LA ALHAMBRA PLANIMETRIA DEL EDIFICIO

$\begin{array}{llllll}0 & 1 & 2 & 3 & 4 & 5 m \\ ⺊ & 1 & 1 & 1 & 1\end{array}$

Plano: Nivel 7

Escala: $\quad 1: 75$ 

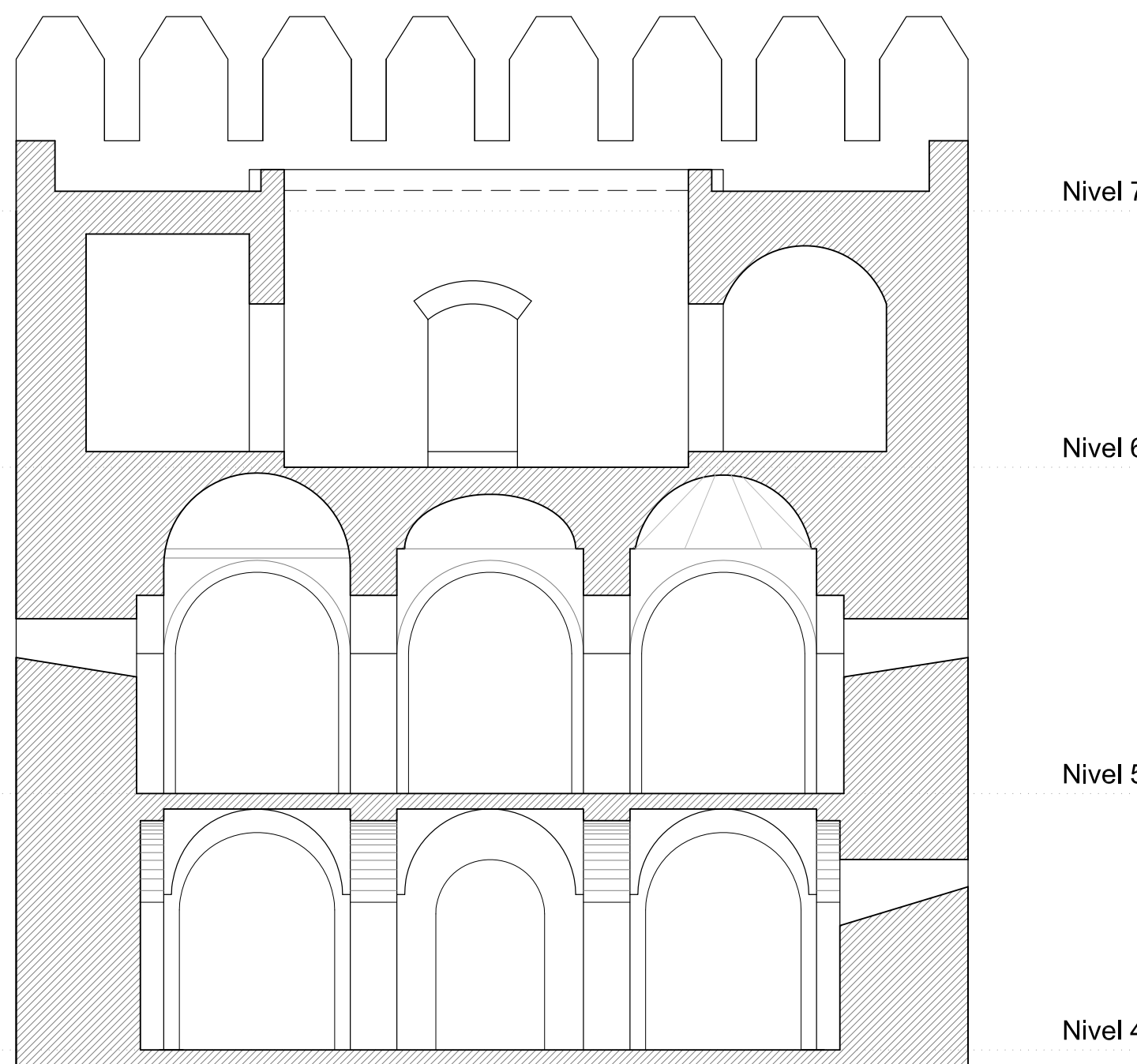

Nivel 4

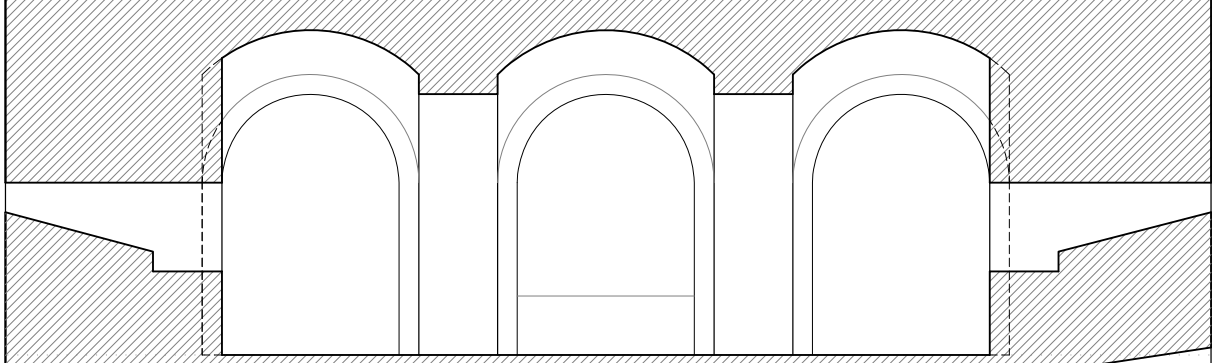

Nivel 5

Nivel 3

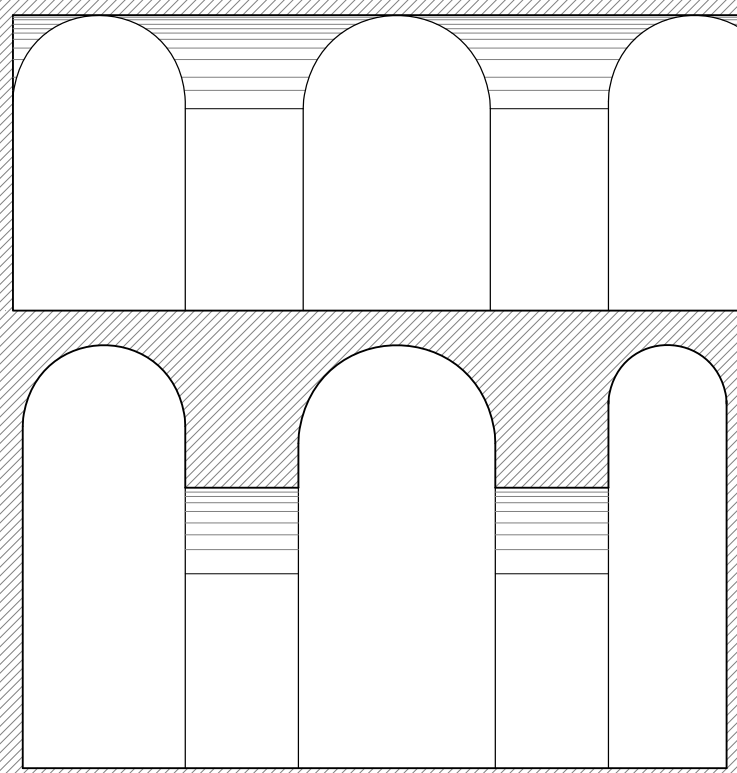

Nivel 2

Nivel 1

TRABAJO FIN DE MÁSTER

TORRE DEL HOMENAJE DE LA ALHAMBRA PLANIMETRÍA DEL EDIFICIO 